Portland State University

PDXScholar

Fall 12-5-2016

\title{
Understanding the Importance of Intermittently Fragmented Stream Habitat for Isolated Westslope Cutthroat Trout (Oncorhynchus clarki lewisi) in the Colville National Forest, Washington
}

Forrest Michael Carpenter

Portland State University

Follow this and additional works at: https://pdxscholar.library.pdx.edu/open_access_etds

Part of the Aquaculture and Fisheries Commons, and the Ecology and Evolutionary Biology Commons Let us know how access to this document benefits you.

\section{Recommended Citation}

Carpenter, Forrest Michael, "Understanding the Importance of Intermittently Fragmented Stream Habitat for Isolated Westslope Cutthroat Trout (Oncorhynchus clarki lewisi) in the Colville National Forest, Washington" (2016). Dissertations and Theses. Paper 3315.

https://doi.org/10.15760/etd.3295

This Thesis is brought to you for free and open access. It has been accepted for inclusion in Dissertations and Theses by an authorized administrator of PDXScholar. Please contact us if we can make this document more accessible: pdxscholar@pdx.edu. 
Understanding the Importance of Intermittently Fragmented Stream Habitat for Isolated Westslope Cutthroat Trout (Oncorhynchus clarki lewisi) in the Colville National Forest, Washington

by

Forrest Michael Carpenter

A thesis submitted in partial fulfillment of the requirements for the degree of

Master of Science

in

Environmental Science and Management

Thesis Committee:

Mark D. Sytsma, Chair

Paul J. Anders

Yangdong Pan

Portland State University

2016 


\begin{abstract}
Climate change and anthropogenic effects have vastly reduced Westslope Cutthroat Trout (Oncorhynchus clarki lewisi, WCT) habitat throughout their range, including the Colville National Forest in northeastern Washington where this study was conducted. Many native salmonid populations have declined in abundance since the early 1900s due to a variety of climate- and human-driven forces. Westslope Cutthroat Trout are especially sensitive to habitat loss or degradation and to climate change. Together, climate change, habitat degradation, and non-native salmonid invasions are contributing to increasingly fragmented WCT populations. Ongoing and predicted future warming trends are expected to further fragment these populations and isolate them in headwater stream reaches, with populations in the spatial margins of their distributions facing greater risk. Native salmonid populations are often separated or isolated by natural or artificial upstream migration barriers (i.e., waterfalls, culverts, etc.). Prior to continuing conservation and management actions targeting WCT, it is imperative to understand habitat requirements of this keystone species in fragmented areas. Field survey data were collected in the summer of 2015 on channel geomorphic characteristics and WCT presence/absence in 26 streams located in the Colville National Forest. A clear spatial separation was observed between Eastern Brook Trout (Salvenius fontinalis, EBT) and WCT above four culvert road crossings and the habitat in both of these areas was compared statistically to identify explicit differences. This dataset was also analyzed using logistic regression modeling to determine the best habitat predictors of the presence of isolated WCT populations existing upstream of these crossing. In general, stream
\end{abstract}


habitat in the Middle and South Forks of Mill Creek had low large substrate, high fine sediments, and exhibited pool-riffle channel morphology. Pool habitat supporting isolated WCT was significantly smaller, in terms of volume and surface area, than pool habitat supporting sympatric populations of WCT and EBT, largely due to the headwater nature of channel units supporting isolated WCT populations. Additionally, due to the extreme drought conditions during 2015, stream flow was substantially diminished in the study area causing these reaches to be highly fragmented and largely disconnected from the rest of the stream channel. Fine sediments were generally higher in headwater reaches supporting isolated WCT, including in pools and riffles, which was unexpected, mainly because they exist above sediment delivery points in the longitudinal extent of the system.

Logistic regression analysis indicated that the presence of isolated WCT populations was primarily positively associated with an increase in large wood and boulders, and negatively associated with increasing gravel, bedrock, habitat unit length, depth, and width (Significant $\chi^{2}, \mathrm{R}^{2}=0.174$, misclassification rate $=14.9 \%, \alpha=0.05$ ). The final model correctly predicted $37.5 \%$ of isolated WCT presence observations and $96.5 \%$ of the WCT/EBT presence observations significantly better than by chance alone $(\kappa=0.81)$. This model, in fact, may be useful in identifying limited habitat due to the fragmented nature of the channel units supporting IWCT. Large wood and boulders were positively correlated to WCT presence, likely because both are important in the formation of pools and cascades. Channel unit length, width, depth, active channel width as well as gravel and bedrock substrates, were all negatively associated with WCT presence. This 
suggests that isolated WCT are primarily associated with small headwater cascades with complex shelter, which may provide greater thermal and predation refuge compared to shallow glide or large pool habitats. Future model analysis should include additional habitat variables such as water temperature, stream gradient, and species interactions to strengthen the prediction of Westslope Cutthroat Trout presence. Overall, I concluded that differences in stream habitat above and below blocking culverts are not driving Westslope Cutthroat Trout distributions in the study area due to confounding factors such as the presence of problematic barriers and small sample size. I also conclude that future conservation and management decisions specific to WCT should prioritize complex cascade habitat in headwater stream reaches because of the type and quantity of habitat they may provide, especially during severe drought or low flow conditions. 


\section{Acknowledgements}

Throughout my experience in the Environmental Sciences and Management program at Portland State University I have received a wide swath of support and encouragement from people both in and outside of the University. A thesis is not an easy task and everyone's experience is different. I was fortunate enough to have a great group of people standing beside me throughout this entire process, for without their support, I wouldn't have been able to complete this final draft. First off, I would like to thank Lauren and Ian Courter for connecting me with my advisor Dr. Mark Sytsma, and for believing in and encouraging me to pursue a master's degree at PSU. I cannot thank Dr. Sytsma and my committee, Dr. Yangdong Pan and Dr. Paul Anders, enough for their support, insight, and encouragement. They provided important feedback and dialogue throughout this process and I am eternally grateful for their insight, guidance, and advice. I also would like to thank Dr. Sytsma individually for providing funding for my education at PSU, I feel extremely fortunate to have had financial support throughout this program. I also want to acknowledge the important group of people at Cramer Fish Sciences who have taken time outside the daily demands of their job to guide me throughout this process, particularly Dr. Ray Timm, Mark Teply, Ken Schrader, Steve Cramer, Dr. Lucius Caldwell, and Dana Stroud. When my original graduate school project didn't receive funding, Cramer Fish Sciences encouraged me to utilize the Mill Creek A-to-Z project dataset, for my thesis project. Without their support, I would likely still be working on finishing a different project and the duration of my program would have been unforeseeably delayed. I also want to thank John Gravelle, Jessica Van 
Lueven, Peter Stevens, Lindsey Belcher, and my dog Calvin for helping collect and process data from the field. I will always have fond memories of the many long days spent clambering through dense brush and over large logs attempting to classify fish habitat. I also want to thank Amelia Johnson, Bern Romey, and Belinda Judelman for their roles in helping me develop the logistic regression component of the analyses included in this paper. I cannot forget to thank Sherie Huffman and the rest of the ESM administrative department for the seamless assistance navigating the ins and outs of this process. Finally, I would like to thank my supportive and beautiful partner, Piper Dobner, as well as my mother, father, and sister, who read countless drafts, listened to numerous ideas, and supported me through every hurdle of this process. I couldn't have done this without them. 
Table of Contents

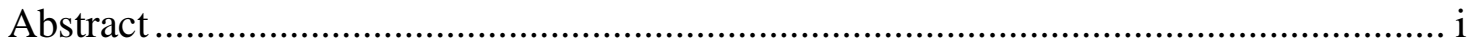

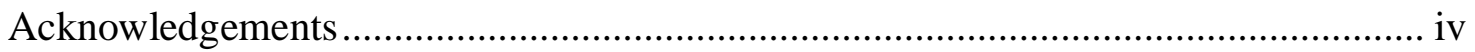

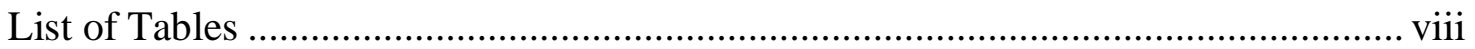

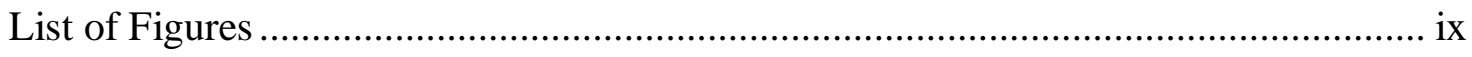

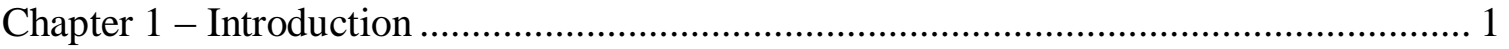

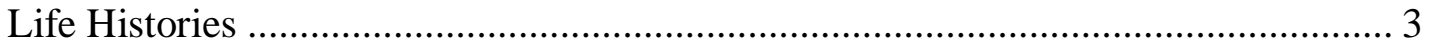

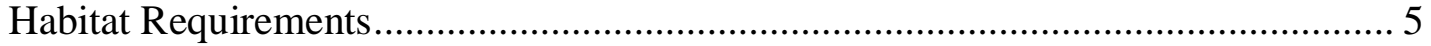

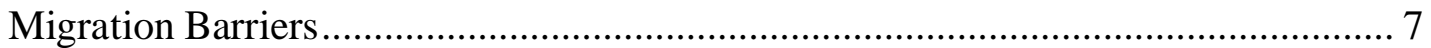

Mill Creek A-To-Z Watershed Restoration Project ............................................... 13

Chapter 2 - Characterization of Isolated Westslope Cutthroat Trout (Oncorhynchus clarki lewisi) Habitat Above Migration Barriers in the Middle and South Fork Mill Creek

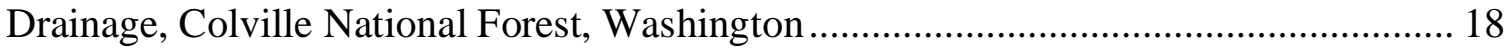

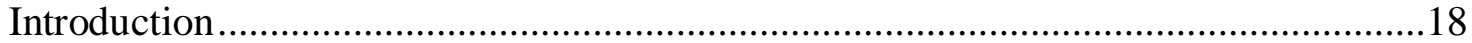

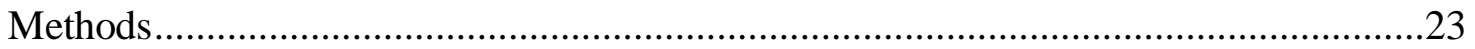

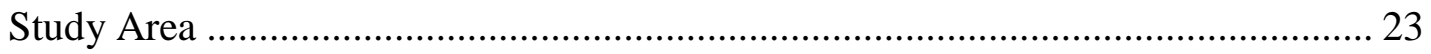

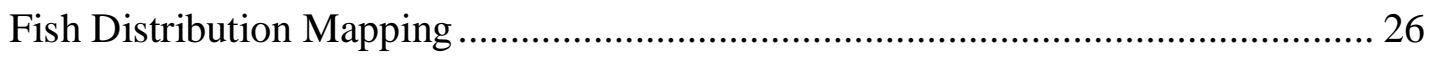

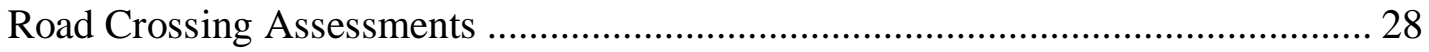

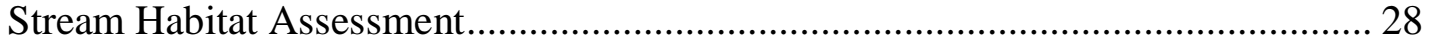

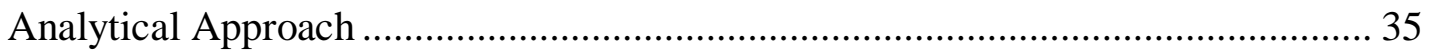

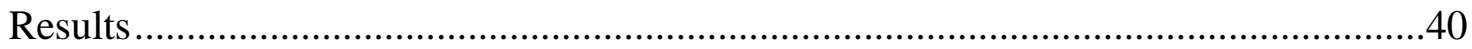

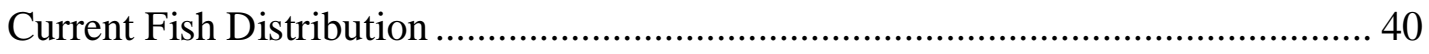

Road Crossings Assessment ....................................................................... 45

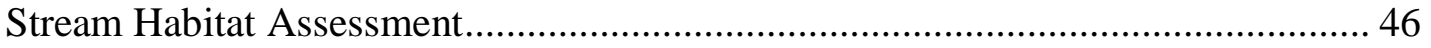

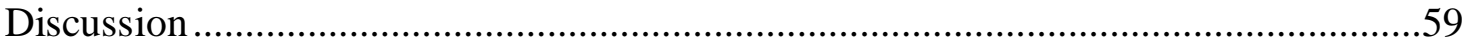

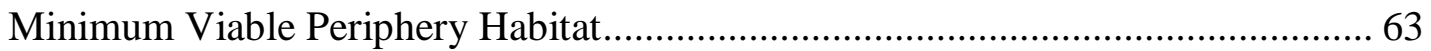

Chapter 3 - Use of a Logistic Regression Model and Physical Habitat Data to Predict Isolated Westslope Cutthroat Trout (Oncorhynchus clarki lewisi) Presence Above Four Migration Barriers in Headwater Streams in Northeastern Washington During Severe

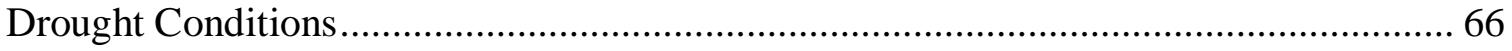

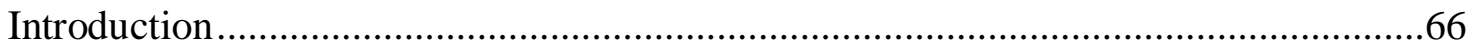

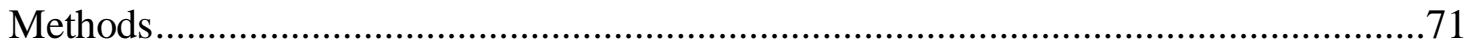




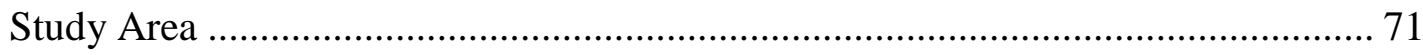

Analytical Approach ……………………………………............................... 71

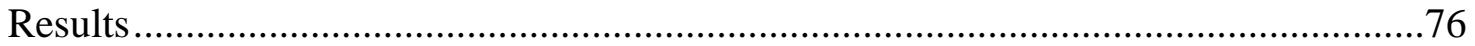

Spatial Variation of Stream Habitat Conditions ………………………………....... 76

Effects of Stream Habitat on Isolated WCT Presence ............................................. 82

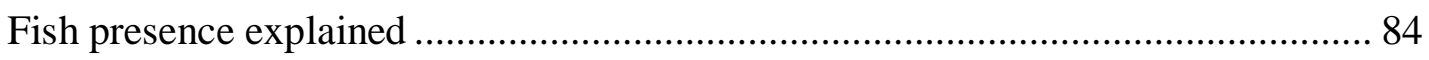

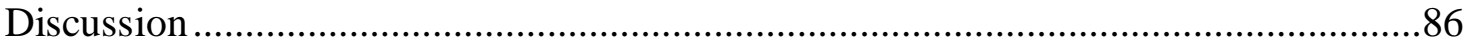

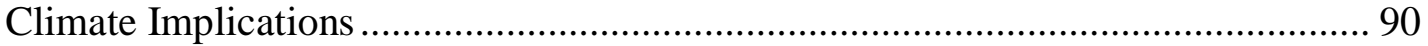

Study Limitations and Suggestions for Further Research.......................................... 91

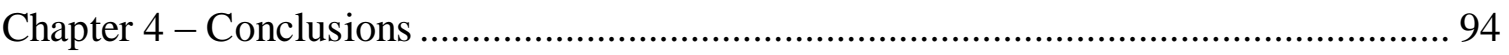

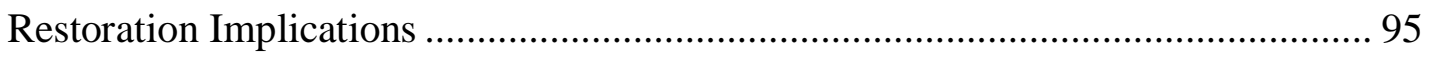

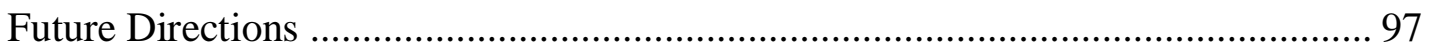

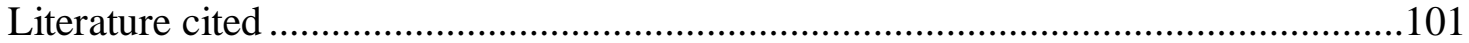




\section{List of Tables}

Table 1-1. Questions designed by Fausch et al. (2006) structured to assist resource managers weight tradeoffs for removing, retaining, or replacing artificial migration barriers. (Table adapted from Fausch et al. (2006)) ................................................... 11

Table 2-1. Descriptions of metrics included in field survey efforts (CAT=Categorical, NUM=Numerical, PER=Percent, and CNT=Count). This table is referenced extensively through this paper.

Table 2-2. Wood complexity ratings and descriptions used during stream habitat surveys (Adapted from Cramer and Ackerman 2009).

Table 2-3. Habitat quality indicators used to assess and characterize fish habitat throughout the MSFMC project area. The associated source is provided for each metric. For detailed descriptions of specific measurements associated with each metric refer to Table 2-1.

Table 2-4. Criteria used to assess passability of each road crossing structure in the study area. If stream channels were absent of water during field assessment they received a passability rating of 0 due to the depth parameter in level B of the assessment process. Revised from Table 3.3 from WDFW 2009 Fish Passage Barrier and Surface Water Diversion Screening and Prioritization Manual used to populate fish passage priority index equation (FPPI).

Table 2-5. Length of fish bearing designation applied to each stream surveyed in the MSFMC project area ( $\mathrm{SF}=$ South Fork and $\mathrm{MF}=$ Middle Fork).

Table 2-6. Summary table of stream priority index rating specific to each stream and various habitat characteristics associated with each road crossing and habitat existing upstream of each crossing (CMP=corrugated metal pipe).

Table 2-7. Summary statistics of habitat indicators along with the results of Wilcoxon rank-sum statistical test for non-parametric data. Results are discussed in the subsequent sections in more detail. An alpha of 0.05 was used to determine statistical significance $\left(W=\right.$ Wilcoxon statistic value and $\chi^{2}=$ Chi-squared test statistic)

Table 3-1. Number of channel unit types grouped by species occurrence (IWCT and WCT/EBT).

Table 3-2. Summary statistics for channel morphology, percent habitat unit substrate, active channel wood observations, and percent canopy cover $(n=1,743)$. See Table 2-1 for a detailed description of each variable.

Table 3-3. Confusion table, correct classification rate of IWCT presence $=36.5 \%$ based on a random subsample of $80 \%$ of the full data set $(\mathrm{n}=1422)$, with $20 \%$ of the original data used for prediction validation. Misclassification rate of $17.5 \%$. 


\section{List of Figures}

Figure 1-1. Historical and current distribution of WCT in the interior western United States as described in Haak et al. (2010). (Figure adapted from Haak et al. 2010).... 2

Figure 1-2. A general diagram of the cutthroat trout life cycle. Trout life history is complex and this diagram would vary based on the species and exhibited life history. (Photo credit clockwise starting with adult: http://montanalinks.com/funstuff/facts/fish/, https://en.wikipedia.org/wiki/Cutthroat_trout, http://rockedge.org/troutcam-troutfry-photos/, Forrest Carpenter (Author)) ..................................................................... 4

Figure 1-3. Bayesian relief network conceptual model from Peterson et al. (2008) depicting the functional relationships between invasion barriers, brook trout presence, and multiple physical habitat factors related to the persistence of WCT. This diagram represents a functioning model that can be used by managers to determine whether to remove or retain passage barriers. Managers can use a range of input values to assess the repercussions of various barrier management decisions.. 12

Figure 1-4. The Mill Creek A-to- $Z$ watershed restoration project is made up of the North Fork Mill Creek (NFMC; dark grey) and the Middle and South Fork Mill Creek (MSFMC; light grey) study areas. The MSFMC is the focus of the following analyses. $(\mathrm{BE}=\mathrm{Bestrom}$ Creek, $\mathrm{BC}=\mathrm{Bible}$ Creek, $\mathrm{TC}=\mathrm{TC}$ Creek, JC=Jacobsen Creek, SF4=South Fork Mill Creek Tributary \#4, HA=Hanson Creek, RB=Robbins Creek, SM=Smith Creek, KG=Kegel Creek, and GM=Green Mountain Creek)..... 15

Figure 2-1. Conceptual model describing the relationships between presence of allopatric isolated population of WCT above migration (IWCT) and various instream habitat specific processes. Yellow boxes represent habitat data collected as part of stream surveys during the summer of 2015 in the MSFMC project area that were used in this analysis. Red arrows represent a negative relationship, green arrows represent a positive relationship, and black arrows represent a variable relationship. Blue boxes represent watershed level factors not used in this analysis, but important drivers in IWCT persistence.

Figure 2-2. The North Fork Mill Creek project area was sampled during 2014 and the Middle and South Fork Mill Creek project area was sampled during 2015 and is the focus of the following analyses. This figure is referenced in both Chapter 2 and Chapter 3 of the following document. $(\mathrm{BE}=\mathrm{Bestrom}$ Creek, $\mathrm{BC}=\mathrm{Bible}$ Creek, $\mathrm{TC}=$ TC Creek, JC=Jacobsen Creek, SF4=South Fork Mill Creek Tributary \#4, $\mathrm{HA}=$ Hanson Creek, $\mathrm{RB}=$ Robbins Creek, $\mathrm{SM}=$ Smith Creek, $\mathrm{KG}=$ Kegel Creek, $\mathrm{CA}=$ Camp Creek, and GM=Green Mountain Creek).

Figure 2-3. Results of extent of fish, fish distribution, and road crossing surveys within the MSFMC project area conducted during the summer of 2015. Blue arrows indicated the locations of four impassable structures preceding allopatric WCT populations (IWCT). Road Crossing Priority index rating refers to the FPPI value 
calculated as part of the WDFW 2009 fish screen and structure assessment. Values are unitless and used to rank location and identify sites with the greatest impact on available fish habitat $(\mathrm{BE}=\mathrm{Bestrom}$ Creek, $\mathrm{BC}=\mathrm{Bible}$ Creek, $\mathrm{TC}=\mathrm{TC}$ Creek, JC=Jacobsen Creek, SF4=South Fork Mill Creek Tributary \#4, HA=Hanson Creek, $\mathrm{RB}=$ Robbins Creek, $\mathrm{SM}=$ Smith Creek, $\mathrm{KG}=$ Kegel Creek, $\mathrm{CA}=$ Camp Creek, and $\mathrm{GM}=$ Green Mountain Creek).

Figure 2-4. Summary of channel units containing IWCT population above migration barriers and channels units containing populations of WCT/EBT.

Figure 2-5. Comparison of physical habitat measures variability for both WCT/EBT (white) and IWCT (grey) to assess assumption of equal variance. Based on this plot the data are assumed to exhibit equal variance across the two groups. (See Table 2-1 for abbreviation definitions).

Figure 2-6. (A) Composition of fine sediments in channel units based on occurrence of IWCT populations in the MSFMC project area. (B) Composition of fine sediments in riffle habitat units based on occurrence of IWCT populations in the MSFMC project area (C) Composition of fine sediment in pool habitats based on occurrence of IWCT populations in the MSFMC project area. (IWCT= populations of allopatric WCT existing above 4 blocking culverts, WCT/EBT=sympatric populations of WCT and EBT.). Red dots represent mean values, the black line in the center of the square is the median, the top line represents the $75^{\text {th }}$ percentile, and the bottom line the $25^{\text {th }}$ percentile. The upper whisker extends from the hinge to the highest value that is within 1.5 times the inter-quartile range (IQR). The lower whisker extends from the hinge to the lowest value within 1.5 times the IQR of the hinge. Data beyond the whiskers are outliers and are plotted as points (black dots).

Figure 2-7. Comparison of pool composition based on occurrence of IWCT populations in the MSFMC project area. (IWCT= populations of allopatric WCT existing above 4 blocking culverts, WCT/EBT=sympatric populations of WCT and EBT.)...

Figure 2-8. (A) Comparison of pool surface area based on occurrence of IWCT populations in the MSFMC project area. (B) Comparison of pool volume based on occurrence of IWCT populations in the MSFMC project area. See Figure 2-6 for a detailed explanation of boxplot components. (IWCT= populations of allopatric WCT existing above 4 blocking culverts, WCT/EBT=sympatric populations of WCT and EBT.)

Figure 2-9. (A) Large woody debris frequency per channel unit based on occurrence of IWCT populations in the MSFMC project area. (B) Wood complexity ratings based on occurrence of IWCT populations in the MSFMC project area. (C) Percent stream shade based on occurrence of IWCT populations in the MSFMC project area. See Figure 2-6 for a detailed explanation of boxplot components. (IWCT= populations of allopatric WCT existing above 4 blocking culverts, WCT/EBT=sympatric populations of WCT and EBT). 
Figure 2-10. (A) Presence of cobble substrate in channel units based on occurrence of IWCT populations in the MSFMC project area (B) Presence of boulder substrate in channel units based on occurrence of IWCT populations in the MSFMC project area. See Figure 2-6 for a detailed explanation of boxplot components. (IWCT= populations of allopatric WCT existing above 4 blocking culverts, WCT/EBT=sympatric populations of WCT and EBT.).

Figure 2-11. Comparison of channel unit width to depth ratios sediments based on occurrence of IWCT populations in the MSFMC project area (IWCT= populations of allopatric WCT existing above 4 blocking culverts, WCT/EBT=sympatric populations of WCT and EBT.). See Figure 2-6 for a detailed explanation of boxplot components.

Figure 3-1. Methodology followed for data exploration, analysis methods, and model selection.

Figure 3-2. Correlation matrix for channel unit morphology predictor variables (see Table 2-1 for predictor abbreviations).

Figure 3-3. Correlation matrix for substrate predictor variables (see Table 2-1 for predictor abbreviations).

Figure 3-4. Correlation matrix for wood/shelter predictor variables (see Table 2-1 for predictor abbreviations).

Figure 3-5. A plot of receiver operating characteristic curves (ROC) for the full (grey line) and reduced (black curved line) models. The straight black line represents the performance of a uniform random variable, the further away the ROC curve is from the uniform random variable. The area under the curve is used to assess the model predictive capacity. A value of 1 is considered perfect model fit. The full model had an associated AUC value of 0.82 and the reduced was very similar, 0.81 indicating that both models fit the data relatively well and do not have significantly different predictive capabilities. 
Chapter 1 - Introduction

Trout and salmon (i.e., salmonids, members of the Salmonidae family) are iconic fish taxa that include numerous species endemic to the western United States. Most of these species have declined in abundance since the early 1900's and have been negatively affected by a variety of climate- and human-driven forces during the last century (Quinn 2011). Salmonids are especially sensitive to habitat degradation and depletion and require relatively unaltered coldwater aquatic habitats that lack invasive species (Williams et al. 2009). Many trout species have been listed as endangered or threatened, as described by the U.S. Endangered Species Act (ESA) (Williams et al. 2009). Listings under the ESA have largely been in response to habitat degradation, interactions with non-native salmonids (i.e. brook trout Salvelinus fontinalis (EBT), brown trout Salmo trutta, and rainbow trout Oncorhynchus mykiss), and over-exploitation (Dunham et al. 2002, Harig and Fausch 2002, Shepard et al. 2005). Cutthroat trout populations, particularly the inland subspecies Westslope Cutthroat Trout (Oncorhynchus clarki lewisi; WCT), have suffered substantial decreases in abundance, and have recently been reported to occupy $<30 \%$ of their historical range (Williams et al. 2009, Haak et al. 2010; Figure 1-1). Other sources cite WCT range declines to $<5 \%$ of historical occupancy (Harig and Fausch 2002) and 27\% of historical range in Montana, with < $2.5 \%$ of remaining populations described as genetically unaltered (Young et al. 1995). 

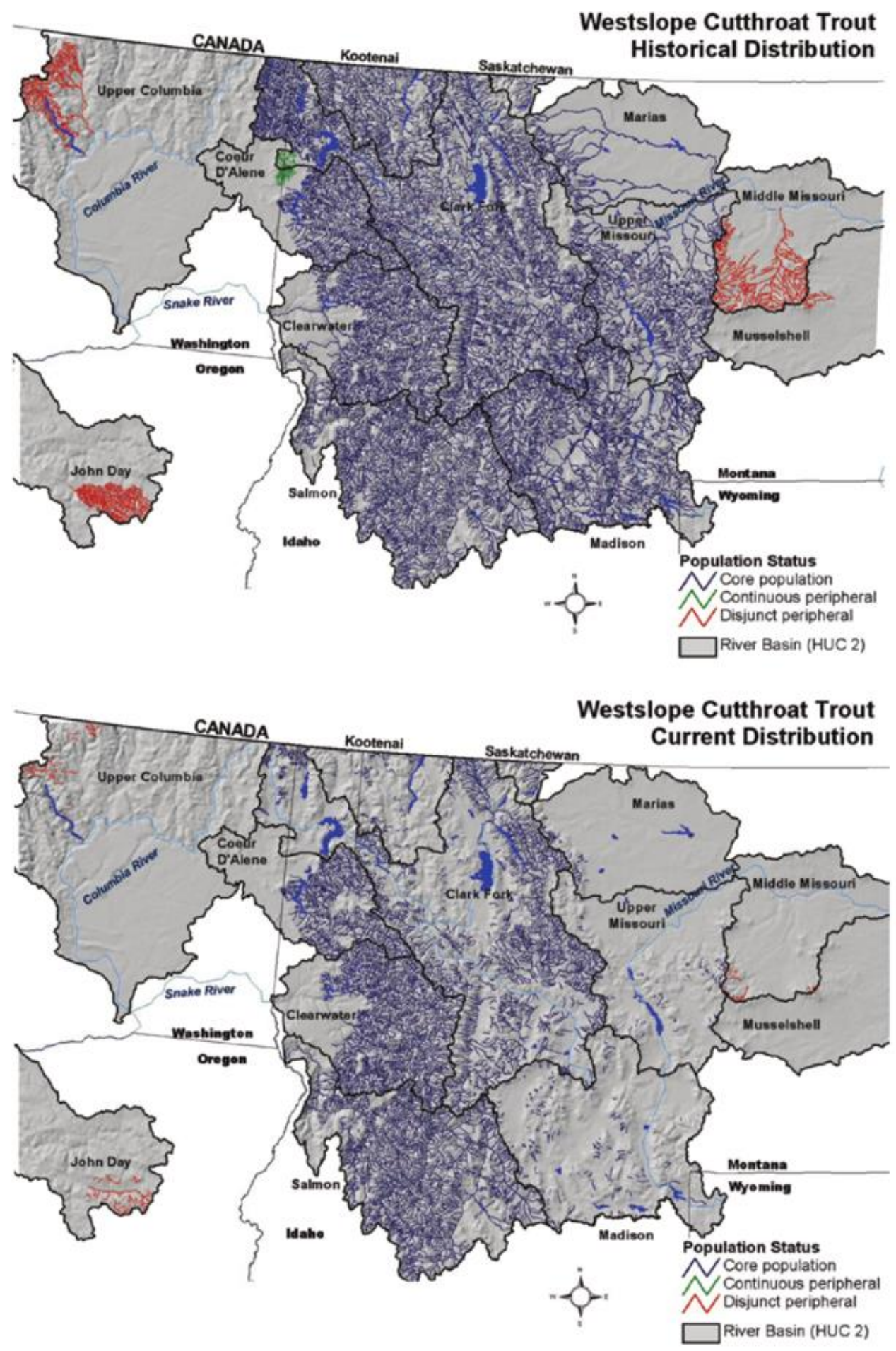

Figure 1-1. Historical and current distribution of WCT in the interior western United States as described in Haak et al. (2010). (Figure adapted from Haak et al. 2010) 
As the effects of instream stressors continue to increase across ecosystems (e.g. air and water temperatures, presence of non-natives, habitat degradation, etc.), understanding whether particularly sensitive species like WCT can thrive under altered conditions has become an increasingly critical issue for their conservation and management (Isaak et al. 2015). Ongoing and predicted future warming trends are expected to further fragment trout populations and isolate them in headwater stream reaches (Young et al. 1995, Harig and Fausch 2002, Isaak et al. 2012a), likely creating peripheral populations in the spatial margins of their distribution. Peripheral populations may harbor rare genetic material that can be important source material for maintaining the genetic integrity of downstream populations (Taylor et al. 2003). However, this valuable function of peripheral populations is becoming increasingly jeopardized due to increasing presence and competitive pressure of non-native species (Dunham et al. 2002) and the added effects of degradation in critical headwater habitats (Muhlfeld et al. 2012).

\section{$\underline{\text { Life Histories }}$}

Westslope Cutthroat Trout historically occupied headwater streams, large rivers, and mountain lakes in drainages throughout the inland western US (Bear et al. 2007), with populations exhibiting fluvial, adfluvial, or resident life histories (Young et al. 1995). Fluvial WCT rear and mature in rivers and migrate to smaller tributaries to spawn, after which they quickly return to the larger fluvial environment (Young et al. 1995). Adfluvial WCT forms, residents of lentic systems, spawn in lake tributaries between March and July, and progeny remain in their natal streams from one to four years before 
migrating downstream to a lake where they grow to maturity (Young et al. 1995).

Resident forms rear and spawn in small tributaries and typically remain under $300 \mathrm{~mm}$ in length (Young et al. 1995). These three life history variants may co-exist in a single basin, with the dominant life history form typically representing the dominant aquatic environment (i.e. lotic or lentic; Young et al. 1995). Westslope Cutthroat Trout are considered iteroparous (capable of repeat spawning) and generally reach initial sexual maturation at age 4 or 5, spawning between March and July when water temperatures average $10^{\circ} \mathrm{C}$ (Figure 1-2)(Young et al. 1995).

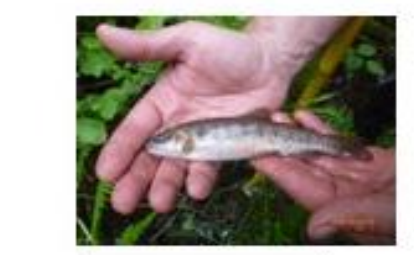
Juvenile trout mature in 3-5 years. Migratory forms generally spend $1-4$ years in natal streams before emigrating.

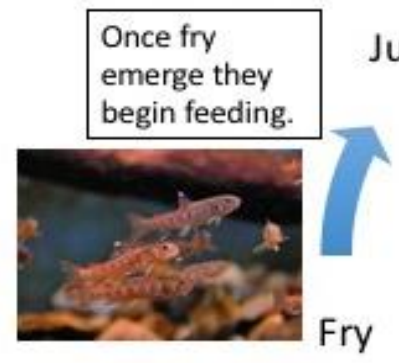

Juvenile

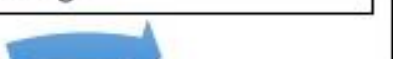

Adults, resident or migratory, return to streams to spawn.

Eggs hatch in about a month, after which they spend 2 weeks in the gravel absorbing the yolk sack.

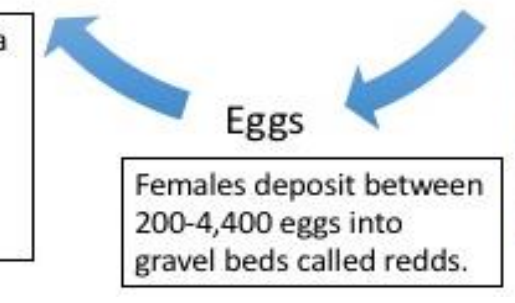

Adult

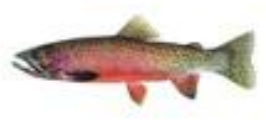

Cutthroat typically spawn in spring when water is Spawn around $10^{\circ} \mathrm{C}$ and flow is high.

Figure 1-2. A general diagram of the cutthroat trout life cycle. Trout life history is complex and this diagram would vary based on the species and exhibited life history. (Photo credit clockwise starting with adult: http://montanalinks.com/funstuff/facts/fish/, https://en.wikipedia.org/wiki/Cutthroat_trout, http://rockedge.org/troutcam-trout-fry-photos/, Forrest Carpenter (Author)) 


\section{Habitat Requirements}

As a coldwater species, WCT require particular habitat and thermal conditions to persist and support all of their life stages and life history forms (Figure 1-2). Habitat must be adequately complex to support their diverse life cycle (Williams et al. 2015), as fish at each life stage often require different stream habitats with different thermal, flow, substrate, and physical attributes (Harig and Fausch 2002). The complexity of the WCT life cycle is particularly challenging to managers responsible for protecting and mitigating complex habitat to support fragmented populations.

Thermal conditions have been frequently cited as a key driver of the historical and current persistence and distribution of WCT populations (Paul and Post 2001, Sloat et al. 2001, de la Hoz Franco and Budy 2005). Thermal conditions are directly tied to water availability, flow regimes, and numerous riparian and watershed influences. Temperature plays a large role in the decline of these populations (Shepard et al. 2005, Roberts et al. 2013, Isaak et al. 2015) as WCT are stenothermic and thermally specific, requiring stable temperatures, typically less than $16^{\circ} \mathrm{C}$ (see Table 1 in Young et al. 1995). Increasingly warmer water at lower elevations has been implicated in observed shifts in WCT distribution, including increased use of low order and headwater steams (Shepard 2004). Headwater lakes and streams are abundant across mountainous and glacially influenced landscapes and provide an important source of water, sediments, and biota for downstream reaches (Clarke et al. 2008). Thus, headwater streams and lakes can play an important role in providing refuge from high thermal and low flow conditions (Clarke et al. 2008), particularly for coldwater species, as well as refuge from competition with non- 
native invaders (Griffith 1970, Dunham et al. 2002, Shepard 2004).

Increasingly common shifts in spatial distributions of WCT to headwater or low order streams are often exacerbated by their competitive disadvantage with non-native brook trout, which are more tolerant of warmer water temperatures (Dunham et al. 2002, Shepard 2004, Bear et al. 2007). In an examination of invasive species, Dunham et al. (2002) found that fish introduced to downstream reaches were less likely to colonize upstream reaches, whereas fish occupying headwater habitats were more likely to colonize downstream reaches. This is likely due to headwater resident WCT facing fewer obstacles such as artificial barriers and high flow areas, and thus being able to readily disperse to downstream areas aided by downstream flows. This condition emphasizes the need to protect headwater populations as a source of genetic diversity and integrity in downstream reaches, which may provide refuge for broodstock. Studies have also found that when in the presence of non-native salmonids, such as rainbow and brook trout, the headwater habitat cutthroat trout tend to disperse to is often highly fragmented and thus isolated from the rest of the stream channel (Harig and Fausch 2002). It is therefore important to understand the minimum viable habitat required (i.e., volume, area, and amount of cover) to support populations (Hodder and Bullock 1997, Harig and Fausch 2002) existing in isolation, especially those isolated in fragmented periphery habitat. Harig and Fausch (2002) examined fine scale microhabitat attributes that promote establishment and persistence of translocated cutthroat trout above migration barriers in high-elevation headwater streams and identified a number of limiting factors influencing the success of translocated populations, including mean pool width and the number of 
deep pools, which have been corroborated in other studies examining habitat features and trout abundance (see Clarkson and Wilson 1995, Kruse et al. 1997). Headwater streams typically include cascade and step pool channels due to the high elevation, steep slope, and confined channel associated with headwater reaches (Montgomery and Buffington 1997). Steep cascade or step pool channels are generally associated with large substrate clasts that may only mobilize during infrequent high flow events, whereas finer substrates are generally stored near flow obstructions such as large woody debris or large grain substrates (Montgomery and Buffington 1997). Cascade and step pool classified reaches generally exhibit less than four channel units in between pool habitat as compared to 5-7 in pool riffle habitat (see Table 1 in Montgomery and Buffington 1997). Given the higher frequency of pool habitat in headwater reaches (Montgomery and Buffington 1997) and the thermal refuge headwater pools provide, these channel reaches will likely become increasingly important to the persistence of coldwater species, such as WCT (Isaak et al. 2012a, 2014, 2015).

\section{Migration Barriers}

River connectivity is vital for the persistence of aquatic species both at the individual and population levels (King et al. 2016). Thus, migration barriers can negatively affect population persistence by reducing connectivity among habitats. Migration barriers can be defined as natural or artificial obstructions that limit or prevent upstream migration, access to rearing or spawning habitat, or shelter from predation and other types of disturbance (King et al. 2016). Barriers can take many forms, including 
improperly sized or placed road crossing structures, which can cause numerous problems for stream morphology and for fish migration (Muhlfeld et al. 2012). Currently, millions of barriers exist worldwide that severely restrict access to important habitat for numerous native and non-native fishes (Peterson et al. 2008, Fausch et al. 2009, Muhlfeld et al. 2012, King et al. 2016).

It has been well documented that habitat degradation, invasive species competition, and increased water temperature regimes continue to limit the distribution of many WCT populations to headwater areas (Muhlfeld et al. 2012). This trend is expected to continue if non-native species invasions, introductions, and range expansion continue to increase. However, cumulative effects of these trends, paired with the continued use and construction of fish migration barriers such as irrigation diversions, dams, and road crossings (Peterson et al. 2008) suggest continued or increasing limitations for WCT populations.

It is important to understand the trade-offs regarding structure improvements and replacement specific to stream morphology and upstream fish migration (Muhlfeld et al. 2012) because it is likely that the prevalence of artificial barriers will increase as the spread of non-native fishes increases, and as some barriers are maintained to limit range expansion of invasive non-native fishes (e.g. isolation management; Fausch et al. 2009). It is therefore likely that WCT populations will continue to be limited to fragmented low order streams upstream from artificial or natural barriers. Isolation management is a commonly considered technique when assessing artificial passage barriers, particularly when species compositions differ upstream and downstream from the crossing. For 
example, an artificial barrier with allopatric populations of WCT existing above and invasive EBT existing downstream, may provide important refuge habitat for WCT from further EBT invasions. In such cases it may be beneficial for the native upstream WCT to leave the structure in place and continue to restrict EBT to downstream reaches. Conversely, retaining such barriers could increase the chance of extinction, decrease genetic and life history diversity, and restrict the upstream populations to increasingly fragmented stream habitat (Fausch et al. 2009, Muhlfeld et al. 2012). The dilemmas resulting from this tension will become increasingly important as the construction and presence of artificial migration barriers becomes more prominent globally (Fausch et al. 2009).

Multiple studies provide decision frameworks for installing or removing fish migration barriers (i.e. Novinger and Rahel 2003, Peterson et al. 2004, 2008, Fausch et al. 2009, Muhlfeld et al. 2012). Retaining barriers that limit passage commonly restricts stream flow and can significantly alter stream morphology, particularly during high flows. An improperly sized culvert can cause significant water to pool, or bottleneck, upstream, increasing sediment loading to downstream reaches. Expert opinion remains divided regarding isolation management, including decisions that can be largely influenced by on the ground habitat conditions (Fausch et al. 2009). Proponents of retaining barriers often cite the benefits of preserving genetic integrity of isolated upstream native fish populations, whereas opponents argue that reconnecting habitat may be more vital to the persistence of the population (Fausch et al. 2009). However, specific 
barrier management decisions may depend largely on the details of each situation, and are best reviewed on a case by case basis.

Numerous studies during the past two decades have examined the challenges or dilemmas of migration barrier isolation management, and several have developed decision frameworks to assist resource managers in deciding whether to retain or remove. Two studies in particular (Fausch et al. 2006, Peterson et al. 2008) and a report by WDFW (Washington Department of Fish and Wildlife 2009) have developed frameworks or models to help resource managers evaluate how retaining or removing structures may affect the streams and the fish populations they support. Fausch et al. (2006) provides four assessment or tradeoff questions to guide decision makers through understanding the important aspects of the current stream conditions (Table 1-1). Answers to these questions form the basis for predicting how barrier removal would affect fish population trends and distributions. Because there are many factors to evaluate, and this framework suggests identifying the types of values (evolutionary, ecological, or socio-economic) prevalent in the stream(s) of interest (Fausch et al. 2006). Evolutionary value pertains mainly to disjunct or fragmented populations, contributing extant genetic diversity and occupying unique or remnant habitats, whereas ecological values pertain to populations contributing significantly to the overall community structure of both aquatic and terrestrial functions (Fausch et al. 2006). Socio-economic values are directly evident and easily quantifiable, and may include increased fishing presence, tourism, other recreation associated activities, and increased development (Fausch et al. 2006). 
Table 1-1. Questions designed by Fausch et al. (2006) structured to assist resource managers weight tradeoffs for removing, retaining, or replacing artificial migration barriers. (Table adapted from Fausch et al. (2006)).

Main Questions

1. Is a native salmonid population of important conservation value present?

2. Is the population vulnerable to invasion and displacement by nonnative salmonids?

3. If the native salmonid is isolated, will it persist? populations of value which ones are priorities for conservation?
Further Dimensions or Considerations

- Evolutionary values

- Ecological values

- Socio-economic values

- Transport and spread

- Establishment

- Displacement

- Coexistence

- Hybridization

- Transmit parasites or pathogens

- "Small population" phenomena

- Loss of genetic variability

- Demographic and Environmental stochasticity

- Catastrophes

- Loss of migratory life histories

- Synergistic factors

- Identify conservation units

- Prioritize populations

- Representation

- Redundancy

- Persistence

- Feasibility

- Consider viability

- Confront uncertainty

Peterson et al. (2008) provided a quantitative approach which uses a Bayesian relief network that allows managers to quantitatively and qualitatively assess habitat and other biotic and abiotic factors to inform management decisions (Figure 1-3). Each node or bubble in Figure 1-3 has an input value that allows managers to gain a better understanding of the important dynamics and functions occurring between the abiotic and biotic features. The authors identified this approach as an effective way to assess 
tradeoffs associated with removing and retaining structures. However, these authors

recommend further research and understanding regarding the complicated relationships

between WCT, EBT, and migration barriers.

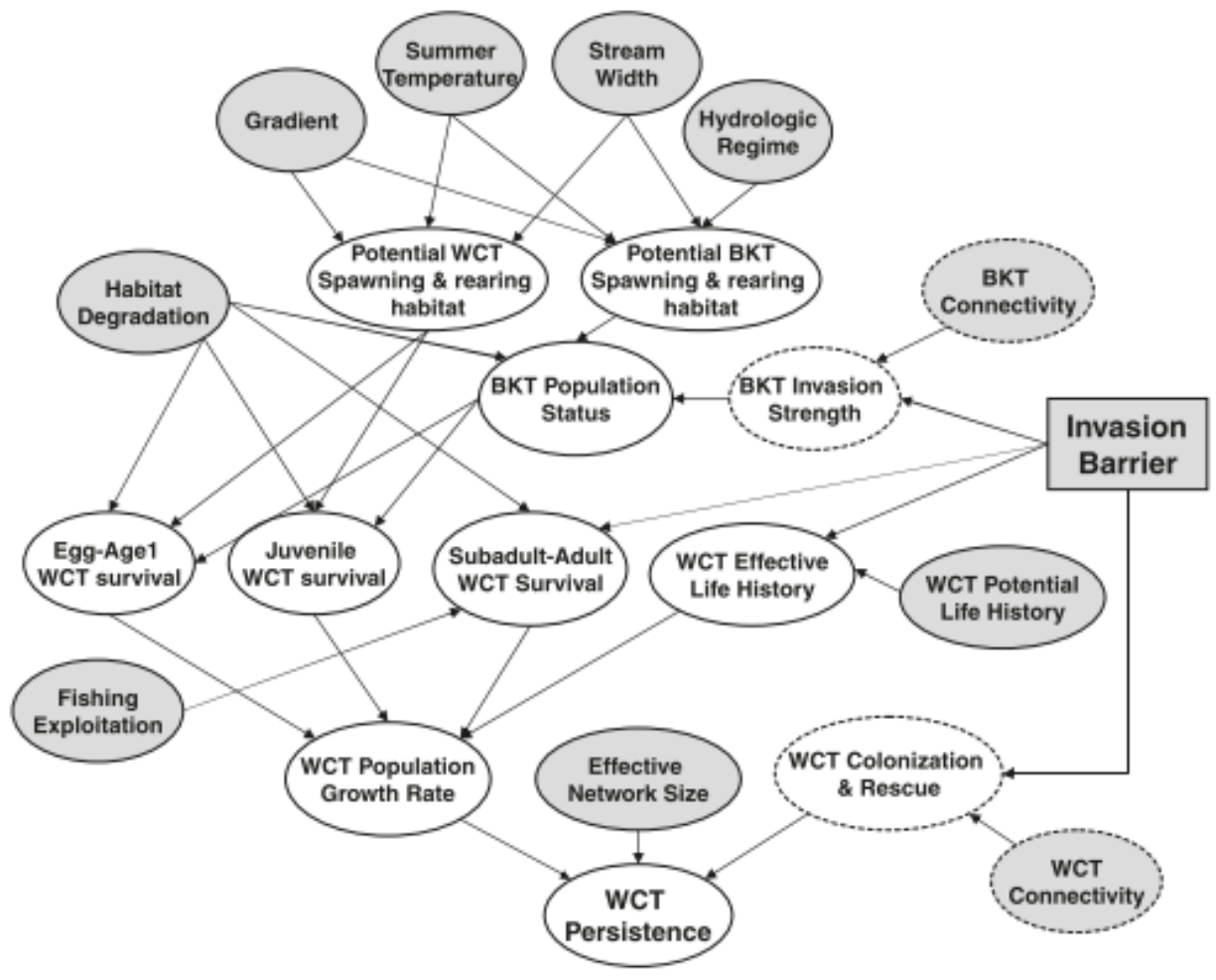

Figure 1-3. Bayesian relief network conceptual model from Peterson et al. (2008) depicting the functional relationships between invasion barriers, brook trout presence, and multiple physical habitat factors related to the persistence of WCT. This diagram represents a functioning model that can be used by managers to determine whether to remove or retain passage barriers. Managers can use a range of input values to assess the repercussions of various barrier management decisions.

During the late 1990s, the Washington Department of Fish and Wildlife produced a fish passage prioritization manual aimed at providing guidance for conducting fish passage and surface water diversion inventories and identifying which structures present the most gains from removal or remediation (Washington Department of Fish and 
Wildlife 2009). This manual has been used widely in the state of Washington and has been continually updated through 2009. This approach focuses on estimating percent passability at artificial barriers by combining professional judgement and the abilities of occupying species to negotiate water surface drop, velocity, and depth (Washington Department of Fish and Wildlife 2009). Structures are evaluated as a total (0\% passable), partial (33\% passable), less severe (67\% passable), or a non-barrier (100\% passable). Once the passage status of a structure is classified, the potential gain in habitat area is estimated and a Priority Index rating is given to the structure, allowing for comparison to other barriers. The structure with the highest rating is identified as the most pressing structure to remove, replace, or improve. However, unlike the first two frameworks described above (Fausch et al. 2006, Peterson et al. 2008), the WDFW model does not account for the presence of non-native fishes. This is important because as described previously, many studies point towards using isolation management to preserve the populations of native fish existing above impassable barriers.

\section{Mill Creek A-To-Z Watershed Restoration Project}

The Mill Creek A-to-Z projects (A to Z) are watershed restoration projects conducted by the United States Forest Service that provided data for this study. The Three Rivers Ranger District proposed two projects under A to Z on a portion of the Colville National Forest northeast of Colville, WA in two adjacent drainages: the North Fork Mill Creek (NFMC) and the Middle and South Forks of Mill Creek (MSFMC) (Figure 1-4). Planning for these projects began in 2013 with the goal of improving overall 
watershed function through habitat improvements and other restoration-focused activities in the Colville National Forest. In accordance with the National Environmental Protection Act (NEPA), detailed inventories of existing natural resources were conducted to inform various management actions and to evaluate potential effects of proposed actions. The NEPA analyses were performed by Cramer Fish Sciences of Lacey, WA under the direction of the Forest Service. Three management alternatives were analyzed in each project. The first would allow the project area to continue to progress naturally with no improvements to roads or forest health treatments. The second would include forest health treatments, reconstruction, maintenance, and decommissioning of detrimental roads, and habitat improvements. The third would be similar to the proposed action, but would not involve construction of temporary roads. 


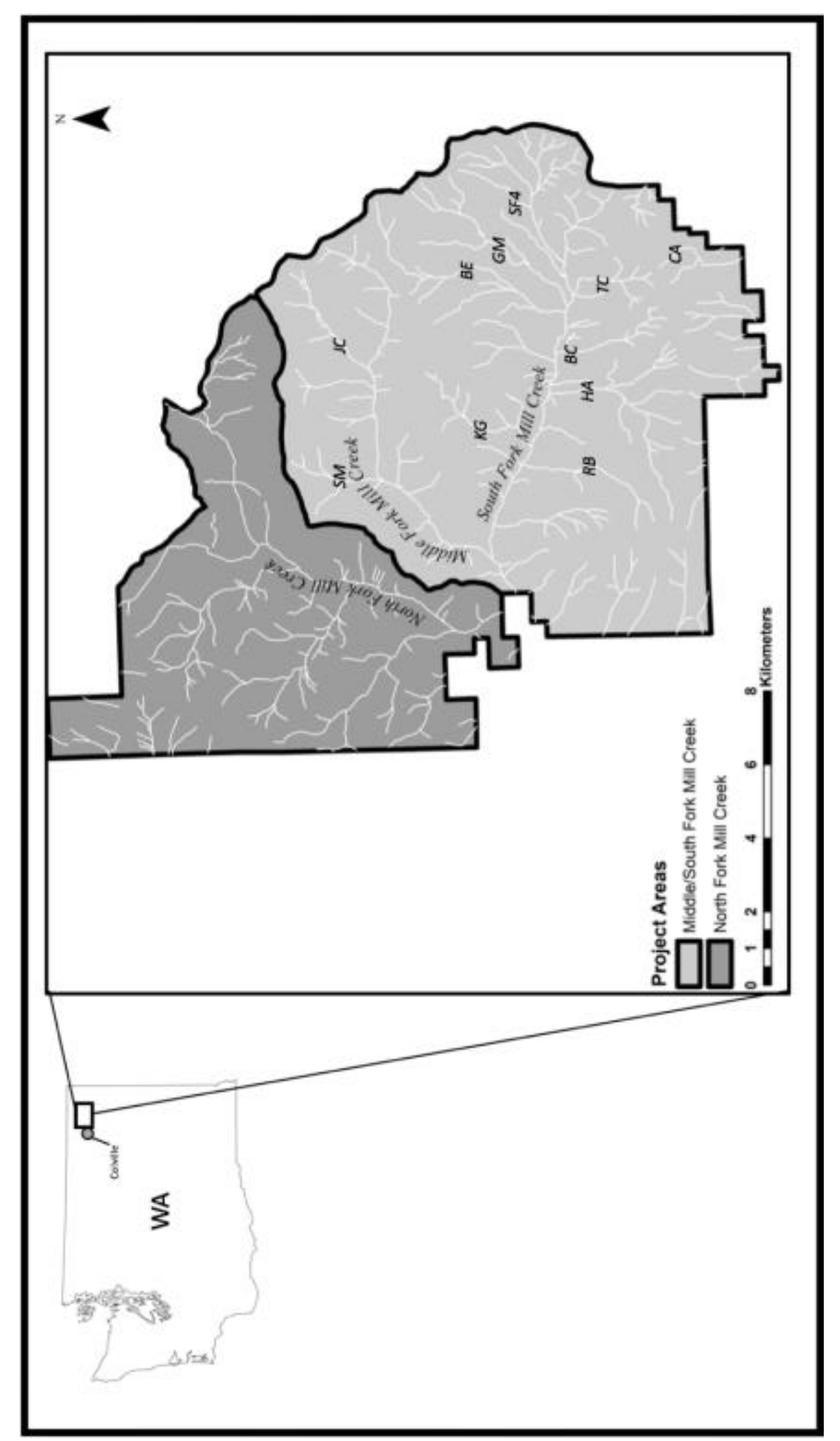

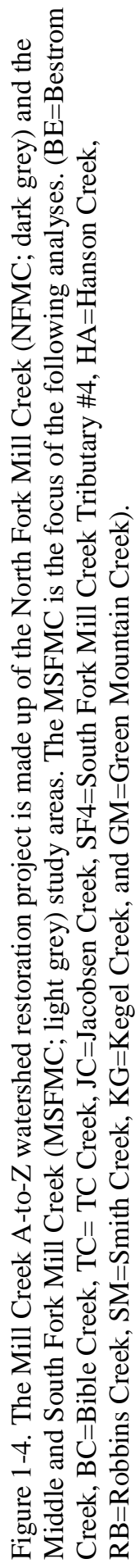


Planning for the North Fork Mill Creek Project began in 2013 and collection of field data was concluded at the end of that year. Planning for the Middle and South Fork Mill Creek Project (MSFMC) began in 2015 and field data collection concluded at the end of that year. As a result of the MSFMC project, a distinct separation of two species of fish distributions was revealed following analysis of fish distribution survey data. Westslope Cutthroat Trout and EBT were found in varying degrees of sympatry throughout the basins, except when streams were impassable or when blocking culverts were present. Numerous blocking culverts separated sympatric WCT and EBT populations existing below the structure from allopatric WCT populations existing above blocking culverts. A number of questions were raised concerning why this separation was occurring and what habitat features were most important to persistence of the isolated populations of WCT above these barriers. The two questions at the heart of this investigation are:

1. Are physical in-stream habitat features driving IWCT distributions in the MSFMC project area?

2. What physical in-stream habitat features are IWCT most associated with?

An important finding was the degree of fragmentation existing in reaches supporting allopatric WCT populations due to the extreme drought experienced by the western United States during 2015. Populations above barriers were surviving in stream reaches that were mostly absent of water and completely disconnected from downstream sections of stream during the peak of the summer. 
The following thesis chapters further address issues associated with WCT habitat use, requirements, and status above and below migration barriers. Chapter 2 characterizes WCT habitat conditions and use within the project area, and provides comparisons between habitat requirements supporting allopatric WCT population above migration barriers and sympatric populations of WCT and EBT. Chapter 3 presents and describes the results of logistic predictive modelling of WCT presence and absence above barriers. Chapter 4 summarizes findings from the previous chapters, draws conclusions, and identifies important areas for future research. 
Chapter 2 - Characterization of Isolated Westslope Cutthroat Trout (Oncorhynchus clarki lewisi) Habitat Above Migration Barriers in the Middle and South Fork Mill Creek Drainage, Colville National Forest, Washington

\section{Introduction}

Stream channels are impacted by biotic, climatic, and hydro-geomorphic processes (Kasprak et al. 2016), while simultaneously coupling aspects of the terrestrial and aquatic ecosystems (Sullivan et al. 1987) with longitudinally variable but predictable physical processes (Vannote et al. 1980). Physical stream processes such as flow conditions directly affect the quality and quantity of available aquatic habitat in the stream channel, which varies across temporal and spatial scales (Sullivan et al. 1987). Salmonids are arguably one of the most important aquatic vertebrate taxa groups in Pacific Northwest rivers, and exhibit a complex, variable, and diverse suite of life histories across populations (Milner et al. 2003). Collectively, they occupy a wide array of stream habitats across life stages and exhibit diverse life histories (Quinn 2011).

Resident trout populations are highly influenced by habitat quality (Lewis 1969) (Figure 2-1) and quantity, the effects of which differ by life stage (Sullivan et al. 1987). Temporal and spatial variability in habitat quality and quantity poses a considerable challenge for managing and conserving sensitive native trout populations. To meet these challenges, natural resource and fisheries management programs in the western United States will need to be increasingly responsive and dynamic, especially in response to the variable predictions of climate change. Current management strategies often involve balancing multiple stakeholder interests with the persistence of important native fish 
populations. Regardless of the positive effects of protective measures and habitat restoration activities, ongoing effects of climate change (e.g., increased precipitation variability, increased frequency and severity of drought and wildfires) will increasingly require fish managers to understand and prioritize components of sensitive salmonid habitats that best contribute to the persistence of sensitive populations, such as populations residing in low order headwater streams.

Of particular importance in the interior west is the native Westslope Cutthroat Trout (Oncorhynchus clarki lewisi, WCT). Historical WCT distributions have substantially declined due to a myriad of anthropogenic and climatic influences (Young et al. 1995, Fausch et al. 2006, Haak et al. 2010) (Figure 2-1). Westslope Cutthroat Trout require a narrow range of habitat conditions to persist in their native environments, including the presence of coldwater pools, limited fine substrate, ample cover and refugia, and limited competition from invasive species (Young et al. 1995). It is well documented that sympatric populations of WCT and eastern brook trout (Salvelinus fontinalis; EBT) tend to occupy different areas of streams due to species-specific differences in habitat requirements. However, despite this spatial resource partitioning, WCT are often displaced by EBT to lower order, headwater areas (Shepard 2004), suggesting that WCT prefer colder water or smaller streams than other salmonids, both of which are characteristic of headwater areas. This observation is supported by empirical rearing distributions of WCT commonly involving cooler upper reaches of watersheds (Young et al. 1995). Displacement of WCT by EBT is also influenced by abiotic factors 
such as water temperature, debris and pool frequencies, erosion and deposition of fine sediments, and combinations of these and other factors (Shepard 2004) (Figure 2-1).

Generally, pools in forested areas are formed around structural elements or obstructions (Sullivan et al. 1987) in the channel. Woody debris is one of the most important factors in determining the distribution of pools in forest streams (Sullivan et al. 1987). Riffles are generally shallow sections of stream with significant surface turbulence and rough bed substrate. Pools and riffles provide important habitat for spawning and rearing of salmonids (Figure 2-1) (Bjornn et al. 1977, Montgomery et al. 1999, Cramer and Ackerman 2009). Glides lack the turbulent flow of riffles and are generally uniform vertically, horizontally, and longitudinally with smooth bed substrate. Glides typically provide refuge and feeding opportunities for rearing juvenile salmonids (Figure 2-1). Finally, rapids and cascades are typically steep in gradient and are often composed of plunge pools due to the steep gradient and the presence of large substrate and woody debris. Detailed habitat unit classification descriptions can be found in Montgomery and Buffington (1997). 


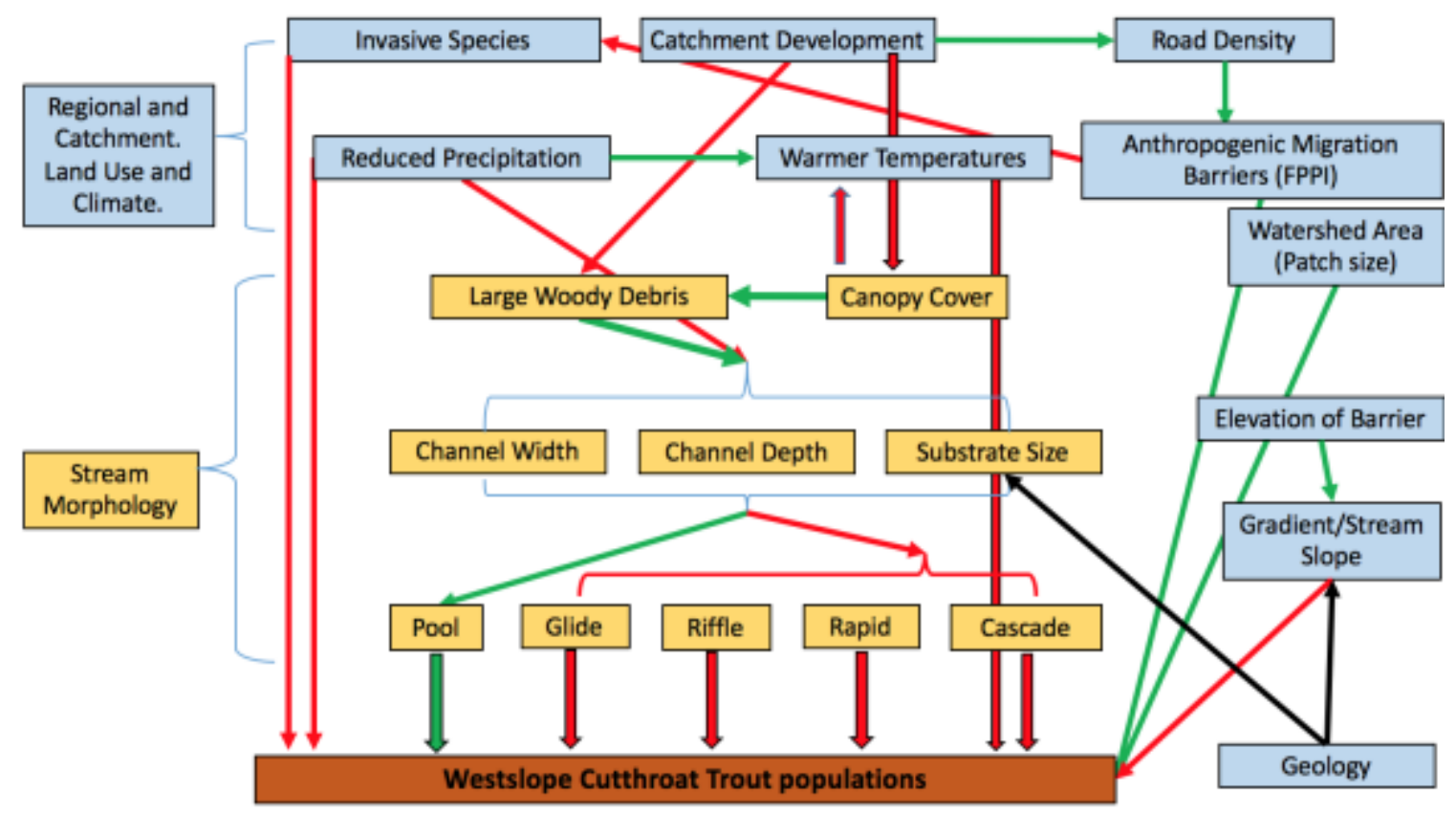

Figure 2-1. Conceptual model describing the relationships between presence of allopatric isolated population of WCT above migration (IWCT) and various instream habitat specific processes. Yellow boxes represent habitat data collected as part of stream surveys during the summer of 2015 in the MSFMC project area that were used in this analysis. Red arrows represent a negative relationship, green arrows represent a positive relationship, and black arrows represent a variable relationship. Blue boxes represent watershed level factors not used in this analysis, but important drivers in IWCT persistence.

As displacement of WCT to low order headwater streams increases in prevalence across the western United States, it will be increasingly important to identify where these changes are occurring to better understand differences in biotic and abiotic factors supporting native and non-native fish up- and downstream of these physical migration barriers, whether artificial or natural.

This paper analyzes empirical fish distribution and stream habitat data collected in the Colville National Forest (CNF), Washington, and characterizes suitable habitat based on the occurrence (presence or absence) of allopatric WCT above four migration barriers. This study focuses on fish distribution, habitat conditions, and barrier occurrence data 
collected during the summer of 2015, a year of extreme drought in the western United States. Westslope Cutthroat Trout were observed in sympatry with EBT (Hereafter WCT/EBT) in the Mill Creek drainage. Isolated WCT populations (Hereafter IWCT) were observed in allopatry above four artificial migration barriers. The objective of this study was to assess differences in physical stream habitat occupied by these two types of WCT populations. Stream habitat quality indicators were used to characterize and statistically compare the occurrence of each of these two population types address the question: Are in stream habitat features driving IWCT distributions in the MSFMC project are? Does in-stream habitat differ significantly among channel units containing populations of IWCT and channel units containing WCT/EBT? Here, I hypothesize that habitat conditions will differ significantly between channel units containing IWCT and those containing WCT/EBT. Specifically, units containing IWCT will likely have more cover (stream shade, large woody debris, and large substrate) than units supporting sympatric populations of WCT/EBT. Results will also be used to identify aspects of physical habitat that would benefit from instream restoration opportunities. Because this analysis was conducted with a single year of data, results are considered preliminary and should be followed with further field observational efforts across seasons and consecutive years. 
Methods

\section{$\underline{\text { Study Area }}$}

The Mill Creek watershed occupies the northeast portion of the Colville National Forest (CNF) (Figure 2-2). The CNF covers over 4,000 $\mathrm{km}^{2}$ including the Kettle River and Selkirk mountain ranges within the US portion of the upper Columbia River Basin. The CNF landscape was formed over long periods of glacial influence. During the Pleistocene, the landscape was covered by a continental sheet ice that descended south into the current study area from British Columbia. Two major advances of glacial ice that encompassed the study area, ranging from 900 to 2,100 meters thick, created the round, gently sloping mountains common in this region (Richmond et al. 1965, Williams et al. 1995). The broader valley bottoms are dominated by kame terrace outwash and lacustrine deposits. Despite being over $500 \mathrm{~km}$ inland, the $\mathrm{CNF}$ is influenced by maritime and continental climate regimes, with the heaviest precipitation occurring during winter and spring. The valleys receive between 38 and 63.5 centimeters of rain, whereas the adjacent mountainous regions receive from 100 to 130 centimeters annually (Williams et al. 1995). Average summer temperatures $\left({ }^{\circ} \mathrm{C}\right)$ range from the upper $10 \mathrm{~s}$ to the $30 \mathrm{~s}$, while winter temperatures $\left({ }^{\circ} \mathrm{C}\right)$ are commonly cold, from -15 to -5 (Williams et al. 1995). Soils in the CNF are mainly composed of glacial till, outwash, lacustrine deposits, colluvium, and alluvium (Williams et al. 1995). Historically, mining, timber harvest, and ranching were the main sources of economic prosperity in the region (USFS 2015). Mining began during the early 1900s and continued into the 1920s, while logging and ranching remain economically important activities throughout the CNF. Twenty thousand acres in the 
CNF were burned by the White Mountain Fire in 1988, while drier parts of the forest burn every twenty or thirty years. Extensive wildfire activity is commonly observed in neighboring regions throughout the summer months (USFS 2015), and has been predicted to increase as regional climates are becoming warmer and drier compared to past and current conditions (ISAB 2007, Tohver et al. 2014). The study area is located in the northeast portion of the CNF northeast of the city of Colville, WA (Figure 2-2). 


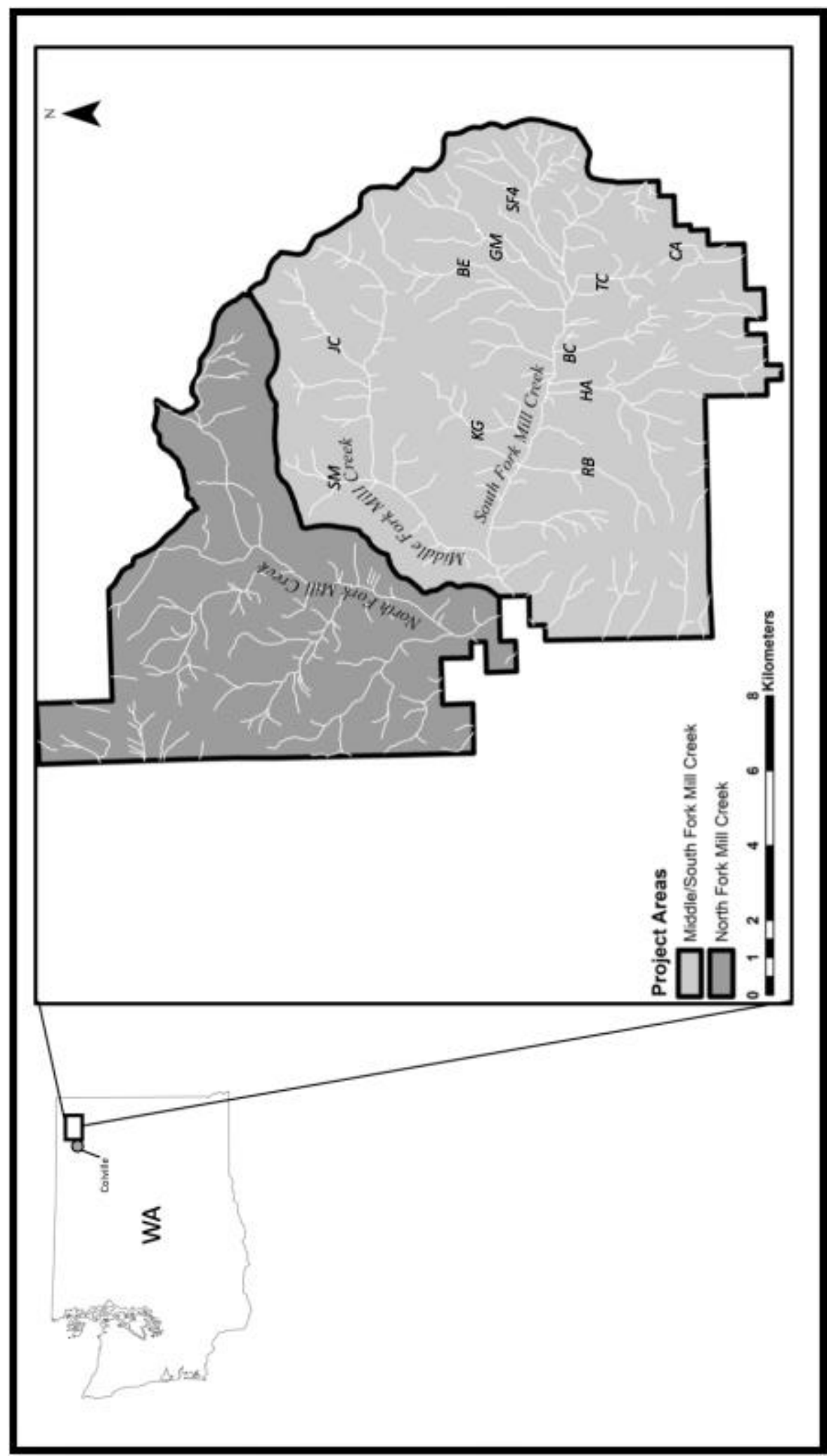

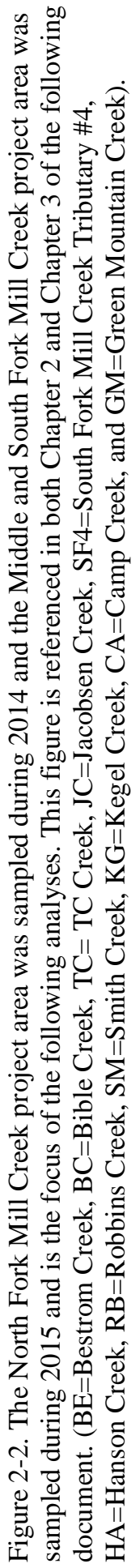




\section{Fish Distribution Mapping}

Fish distribution surveys were performed by field crews that visited every tributary adjacent to or within the MSFMC project area (Figure 2-2) between June and July 2015. Surveys started at the currently mapped extent of fish bearing streams and/or at the furthest downstream extent of USFS ownership. Potential fish habitat, was defined by a channel with "sufficient water," was surveyed by a two-person electrofishing crew following approved electrofishing guidelines (NMFS 2000). Sufficient water referred to the quantity and quality of water present in the stream channel at the time of sampling, defined as water less than $18^{\circ} \mathrm{C}$, with adequate volume to maintain a $1 / 2$ meter distance from the anode of the electro-fisher to fish present in the stream (NMFS 2000). A SmithRoot LRB24 electrofishing backpack was used and settings were adjusted based on stream conductivity to ensure that the adverse effect of electrofishing on fish was minimized. Field crews walked all mapped streams, while also documenting streams not identified by previous mapping efforts. In areas lacking a defined channel (wet or dry), mapped stream segments were recorded as having "no defined channel" and in such cases no further data were collected. Well-defined channels lacking water were recorded as the "maximum potential extent of fish distribution." Streams were surveyed during late spring to ensure that water levels and fish distributions were sampled at their maximum seasonal extent. An impassible waterfall on Mill Creek downstream of the project area precluded anadromous fish (i.e. migratory fish that spawn in freshwater but mature in the ocean) from accessing streams in the project area, eliminating the need to account for their presence in this study. 
Each stream was either electrofished along its entire length throughout the study unit boundary or for 400 meters past last fish designation, whichever was greater. Fish distribution survey protocols (WDNR 2002, Cole and Lemke 2003) required surveyors to investigate 400 meters or a total of 12 high quality pools (approximately $1 \mathrm{~m}^{2} \mathrm{x} 0.3 \mathrm{~m}$ deep) upstream from the last detected fish during each survey to ensure detection of the upstream limit of fish distribution. However, some stream reaches did not contain 12 high quality pools. In such cases, habitat data were collected to confirm that the minimum number of pools did not exist. Basic habitat survey data including bank full and wetted width, depth, length, and longitudinal gradients were collected to substantiate the absence of high quality pools and corroborate fish bearing and non-fish bearing status. Survey efforts ceased upstream from the point of last known fish use if stream channel gradient increased above 20 percent and persisted, or if the defined channel went dry and did not reappear. Sufficient habitat for fish bearing streams was defined as sections of stream containing fish upstream from USFS Class I/II designated waters.

Any additional fish bearing streams (USFS Class I/II) located as part of these surveys along or within proposed treatment units were mapped with a handheld Garmin GPS unit with +/- 5m accuracy. Additional spatially explicit data were collected, including GPS points of the upper extent of fish bearing water in tributaries/headwaters, and locations of individually detected fish, as identified by species. These data were used to estimate the total length of fish bearing streams on NFS lands within the project area by overlaying the result onto existing stream GIS layers provided by the USFS. The stream layers were then adjusted to reflect any changes from the extent of fish surveys. 


\section{$\underline{\text { Road Crossing Assessments }}$}

The locations of road crossings and habitat conditions 100m upstream and downstream from those crossings were recorded at the end of July 2015 to document the effect of that structure on the stream channel. The type of structure associated with each crossing (e.g., culvert or bridge) was characterized, measured, and photographed. Artificial barriers were evaluated using Washington Department of Fish and Wildlife's 2009 Fish Passage Barrier and Surface Water Diversion Screening and Prioritization Manual (Washington Department of Fish and Wildlife 2009) to help guide restoration opportunities within the project area.

\section{Stream Habitat Assessment}

Based on the results of fish distribution mapping, habitat surveys were performed from early August to late September and subsequently analyzed to characterize physical attributes of stream habitat. We used methods adapted from Cramer and Ackerman (2009) that were designed to collect basic stream channel characteristics important to salmonids (Table 2-1 and Table 2-2). A 20\% subsample of fish bearing streams was surveyed, unless roads crossed these streams, in which case $100 \%$ of the habitat area 100 meters upstream and downstream from the crossing location was sampled. This methodology was used to efficiently sample a large range of habitat while accounting for potential localized effects of disturbances like roads that could have a strong influence on a small spatial scale (Hankin and Reeves 1988). Stream dimensions were determined 
using a surveyor caliber stadia rod (25ft/7.6m SK Level Rod) and an engineering level distance laser range finder (Leica DISTO 3000 Laser Distance Meter). Stream shade was determined using a forester grade spherical crown densiometer (Forestry Suppliers Spherical Crown Densiometers). Substrate was qualitatively assessed in each sampled channel unit by visually estimating percent coverage of each substrate category (Table 2-1). 
Table 2-1. Descriptions of metrics included in field survey efforts (CAT=Categorical, NUM=Numerical, PER=Percent, and CNT=Count). This table is referenced extensively through this paper.

\begin{tabular}{|c|c|c|c|c|c|}
\hline Metric & Description & Units & $\begin{array}{l}\text { Data } \\
\text { Type }\end{array}$ & Abbreviation & Citation \\
\hline $\begin{array}{l}\text { Geomorphic } \\
\text { unit type }\end{array}$ & $\begin{array}{l}\text { Subjectively } \\
\text { marked as a pool, } \\
\text { riffle, glide, } \\
\text { rapid, cascade, or } \\
\text { beaver pond } \\
\text { based on specific } \\
\text { features observed } \\
\text { in stream } \\
\text { gradient, water } \\
\text { velocity and } \\
\text { depth, and } \\
\text { channel } \\
\text { morphology. }\end{array}$ & $\begin{array}{l}\mathrm{P}, \mathrm{RI}, \mathrm{GL}, \\
\mathrm{RA} \text {, or CA }\end{array}$ & CAT & $\begin{array}{l}\text { Pool }(\mathrm{P}), \\
\text { riffle (RI), } \\
\text { glide (GL), } \\
\text { rapid (RA), } \\
\text { cascade } \\
(\mathrm{CA})\end{array}$ & $\begin{array}{l}\text { (Montgomery } \\
\text { and } \\
\text { Buffington } \\
\text { 1997) }\end{array}$ \\
\hline $\begin{array}{l}\text { Geomorphic } \\
\text { unit length }\end{array}$ & $\begin{array}{l}\text { The total } \\
\text { geomorphic unit } \\
\text { length of each } \\
\text { identified unit's } \\
\text { upper and lower } \\
\text { bounds in the } \\
\text { stream channel. }\end{array}$ & Meters & NUM & LENG_m & $\begin{array}{l}\text { (Montgomery } \\
\text { and } \\
\text { Buffington } \\
\text { 1997) }\end{array}$ \\
\hline $\begin{array}{l}\text { Geomorphic } \\
\text { channel } \\
\text { width }\end{array}$ & $\begin{array}{l}\text { Average width is } \\
\text { estimated by } \\
\text { observing the } \\
\text { wetted edges of } \\
\text { the stream along } \\
\text { the longitudinal } \\
\text { axis of the unit. }\end{array}$ & Meters & NUM & WID_m & $\begin{array}{l}\text { (Montgomery } \\
\text { and } \\
\text { Buffington } \\
\text { 1997) }\end{array}$ \\
\hline $\begin{array}{l}\text { Stream } \\
\text { depth }\end{array}$ & $\begin{array}{l}\text { Average depths } \\
\text { were recorded for } \\
\text { all channel unit } \\
\text { classifications } \\
\text { except for pools } \\
\text { where maximum } \\
\text { depth was } \\
\text { recorded. }\end{array}$ & Meters & NUM & DEP_m & $\begin{array}{l}\text { (Montgomery } \\
\text { and } \\
\text { Buffington } \\
\text { 1997) }\end{array}$ \\
\hline
\end{tabular}


Table 2.1. Continued

\begin{tabular}{|c|c|c|c|c|c|}
\hline $\begin{array}{l}\text { Substrate } \\
\text { classificatio } \\
\text { ns }\end{array}$ & $\begin{array}{l}\text { Stream bed } \\
\text { substrate } \\
\text { compositions } \\
\text { were estimated } \\
\text { visually for the } \\
\text { extent of each } \\
\text { individual unit. }\end{array}$ & $\begin{array}{l}\text { Fine } \\
(<2 \mathrm{~mm}), \\
\text { gravel }(2- \\
64 \mathrm{~mm}), \\
\text { cobble }(64- \\
256 \mathrm{~mm}), \\
\text { boulder } \\
\text { (>256mm), } \\
\text { and } \\
\text { bedrock. }\end{array}$ & PER & $\begin{array}{l}\text { Fine (FI), } \\
\text { Gravel } \\
\text { (GRA), } \\
\text { Cobble } \\
\text { (COB), } \\
\text { Boulder } \\
\text { (BD), or } \\
\text { Bedrock } \\
\text { (BDR) }\end{array}$ & $\begin{array}{l}\text { (Wentworth } \\
\text { 1922) }\end{array}$ \\
\hline $\begin{array}{l}\text { Large } \\
\text { woody } \\
\text { debris } \\
\text { counts }\end{array}$ & $\begin{array}{l}\text { Large woody } \\
\text { debris was } \\
\text { counted for two } \\
\text { categories. }\end{array}$ & $\begin{array}{l}\text { 1) small } \\
\text { wood: } \\
>10 \mathrm{~cm} \\
\text { diameter } \\
\text { and }>2 \mathrm{~m} \\
\text { length and } \\
2 \text { ) PIBO } \\
\text { (large) } \\
\text { wood: }>1 \mathrm{~m} \\
\text { diameter } \\
\text { and }>8 \mathrm{~m} \text { in } \\
\text { length. }\end{array}$ & CNT & $\begin{array}{l}\text { Large wood } \\
\text { debris small } \\
\text { pieces } \\
\text { (LWDS) or } \\
\text { large pieces } \\
\text { (LWDP) }\end{array}$ & $\begin{array}{l}\text { (Beechie and } \\
\text { Sibley 1997) }\end{array}$ \\
\hline $\begin{array}{l}\text { Active } \\
\text { channel } \\
\text { width }\end{array}$ & $\begin{array}{l}\text { Active channel } \\
\text { width can be } \\
\text { defined by the } \\
\text { distance across } \\
\text { the channel at } \\
\text { "bankfull" flow } \\
\text { which is typically } \\
\text { attained every } 1.5 \\
\text { years and visible } \\
\text { at vegetation and } \\
\text { high water marks. }\end{array}$ & Meters & NUM & ACW_m & $\begin{array}{l}\text { (Montgomery } \\
\text { and } \\
\text { Buffington } \\
\text { 1997; Cramer } \\
\text { and } \\
\text { Ackerman } \\
2009 \text { ) }\end{array}$ \\
\hline $\begin{array}{l}\text { Thalweg } \\
\text { height }\end{array}$ & $\begin{array}{l}\text { Height from the } \\
\text { streambed to } \\
\text { active channel } \\
\text { delineation }\end{array}$ & Meters & NUM & $\mathrm{TH}$ & $\begin{array}{l}\text { (Montgomery } \\
\text { and } \\
\text { Buffington } \\
\text { 1997) }\end{array}$ \\
\hline
\end{tabular}


Table 2-1. Continued.

\begin{tabular}{|llllll|}
$\begin{array}{|lllll|}\text { Canopy } \\
\text { cover }\end{array}$ & $\begin{array}{l}\text { percent cover was } \\
\text { estimated using a }\end{array}$ & Rating of 0- & CAT & CC & (WDNR \\
& $\begin{array}{l}\text { forestry } \\
\text { densitometer }\end{array}$ & & & 2002) \\
& & & & \\
\hline
\end{tabular}

Table 2-2. Wood complexity ratings and descriptions used during stream habitat surveys (Adapted from Cramer and Ackerman 2009).

\section{Wood Complexity Definition Rating}

\begin{tabular}{|ll|}
\hline 1 & Wood debris absent or very low \\
& $\begin{array}{l}\text { Wood present, but contributes little to habitat complexity. Small } \\
\text { pieces creating little cover. }\end{array}$ \\
& $\begin{array}{l}\text { Wood present as combination of single pieces and small } \\
\text { accumulations. Providing cover and some complex habitat at low } \\
\text { to moderate discharge. }\end{array}$ \\
& $\begin{array}{l}\text { Wood present with medium and large pieces comprising } \\
\text { accumulations and debris jams that incorporate smaller root wads } \\
\text { and branches. Good cover for fish over most flow levels. }\end{array}$ \\
& $\begin{array}{l}\text { Wood present as large single pieces, accumulations, and jams that } \\
\text { trap large amounts of additional material and create a variety of } \\
\text { cover and refuge habitats. Woody debris providing excellent } \\
\text { persistent and complex habitat. Complex flow patterns will exist } \\
\text { at all discharge levels. }\end{array}$ \\
5 &
\end{tabular}




\section{Habitat Quality Indicators}

Specific habitat quality indicator values (Table 2-3) were compared between IWCT and WCT/EBT (see pg. 23 for definition) populations to assess potential differences in habitat requirements and to better understand and prioritize restoration opportunities in the study area. Differences in habitat occupancy by these two types of populations were determined by comparing percent fine sediment composition, pool composition and available habitat, presence of large woody debris (LWD), wood complexity ratings, percent stream shade, percent composition of large substrate (cobble and boulders), and width to depth ratios (Table 2-3). These indicators have been shown by multiple studies to accurately predict habitat occupancy by salmonids in the Pacific Northwest (Table 2-3). 
Table 2-3. Habitat quality indicators used to assess and characterize fish habitat throughout the MSFMC project area. The associated source is provided for each metric. For detailed descriptions of specific measurements associated with each metric refer to Table 2-1.

Indicator

Metric

Citation

\begin{tabular}{|c|c|c|}
\hline $\begin{array}{l}\text { Percentage of Fines Substrate } \\
\text { Percentage of Fine Substrate in } \\
\text { Pools and Riffles }\end{array}$ & $\begin{array}{c}\% \text { composition of all total } \\
\text { substrate is each channel unit; } \\
>20 \%\end{array}$ & $\begin{array}{c}\text { Bjorrn (1977); Young et al. } \\
\text { (1995) }\end{array}$ \\
\hline Pool Composition & $\%$ composition of pools & $\begin{array}{c}\text { Shepard (1983), Pratt (1984), } \\
\text { Young et al. (1995) }\end{array}$ \\
\hline $\begin{array}{l}\text { Available Pool Habitat: } \\
\text { Pool Surface Area }(\mathrm{SA})\left(\mathrm{m}^{2}\right) \\
\text { Pool Volume }\left(\mathrm{m}^{3}\right)\end{array}$ & $\begin{array}{l}=(\text { Channel Unit Length }(\mathrm{m})) \\
*(\text { Channel Unit Width }) \\
=\mathrm{SA}^{*}(\text { Channel Unit Depth })\end{array}$ & Bisson et al. (2006) \\
\hline $\begin{array}{c}\text { Frequency of Large Woody } \\
\text { Debris }\end{array}$ & $\begin{array}{l}=(\text { LWDP+LWDS }) \\
\text { Channel Unit Length }\end{array}$ & Archer et al. (2012) \\
\hline Wood Complexity & Rating 1-5 & Young et al. (1995) \\
\hline Stream Shade & $\%$ Stream shade & See Young et al. (1995) \\
\hline $\begin{array}{l}\text { Percentage of Large Substrate } \\
\text { (cobble and boulders) }\end{array}$ & $\begin{array}{c}\% \text { composition of each type of } \\
\text { large substrate } \\
\text { (cobble/boulder) }\end{array}$ & $\begin{array}{l}\text { Wilson et al. (1987), Peters } \\
\qquad(1988)\end{array}$ \\
\hline Width to Depth Ratio & $<10 ; 18$ (CNF PIBO) & Archer et al. (2012) \\
\hline
\end{tabular}




\section{$\underline{\text { Analytical Approach }}$}

\section{Fish Distribution}

Results from the extent of fish survey results were overlaid on GIS stream layers to visually assess species distribution and to calculate individual and total longitudinal channel length in fish bearing streams. These results were used to distinguish channel units occupied by IWCT populations from those occupied by WCT/EBT populations.

\section{Road Crossing Analysis}

Mapped road crossings on fish bearing streams were classified as having partial or complete blockages to upstream fish movement during the flow conditions that occurred during field visits based on criteria in WDFW's 2009 Fish Passage Barrier and Surface Water Diversion Screening and Prioritization Manual (See Table 2-4 and Chapter 10 WDFW 2009). This classification process takes the physical dimensions of the structure along with the existing habitat conditions upstream and downstream, and rates each structure in terms of priority for removal, expressed as a fish passage priority index (FPPI) value (Table 2-4). Suitable fish habitat upstream of barriers was quantified to prioritize their potential removal or replacement values based on their corresponding FPPI rating. Suitable upstream fish habitat was estimated by averaging the wetted stream width and multiplying by the length of stream present upstream of the road crossing. 
Table 2-4. Criteria used to assess passability of each road crossing structure in the study area. If stream channels were absent of water during field assessment they received a passability rating of 0 due to the depth parameter in level B of the assessment process. Revised from Table 3.3 from WDFW 2009 Fish Passage Barrier and Surface Water Diversion Screening and Prioritization Manual used to populate fish passage priority index equation (FPPI).

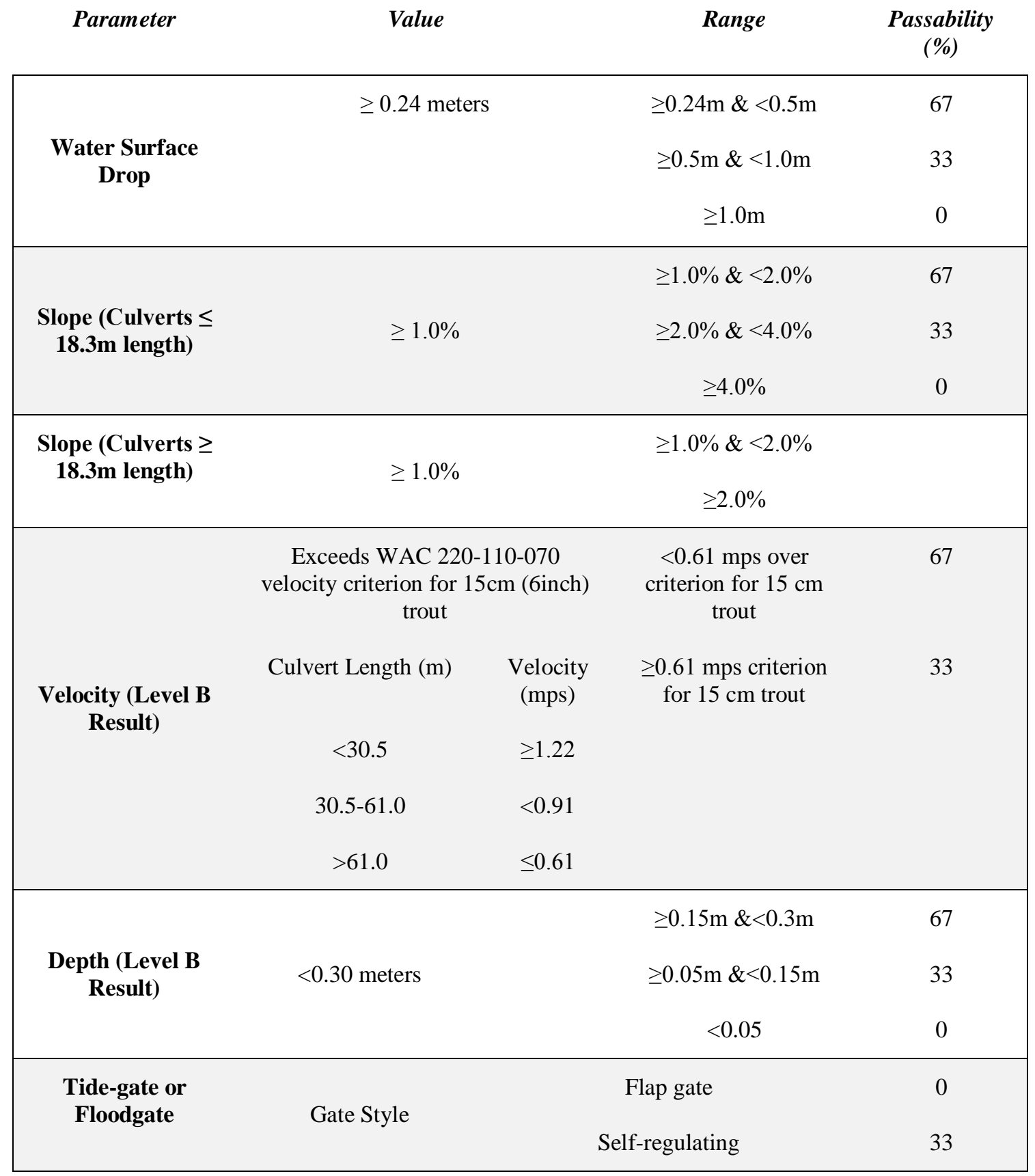




\section{Stream Habitat Assessment}

Habitat surveys in fish bearing streams were completed to characterize the current conditions of the affected environment based on specific habitat quality indicators important to native salmonid persistence across life stages. Indicators included: 1) average percent composition of fines substrate, 2) composition of pools and amount of available pool habitat, 3) large woody debris frequency, 4) wood complexity rating, 5) stream shade (canopy cover), 6) percent of large substrate (cobble and boulders), and 7) width to depth ratios (Table 2-3). Pool composition was calculated as the number of pools observed throughout the project area divided by the total units sampled. Pool surface area and volume were measured using methods modified from Bisson et al. 2006. Pool surface area was calculated by multiplying length and width measurements of each pool channel unit sampled. Pool volume was calculated by multiplying pool area by the maximum pool thalweg depth measurement. Substrate composition was measured for each channel unit sampled (i.e. fine sediment, gravel, cobble, and boulder substrate). Large woody debris frequency was calculated by adding counts of LWDP and LWDS (see Table 2-1) and dividing it by channel unit length. Wood complexity ratings were determined for each unit in the field. Stream shade was measured in the field using a forester grade densiometer. Width to depth ratios were calculated by dividing the channel unit width by channel unit depth. Habitat quality indicators were analyzed based on species compositions according to extent of fish and fish distribution mapping surveys; channel units containing IWCT were compared to channel units containing WCT/EBT. 


\section{Habitat Quality Indicators}

A Shapiro-Wilk test of normality was used to determine if data distributions adhered to assumptions of normality. Appropriate transformations were applied as determined by a BoxCox power transformation method to attempt to meet parametric assumptions. Equal variance was visually assessed using boxplots for each grouping of data (IWCT and WCT/EBT). All data analyses were performed using R statistical software (R version 3.2.2, CRAN Team) and include multiple statistical packages (Wickam 2009, Wickam and Francois 2015, Wickam 2016). A Wilcoxon Rank Sum test with continuity corrections was used to test the null hypothesis that the median difference between pairs of observations (IWCT and WCT/EBT) was zero. A Wilcoxon Rank Sum test (the non-parametric test equivalent of a $t$-test; also referred to as a Mann-Whitney $\mathrm{U}$ test), was used when assumptions of normality and equal sample size were not met. For habitat quality predictors measured using a rating scheme (i.e. Wood complexity rating, see Table 2-2), a Pearson's Chi-square contingency test was used due to the categorical nature of those variables. Collectively, these comparisons provided an indication of current physical fish habitat conditions in the project area and of differences in habitat required for each population occurrence. An alpha of 0.05 was used in this study and is commonly used in hypothesis testing in similar studies (Bozek and Hubert 1992, Novinger and Rahel 2003, Penaluna et al. 2015). However, it is important to keep in mind the errors that are associated with hypothesis testing, namely, type I error which is defined as falsely rejecting a null hypothesis that is actually true. (Gotelli and Ellison 2013). To control for type I error a low alpha value is generally used to reduce the chance 
of falsely rejecting a null hypothesis. Type II error is when a false null hypothesis is incorrectly accepted. However, controlling for type I error inherently increases the risk for type II error to occur. For this study, an alpha of 0.5 will be sufficient to minimize the chance of committing both type I and II error.

An important note to keep in mind when interpreting the following results is the timing of each of the surveys described in the analytical methods sections. Extent of fish surveys were conducted in early June and July. Road crossing assessments were finished by the end of July. Habitat characterization surveys were conducted last, beginning in August and wrapping up shortly after October 1. Most important to the analysis presented here is the time difference between the extent of fish and stream habitat characterization surveys, because a substantial amount of habitat characterized to support fish in June and July no longer contained water when reexamined in August, September or October. However, if channel units that were dry landed in the subsample of habitat to be measured the unit was measured, but channel unit width and depth were recorded as " 0 " because the channel was absent of water. Units recorded as dry were not included in the habitat quality indicators analysis nor the logistic regression analysis presented in Chapter 3. 
Results

\section{Current Fish Distribution}

Over $56 \mathrm{~km}$ of the Middle and South Forks of the Mill Creek were surveyed to determine the extent of occupancy by fish within the project area (Figure 2-3). Approximately 30 fish bearing stream segments were identified as part of this effort, including named and unnamed tributaries in the Middle and South Forks of the Mill Creek (Figure 2-3 and Table 2-5). Fish bearing designation was applied to approximately $41 \mathrm{~km}(\approx 73.2 \%)$ of the total stream kilometers surveyed (Table 2-5). Extent of fish surveys indicated that fish bearing streams were inhabited predominantly by WCT and EBT, both exhibiting resident life histories. Non-native EBT were distributed throughout the study area, except upstream from four fish blocking culverts (see Table 2-6). Abundance was relatively low for both species, 110 WCT and 66 EBT were encountered in the study area, respectively and spatially marked with GPS. 


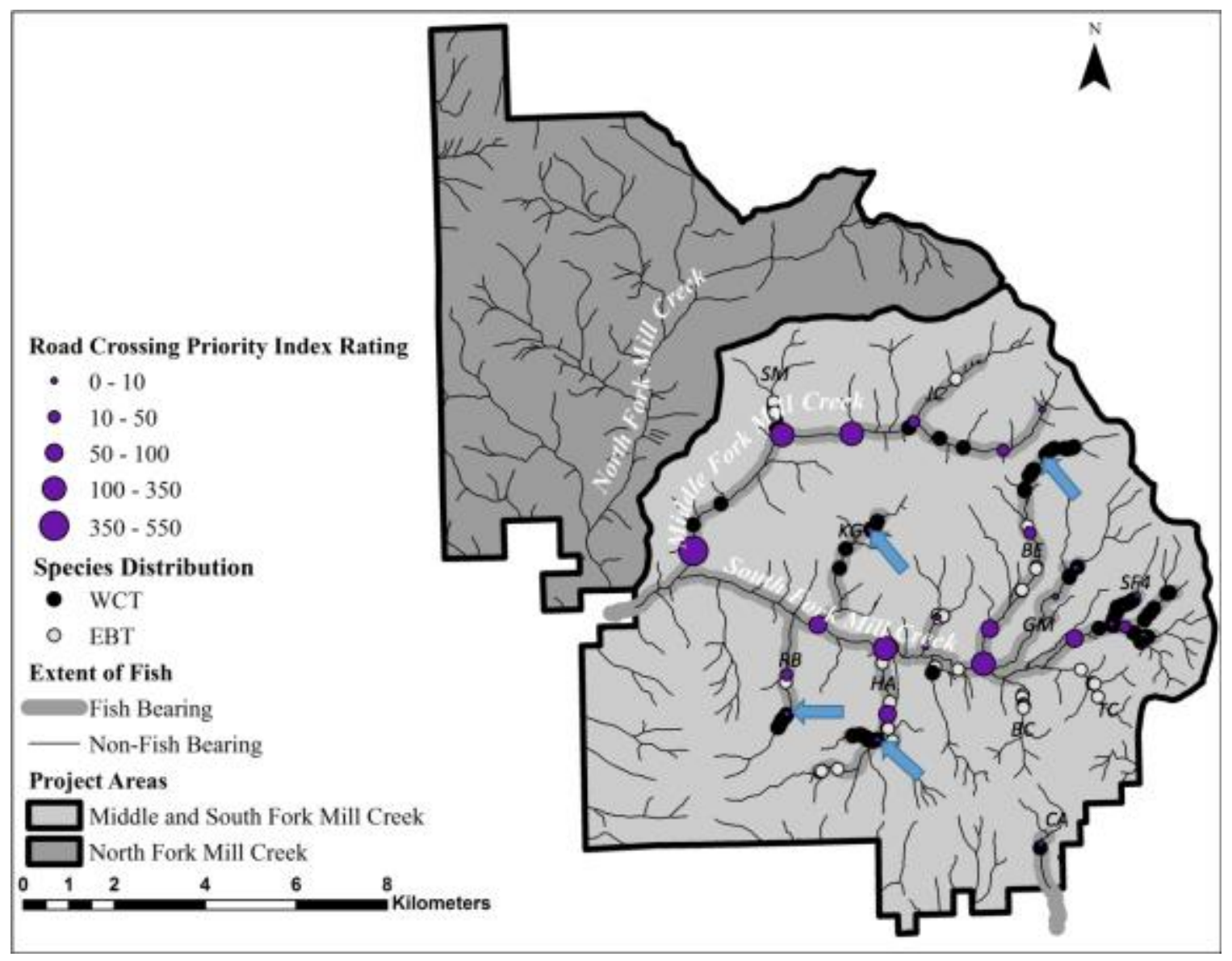

Figure 2-3. Results of extent of fish, fish distribution, and road crossing surveys within the MSFMC project area conducted during the summer of 2015. Blue arrows indicated the locations of four impassable structures preceding allopatric WCT populations (IWCT). Road Crossing Priority index rating refers to the FPPI value calculated as part of the WDFW 2009 fish screen and structure assessment. Values are unitless and used to rank location and identify sites with the greatest impact on available fish habitat (BE=Bestrom Creek, BC=Bible Creek, TC= TC Creek, JC=Jacobsen Creek, SF4=South Fork Mill Creek Tributary \#4, $\mathrm{HA}=$ Hanson Creek, $\mathrm{RB}=$ Robbins Creek, $\mathrm{SM}=$ Smith Creek, $\mathrm{KG}=$ Kegel Creek, $\mathrm{CA}=$ Camp Creek, and $\mathrm{GM}=$ Green Mountain Creek). 
Table 2-5. Length of fish bearing designation applied to each stream surveyed in the MSFMC project area ( $\mathrm{SF}=$ South Fork and MF= Middle Fork).

\begin{tabular}{|c|c|c|}
\hline Stream Name & Watershed & $\begin{array}{l}\text { Length of Fish bearing Designation } \\
\qquad(\mathrm{km})\end{array}$ \\
\hline Bestrom Creek & $\mathrm{SF}$ & 6.00 \\
\hline Bestrom Creek Tributary \#2 & SF & 0.02 \\
\hline Bible Creek & SF & 0.18 \\
\hline Camp Creek & $\mathrm{SF}$ & 1.26 \\
\hline Green Mountain Creek & SF & 3.70 \\
\hline Green Mountain Creek Tributary \#3 & SF & 0.29 \\
\hline Green Mountain Tributary \#5 & SF & 0.27 \\
\hline Hanson Creek & $\mathrm{SF}$ & 3.86 \\
\hline Hanson Creek Tributary \#2 & SF & 0.56 \\
\hline Hanson Creek Tributary \#3 & $\mathrm{SF}$ & 0.01 \\
\hline Hanson Creek Tributary \#4 & $\mathrm{SF}$ & 0.48 \\
\hline Jacobsen Creek & MF & 2.09 \\
\hline Kegel Creek & $\mathrm{SF}$ & 3.38 \\
\hline Middle Fork Mill Creek & MF & 7.24 \\
\hline Robbins Creek & SF & 2.25 \\
\hline Robbins Creek Tributary \#2 & SF & 0.02 \\
\hline Smith Creek & MF & 0.98 \\
\hline South Fork Mill Creek & SF & 4.62 \\
\hline South Fork Mill Creek Tributary \#10 & SF & 0.45 \\
\hline South Fork Mill Creek Tributary \#10A & SF & 0.24 \\
\hline South Fork Mill Creek Tributary \#14 & SF & 0.21 \\
\hline South Fork Mill Creek Tributary \#2 & SF & 1.05 \\
\hline South Fork Mill Creek Tributary \#3 & SF & 0.16 \\
\hline South Fork Mill Creek Tributary \#4 & $\mathrm{SF}$ & 0.40 \\
\hline South Fork Mill Creek Tributary \#5 & SF & 0.53 \\
\hline South Fork Mill Creek Tributary \#9 & $\mathrm{SF}$ & 0.02 \\
\hline TC Creek & SF & 0.80 \\
\hline TC Creek Tributary \#2 & SF & 0.02 \\
\hline TC Creek Tributary \#3 & SF & 0.02 \\
\hline Total & & 41.11 \\
\hline
\end{tabular}


Table 2-6. Summary table of stream priority index rating specific to each stream and various habitat characteristics associated with each road crossing and habitat existing upstream of each crossing $(\mathrm{CMP}=$ corrugated metal pipe, Struct. $=$ Structure, Wid. $=$ width, IWCT? = Isolated WCT existing above structure).

\begin{tabular}{|c|c|c|c|c|c|c|c|c|c|c|}
\hline $\begin{array}{c}\text { Cross } \\
\text { ID }\end{array}$ & $\begin{array}{l}\text { Stream } \\
\text { Name }\end{array}$ & $\begin{array}{c}\text { Struct. } \\
\text { Type }\end{array}$ & $\begin{array}{l}\text { Wid. } \\
(m)\end{array}$ & $\begin{array}{l}\text { Struct. } \\
\text { Length } \\
(\boldsymbol{m})\end{array}$ & $\begin{array}{c}\text { Water } \\
\text { Depth } \\
\text { (m) }\end{array}$ & $\begin{array}{c}\text { Slope } \\
(\%)\end{array}$ & $\begin{array}{c}\text { Hydra } \\
\text { ulic } \\
\text { Drop } \\
(m)\end{array}$ & $\begin{array}{c}\text { (\%) } \\
\text { Passa } \\
\text { ble }\end{array}$ & $\begin{array}{c}\text { Habitat } \\
\text { Existing } \\
\text { Above }\left(m^{2}\right)\end{array}$ & IWCT? \\
\hline $\begin{array}{l}\text { BE1- } \\
\text { RC1 }\end{array}$ & $\begin{array}{l}\text { Bestrom } \\
\text { Creek }\end{array}$ & $\begin{array}{l}\text { Double } \\
\text { CMP }\end{array}$ & 0.60 & 11.6 & 0.05 & 8.00 & 0.58 & 0 & 409 & Yes \\
\hline $\begin{array}{l}\text { BE1- } \\
\text { RC2 }\end{array}$ & $\begin{array}{l}\text { Bestrom } \\
\text { Creek }\end{array}$ & CMP & 0.90 & 7.00 & 0.00 & 2.00 & 0.25 & 33 & 3,631 & No \\
\hline $\begin{array}{l}\text { BE1- } \\
\text { RC3 }\end{array}$ & $\begin{array}{l}\text { Bestrom } \\
\text { Creek }\end{array}$ & CMP & 0.80 & 6.70 & 0.10 & 3.00 & 0.00 & 33 & 7,531 & No \\
\hline $\begin{array}{l}\text { BE1- } \\
\text { RC4 }\end{array}$ & $\begin{array}{l}\text { Bestrom } \\
\text { Creek }\end{array}$ & CMP & 1.30 & 9.70 & 0.06 & 4.00 & 0.10 & 0 & 9,656 & No \\
\hline $\begin{array}{l}\text { CA1 } \\
\text { RC1 }\end{array}$ & $\begin{array}{l}\text { Camp } \\
\text { Creek }\end{array}$ & CMP & 0.80 & 10.10 & 0.15 & 9.00 & 0.20 & 0 & 356 & No \\
\hline $\begin{array}{l}\text { GM1- } \\
\text { RC1 }\end{array}$ & $\begin{array}{l}\text { Green } \\
\text { Mountai } \\
\text { n Creek }\end{array}$ & CMP & 0.83 & 9.30 & 0.00 & 3.50 & 0.10 & 33 & 8 & No \\
\hline $\begin{array}{l}\text { GM1- } \\
\text { RC2 }\end{array}$ & $\begin{array}{l}\text { Green } \\
\text { Mountai } \\
\text { n Creek }\end{array}$ & CMP & 0.85 & 8.60 & 0.00 & 7.50 & 0.65 & 0 & 82 & No \\
\hline $\begin{array}{l}\text { HA1- } \\
\text { RC1 }\end{array}$ & $\begin{array}{l}\text { Hanson } \\
\text { Creek }\end{array}$ & CMP & 1.40 & 10.00 & 0.05 & 5.00 & 0.00 & 0 & 3,554 & No \\
\hline $\begin{array}{l}\text { HA4- } \\
\text { RC1 }\end{array}$ & $\begin{array}{l}\text { Tributar } \\
\text { y to } \\
\text { Hanson } \\
\text { Creek }\end{array}$ & CMP & 2.00 & 7.60 & 0.00 & 3.50 & 0.61 & 33 & 539 & Yes \\
\hline $\begin{array}{l}\mathrm{JC} 1- \\
\mathrm{RC} 1\end{array}$ & $\begin{array}{l}\text { Jacobso } \\
\text { n Creek }\end{array}$ & CMP & 0.92 & 5.70 & 0.16 & 5.00 & 0.00 & 0 & 2,497 & No \\
\hline $\begin{array}{l}\text { KG1- } \\
\text { RC1 }\end{array}$ & $\begin{array}{l}\text { Kegel } \\
\text { Creek }\end{array}$ & CMP & 0.62 & 6.30 & 0.01 & 7.50 & 0.25 & 0 & 0.00 & Yes \\
\hline $\begin{array}{l}\text { KG1- } \\
\text { RC2 }\end{array}$ & $\begin{array}{l}\text { Kegel } \\
\text { Creek }\end{array}$ & CMP & 1.10 & 9.20 & 0.05 & 4.50 & 0.20 & 0 & 4,880 & No \\
\hline
\end{tabular}


Table 2-6. Continued

\begin{tabular}{|c|c|c|c|c|c|c|c|c|c|c|}
\hline $\begin{array}{l}\text { MF1- } \\
\text { RC1 }\end{array}$ & $\begin{array}{l}\text { Middle } \\
\text { Fork Mill } \\
\text { Creek }\end{array}$ & CMP & 1.75 & 9.80 & 0.15 & 7 & 0.00 & 0 & 17,848 & No \\
\hline $\begin{array}{l}\text { MF1- } \\
\text { RC2 }\end{array}$ & $\begin{array}{l}\text { Middle } \\
\text { Fork Mill } \\
\text { Creek }\end{array}$ & $\begin{array}{c}\text { Bridg } \\
\mathrm{e}\end{array}$ & 0.43 & 8.50 & 0.10 & NA & 0.00 & 100 & NA & NA \\
\hline $\begin{array}{l}\text { MF1- } \\
\text { RC3 }\end{array}$ & $\begin{array}{l}\text { Middle } \\
\text { Fork Mill } \\
\text { Creek }\end{array}$ & CMP & 0.83 & 9.50 & 0.08 & 5.00 & 0.15 & 0 & 1,360 & No \\
\hline $\begin{array}{l}\text { MF1- } \\
\text { RC4 }\end{array}$ & $\begin{array}{l}\text { Middle } \\
\text { Fork Mill } \\
\text { Creek }\end{array}$ & СMP & 0.60 & 9.40 & 0.01 & 2.00 & 0.01 & 33 & 8 & No \\
\hline $\begin{array}{l}\text { MF1- } \\
\text { RC5 }\end{array}$ & $\begin{array}{l}\text { Middle } \\
\text { Fork Mill } \\
\text { Creek }\end{array}$ & $\begin{array}{c}\text { Doub } \\
\text { le } \\
\text { CMP }\end{array}$ & 1.21 & 10.70 & 0.05 & 6.00 & 0.115 & 0 & 27,226 & No \\
\hline $\begin{array}{l}\text { RB1- } \\
\text { RC1 }\end{array}$ & $\begin{array}{l}\text { Robins } \\
\text { Creek }\end{array}$ & CMP & 1.00 & 13.30 & 0.02 & 8.00 & 0.37 & 0 & 407 & Yes \\
\hline $\begin{array}{l}\text { RB1- } \\
\text { RC2 }\end{array}$ & $\begin{array}{l}\text { Robins } \\
\text { Creek }\end{array}$ & CMP & 1.06 & 11.60 & 0.01 & 9.00 & 0.45 & 0 & 969 & No \\
\hline $\begin{array}{l}\text { SF1- } \\
\text { RC1 }\end{array}$ & $\begin{array}{l}\text { South } \\
\text { Fork Mill } \\
\text { Creek }\end{array}$ & CMP & 1.30 & 10.90 & 0.01 & 5.00 & 0.45 & 0 & 3,918 & No \\
\hline $\begin{array}{l}\text { SF1- } \\
\text { RC2 }\end{array}$ & $\begin{array}{l}\text { South } \\
\text { Fork Mill } \\
\text { Creek }\end{array}$ & CMP & 1.25 & 13.60 & 0.01 & 4.00 & 0.35 & 0 & 1,065 & No \\
\hline $\begin{array}{l}\text { SF1- } \\
\text { RC3 }\end{array}$ & $\begin{array}{l}\text { South } \\
\text { Fork Mill } \\
\text { Creek }\end{array}$ & CMP & 2.70 & 14.00 & 0.10 & 2.00 & 0.00 & 33 & 18,701 & No \\
\hline $\begin{array}{l}\text { SF2- } \\
\text { RC1 }\end{array}$ & $\begin{array}{l}\text { Tributary } \\
\text { to South } \\
\text { Fork Mill } \\
\text { Creek }\end{array}$ & CMP & 0.56 & 6.50 & 0.00 & 5.00 & 0.10 & 0.00 & 8 & No \\
\hline $\begin{array}{l}\text { SF3- } \\
\text { RC1 }\end{array}$ & $\begin{array}{l}\text { Tributary } \\
\text { to South } \\
\text { Fork Mill } \\
\text { Creek }\end{array}$ & CMP & 0.50 & 8.50 & 0.00 & 3.00 & 0.00 & 0.00 & 0 & No \\
\hline
\end{tabular}


Table 2-6 Continued

\begin{tabular}{|c|c|c|c|c|c|c|c|c|c|c|}
\hline $\begin{array}{l}\text { SF4- } \\
\text { RC1 }\end{array}$ & $\begin{array}{l}\text { Tributary } \\
\text { to South } \\
\text { Fork Mill } \\
\text { Creek }\end{array}$ & CMP & 0.40 & 6.20 & 0.00 & $\begin{array}{c}11.0 \\
0\end{array}$ & 0.00 & 0 & 0 & No \\
\hline $\begin{array}{l}\text { SF5 } \\
\text { RC1 }\end{array}$ & $\begin{array}{l}\text { Tributary } \\
\text { to South } \\
\text { Fork Mill } \\
\text { Creek }\end{array}$ & CMP & 0.60 & 11.50 & 0.01 & 6.00 & 0.00 & 0 & 2 & No \\
\hline
\end{tabular}

\section{$\underline{\text { Road Crossings Assessment }}$}

A total of 26 road crossings were identified as impediments to upstream fish migration. Of these, 17 (65.4\%) were prioritized for replacement. These 17 included some roads that were prioritized for removal associated with road de-commissioning based on available upstream habitat and percent passability (Table 2-6). The remaining nine road crossings were identified as low priority for replacement. One of these was a bridge on the Middle Fork that posed no passage barrier while the remaining crossings were low priority because of minimal habitat gains (wetted channel area) upstream of the culverts. Finally, four culverts that were known barriers to upstream fish migration are currently being retained because they have effectively precluded upstream invasion of EBT into areas occupied by isolated WCT populations (Table 2-6).

Fourteen fish-blocking culverts identified as the highest priority for replacement were identified on the following creeks: Bestrom Creek (3), Green Mountain Creek (1), Hanson Creek (1), Jacobson Creek (1), Kegel Creek (1), Middle Fork of Mill Creek (3), 
Robins Creek (1), and the South Fork of Mill Creek (3). Expected increase in the amount of fish habitat was the primary factor used to prioritize these culvert replacements; values ranged from $<10 \mathrm{~m}^{2}$ to nearly $30,000 \mathrm{~m}^{2}$ of instream habitat gains (Table 2-6). As expected, the largest habitat gains were on the largest streams (i.e., Middle and South Forks of Mill Creek), while smaller amounts of habitat were gained from reconnection in smaller streams (e.g., Camp Creek, Hanson Creek).

\section{$\underline{\text { Stream Habitat Assessment }}$}

A total of 2,112 channel units were sampled in the project area, of which 369 $(17.5 \%)$ were dry and were removed from analysis. Of the 1,743 channel units containing water, 367 (21\%) supported populations of IWCT located upstream from migration barriers (Figure 2-4). Interestingly, of the total channel units containing IWCT $(n=563)$ $36 \%$ were absent of water $(n=196)$, due to the difference in timing of the extent of fish surveys and stream habitat assessments which occurred about a month and a half apart. In total, $3.1 \mathrm{~km}$ of stream supported IWCT and $37.8 \mathrm{~km}$ of stream supported WCT/EBT. Prior to statistical comparisons, habitat data were determined to violate normality assumptions, despite Box-Cox transformations (Shapiro Wilk test, $p<0.05$ ). Visual comparisons of variance appeared consistent across groups (Figure 2-5). Therefore, the original untransformed data were used in the following analyses. 

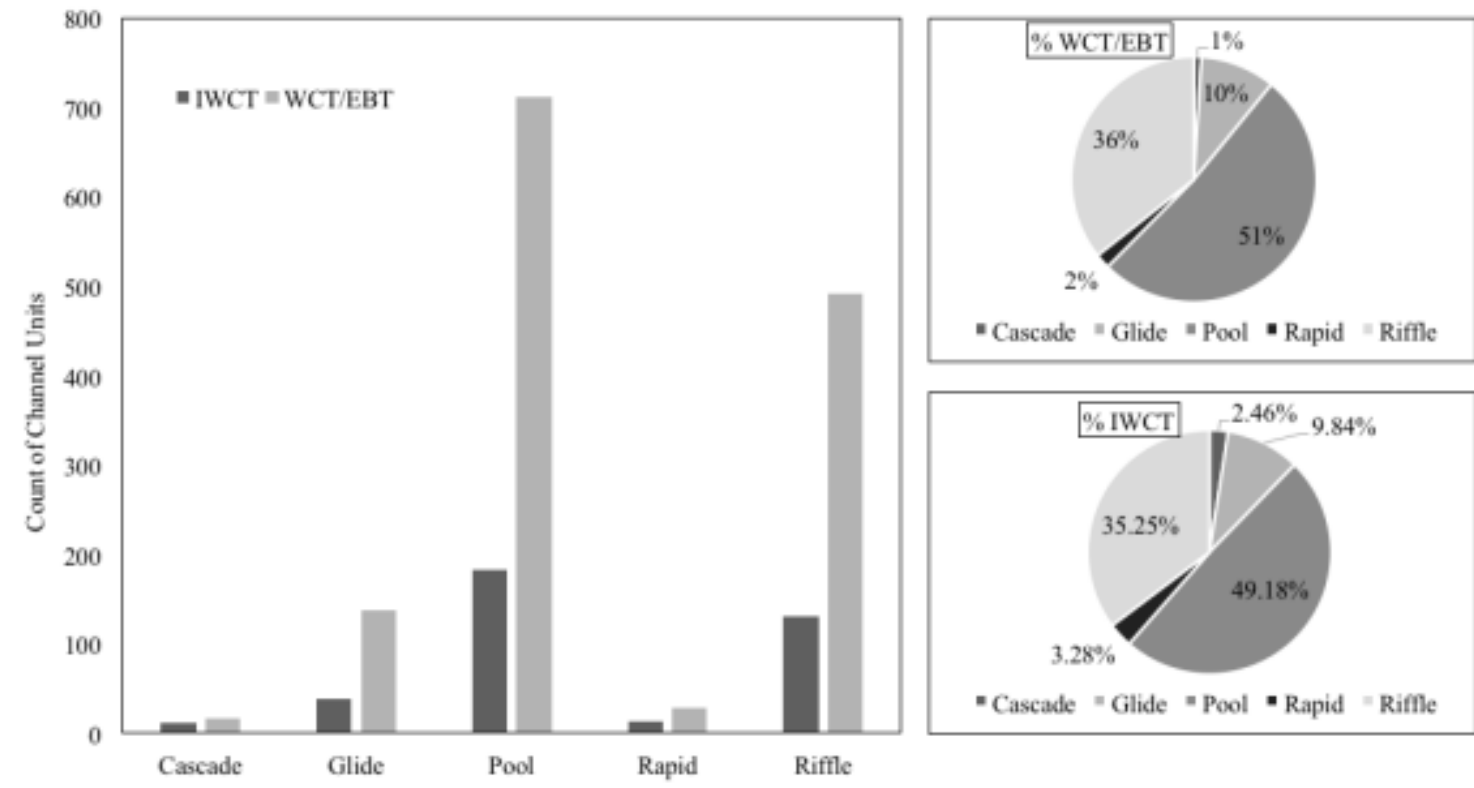

" Cascade " Glide " Pool " Rapid "Riffle

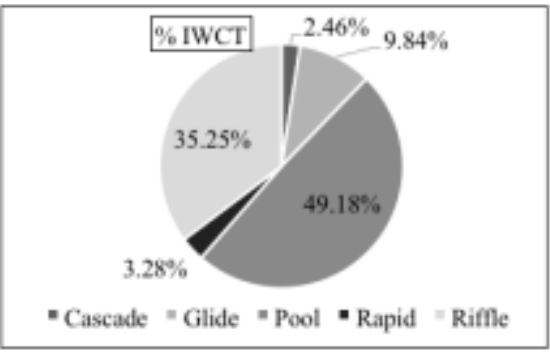

Figure 2-4. Summary of channel units containing IWCT population above migration barriers and channels units containing populations of WCT/EBT.
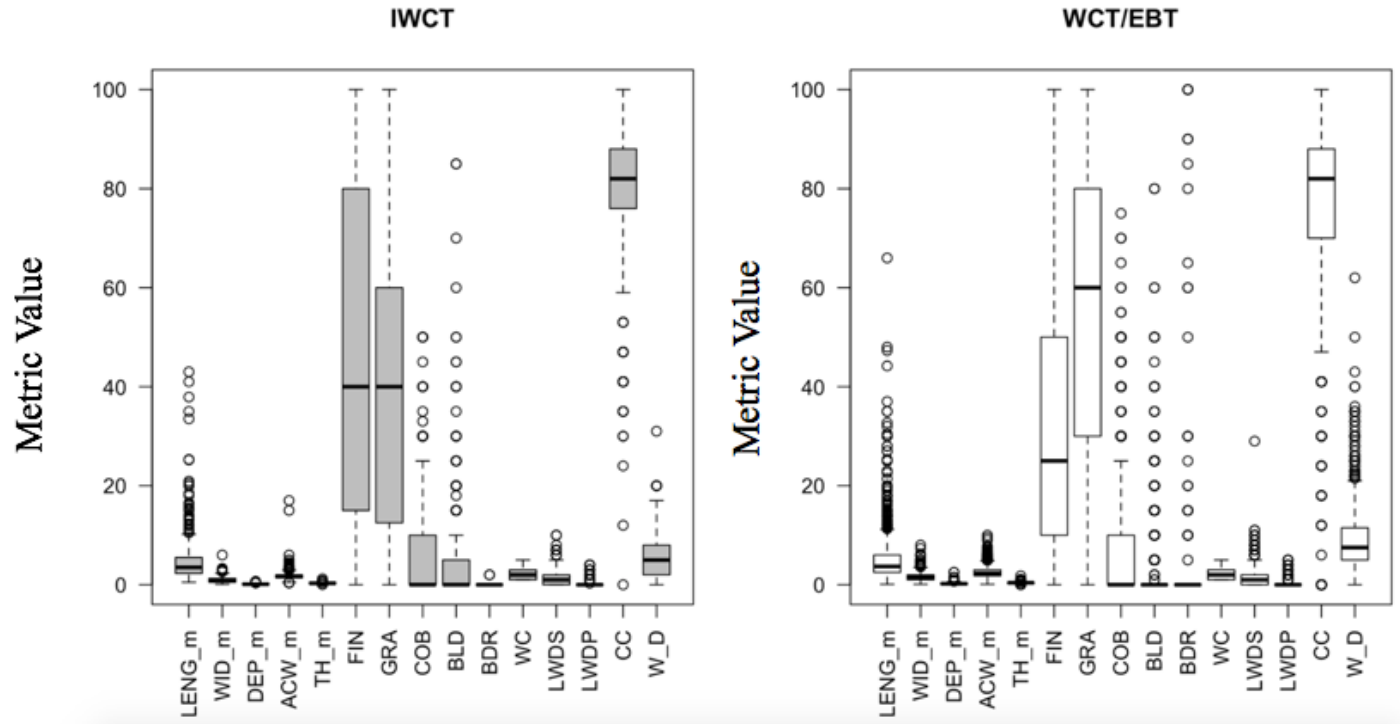

\section{In-stream habitat metrics}

Figure 2-5. Comparison of physical habitat measures variability for both WCT/EBT (white) and IWCT (grey) to assess assumption of equal variance. Based on this plot the data are assumed to exhibit equal variance across the two groups. (See Table 2-1 for abbreviation definitions). 


\section{Stream Habitat Quality Indicators}

Of the 11 habitat quality indicators that were analyzed based on population occurrence (Table 2-3), 7 were found to differ significantly (Table 2-7), leading to the rejection of the null hypothesis (see pg. 24) that the median difference between comparison groups was zero. Further differences are discussed in the subsequent results sections. 
Table 2-7. Summary statistics of habitat indicators along with the results of Wilcoxon rank-sum statistical test for non-parametric data. Results are discussed in the subsequent sections in more detail. An alpha of 0.05 was used to determine statistical significance $\left(W=W\right.$ ilcoxon statistic value and $\chi^{2}=$ Chi-squared test statistic).

\begin{tabular}{|c|c|c|c|c|c|c|}
\hline \multirow{2}{*}{$\begin{array}{c}\text { Habitat } \\
\text { Indicators }\end{array}$} & \multicolumn{2}{|c|}{ Range } & \multicolumn{2}{|c|}{ Median } & \multicolumn{2}{|c|}{$\begin{array}{c}\text { Hypothesis Test } \\
\text { Results }\end{array}$} \\
\hline & WCT/EBT & $I W C T$ & WCT/EBT & $I W C T$ & $\begin{array}{c}\text { Test } \\
\text { Statistic }\end{array}$ & $p$ \\
\hline Fines (\%) & $0-100$ & $0-100$ & 25.00 & 40.00 & $202,410(W)$ & $<0.001$ \\
\hline $\begin{array}{c}\text { Fines in Riffle } \\
(\%)\end{array}$ & $0-100$ & $0-100$ & 10.00 & 25.00 & $\begin{array}{l}20,551 \\
(W)\end{array}$ & $<0.001$ \\
\hline $\begin{array}{c}\text { Fines in Pools } \\
(\%)\end{array}$ & $0-100$ & $0-100$ & 40.00 & 55.00 & $\begin{array}{l}52,894 \\
(W)\end{array}$ & $<0.001$ \\
\hline Pool SA $\left(m^{2}\right)$ & $0.25-163.5$ & $0.25-15.3$ & 5.25 & 2.55 & $\begin{array}{c}94,130 \\
(W)\end{array}$ & $<0.001$ \\
\hline $\begin{array}{c}\text { Pool Volume } \\
\left(\mathrm{m}^{3}\right)\end{array}$ & $0-121.5$ & $0-7.65$ & 1.29 & 0.40 & $\begin{array}{c}98,133 \\
(W)\end{array}$ & $<0.001$ \\
\hline $\begin{array}{c}\text { LWD } \\
\text { Frequency } \\
(L W D P+L W D S \\
/ \mathrm{m})\end{array}$ & $0-16.67$ & $0-2.67$ & 0.00 & 0.00 & $\begin{array}{l}242,990 \\
(W)\end{array}$ & 0.114 \\
\hline $\begin{array}{c}\text { Wood } \\
\text { Complexity } \\
\text { Rating (see }\end{array}$ & $1-5$ & $1-5$ & 2.00 & 2.00 & $\begin{array}{c}11.59 \\
\left(\chi^{2}\right)\end{array}$ & 0.021 \\
\hline $\begin{array}{c}\text { Stream Shade } \\
(\%)\end{array}$ & $0-100$ & $0-100$ & 82.00 & 82.00 & $\begin{array}{l}234,430 \\
(W)\end{array}$ & 0.032 \\
\hline Cobble (\%) & $0-75$ & $0-50$ & 0.00 & 0.00 & $\begin{array}{c}249,860 \\
(W)\end{array}$ & 0.729 \\
\hline Boulder (\%) & $0-80$ & $0-85$ & 0.00 & 0.00 & $\begin{array}{l}224,130 \\
(W)\end{array}$ & $<0.001$ \\
\hline $\begin{array}{l}\text { Width }(m) \text { : } \\
\text { Depth }(m)\end{array}$ & $0-62$ & $0-31$ & 7.50 & 5.00 & $\begin{array}{c}211,600 \\
(W)\end{array}$ & $<0.001$ \\
\hline
\end{tabular}

\section{Fine Sediment Composition}

When percent composition of fine sediment was compared based on channel unit population occurrence, units containing IWCT had significantly more fine sediments than channel units containing WCT/EBT (Wilcoxon rank-sum test, $W=202410, p<0.001$;

Table 2-7 and Figure 2-6A). Riffle habitat containing IWCT populations also contained significantly more fine sediment than seen in riffles containing WCT/EBT $(\mathrm{p}<0.05$; Table 
2-7 and Figure 2-6C). A similar significant trend was observed in pool habitat (Wilcoxon rank-sum test, $W=52894, p=0.000375$; Table 2-7 and Figure 2-6B). Percent fine sediment composition exhibited greater variance in channel units existing above barriers (Figure 2-6A). 


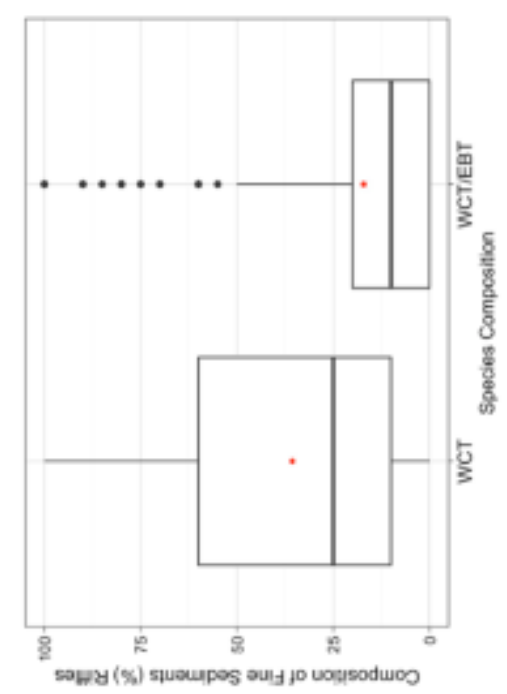

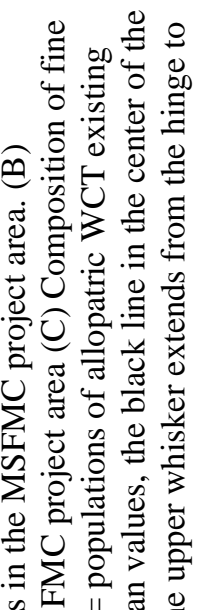

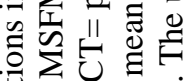

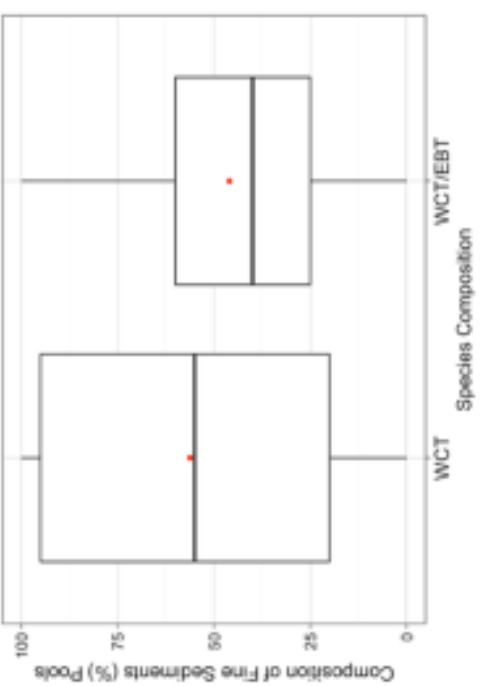

壱氖苞皇

ถั.

$\varphi$ 言 す

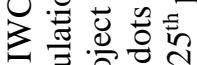

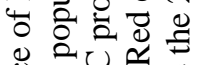

它记富夰

焉空公

Oั0

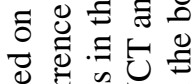

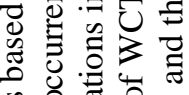

记

春 。言 气

च

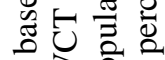

光虽

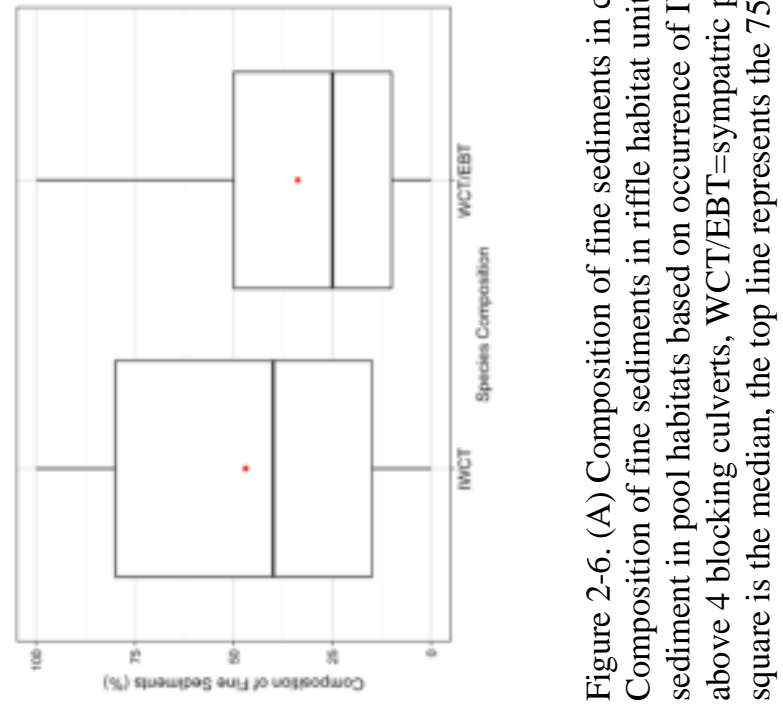




\section{Pool Analysis}

Comparison of pool composition based on population occurrence was similar, at approximately 50\% (Figure 2-7). However, mean pool surface area and volume were significantly lower in channel units containing IWCT populations than for pools supporting populations of WCT/EBT (Wilcoxon rank-sum test, $\mathrm{p}<0.05$; Table 2-7; Figure $2-8 \mathrm{~A}$ and $\mathrm{B})$

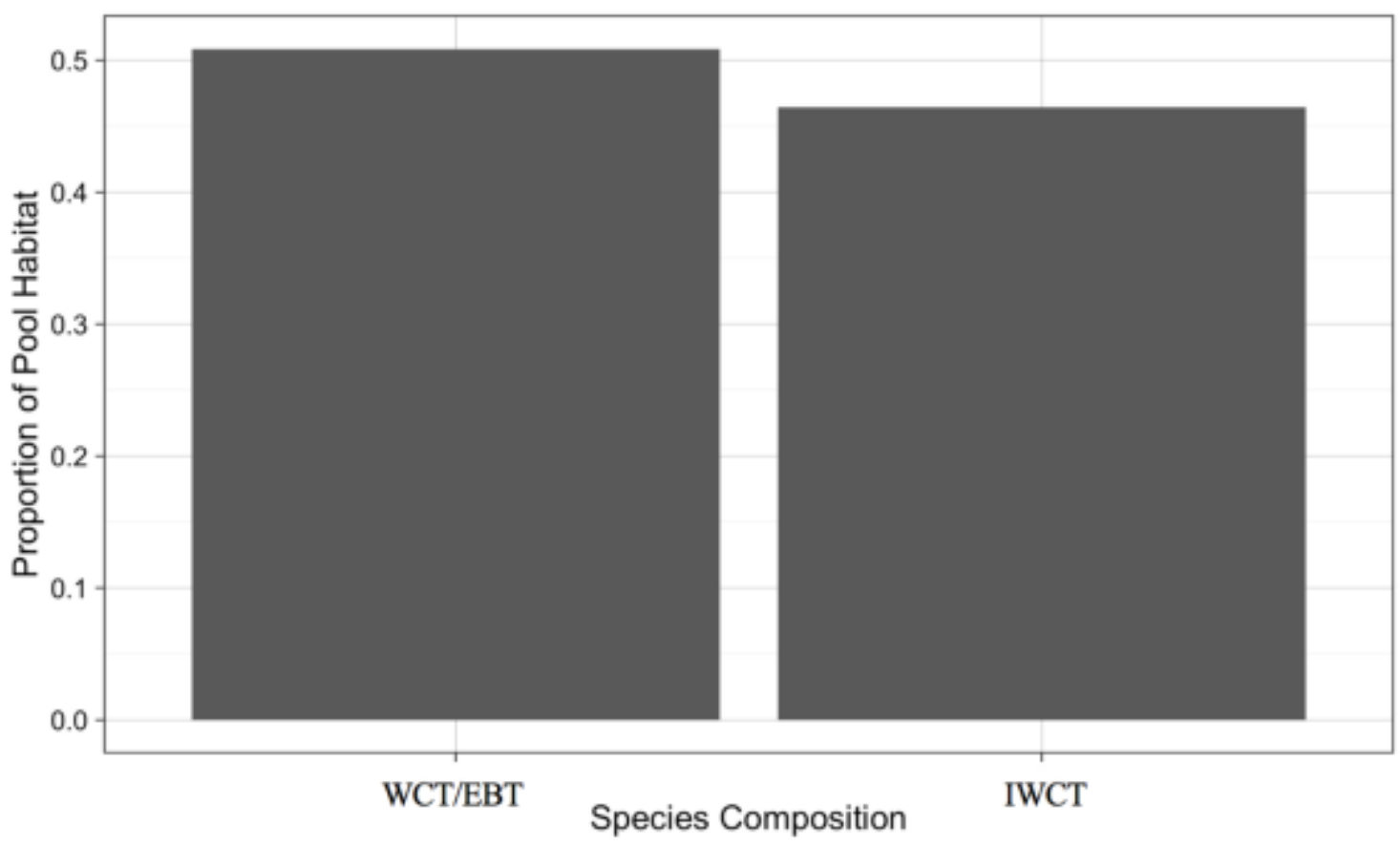

Figure 2-7. Comparison of pool composition based on occurrence of IWCT populations in the MSFMC project area. (IWCT= populations of allopatric WCT existing above 4 blocking culverts, $\mathrm{WCT} / \mathrm{EBT}=$ sympatric populations of WCT and EBT.) 

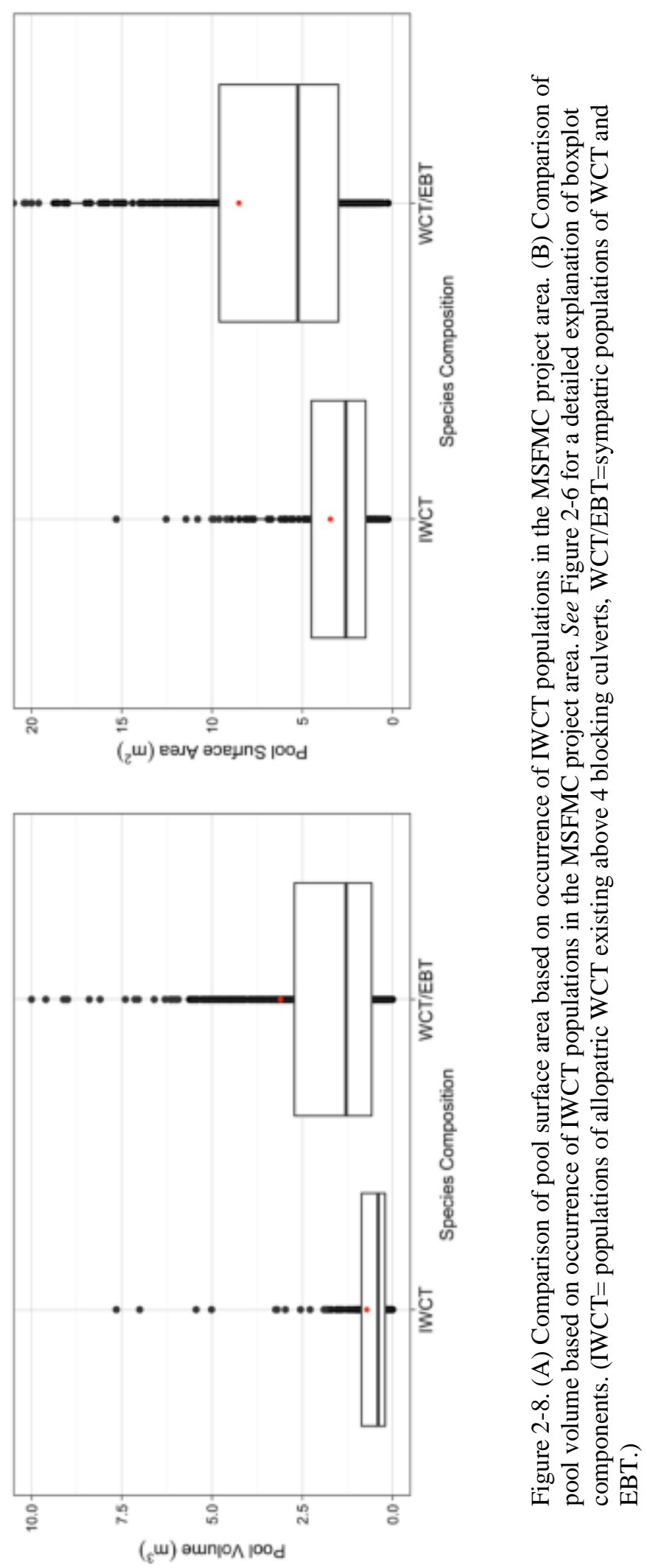


\section{Presence of Large Woody Debris}

Throughout the project area, large woody debris (LWD; described in Table 2-3) frequency ranged from 0 pieces per kilometer to 186 pieces per kilometer, with an average count of LWD of $<1$ piece per channel unit and a maximum of 5 pieces of LWD per channel unit (Figure 2-9A). Similarly, LWD frequency was limited in channel units supporting IWCT and WCT/EBT, and was not significantly different between the two classifications (Table 2-7 and Figure 2-9A).

\section{Wood Complexity}

Wood complexity ratings were nearly identical across channel units with an average rating of two. However, significant differences were noted in wood complexity ratings based on population occurrence in the project area (Chi-squared test, $\chi^{2}=11.559$, $p=0.02095$; Table 2-7 and Figure 2-9B).

\section{Stream Shade}

Stream shade was consistently high across the project area, averaging $75 \%$. However, stream shade was significantly higher in channel units supporting IWCT populations than channel units supporting WCT/EBT (Wilcoxon rank-sum test, $\mathrm{W}=234430, \mathrm{p}=0.03233$; Table 2-7 and Figure 2-9C). 

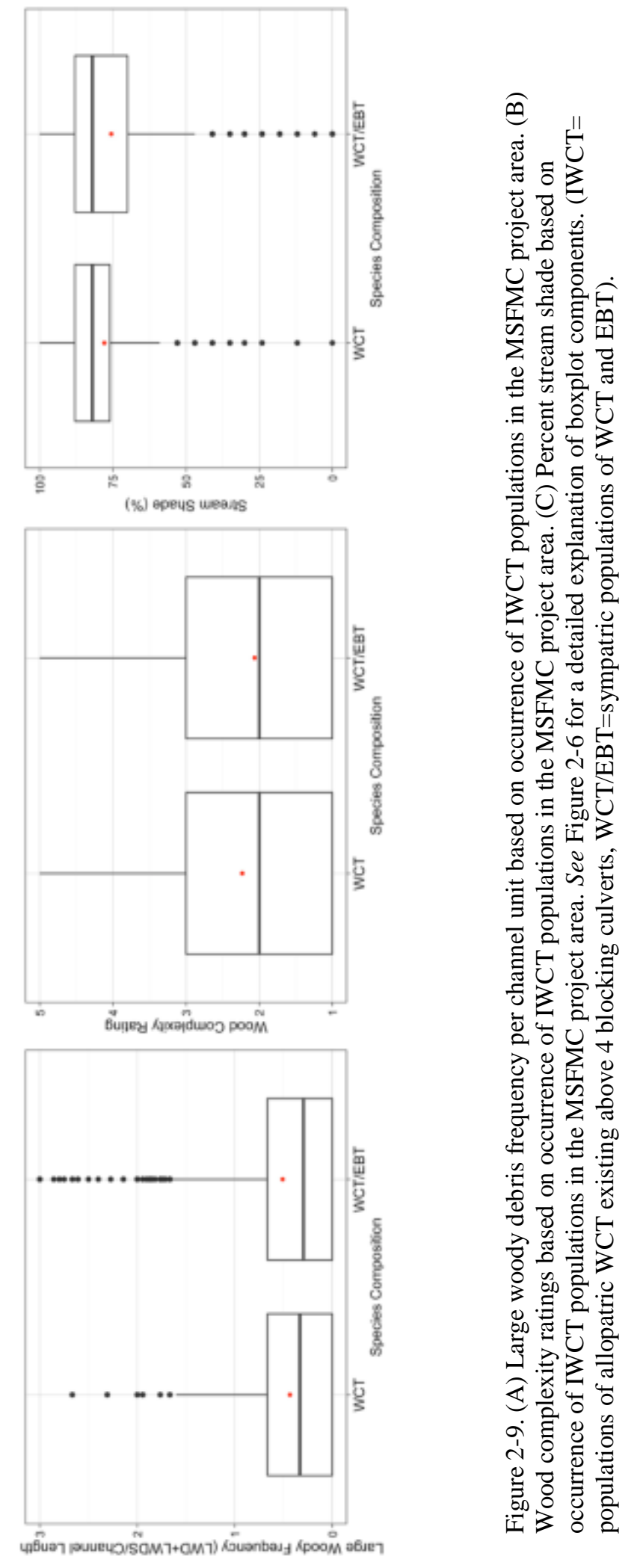


\section{Large Sediment Composition}

Large cobble and boulder substrate throughout the project area averaged between $3.9 \%$ and $6.7 \%$ composition across all channel units, respectively. Large substrate composition was not significantly different between stream units IWCT and WCT/EBT distinctions (Wilcoxon rank-sum test, $W=249860, p=0.7292$; Table 2-7; Figure 2-10A and B). 

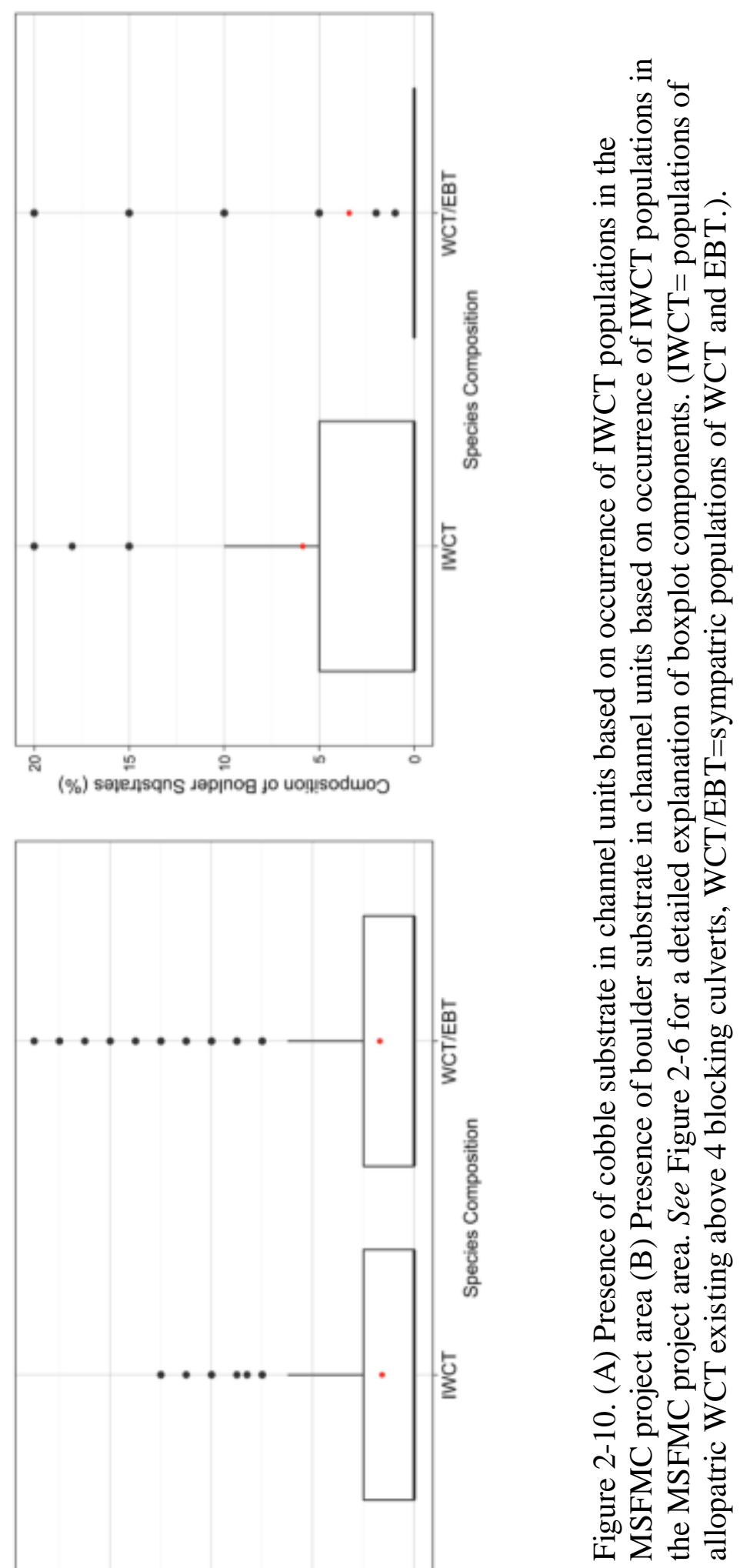

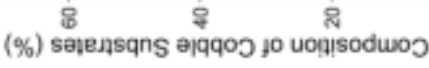




\section{Width to Depth Ratio}

Width to depth ratios in the MSFMC project were on average 15 with a median value of seven. Ratios were significantly lower in channel units above migration barriers supporting IWCT than in areas supporting both WCT and EBT (Wilcoxon rank-sum test, $W=211600, p=4.11 \mathrm{e}-10 ;$ Table 2-7 and Figure 2-11).

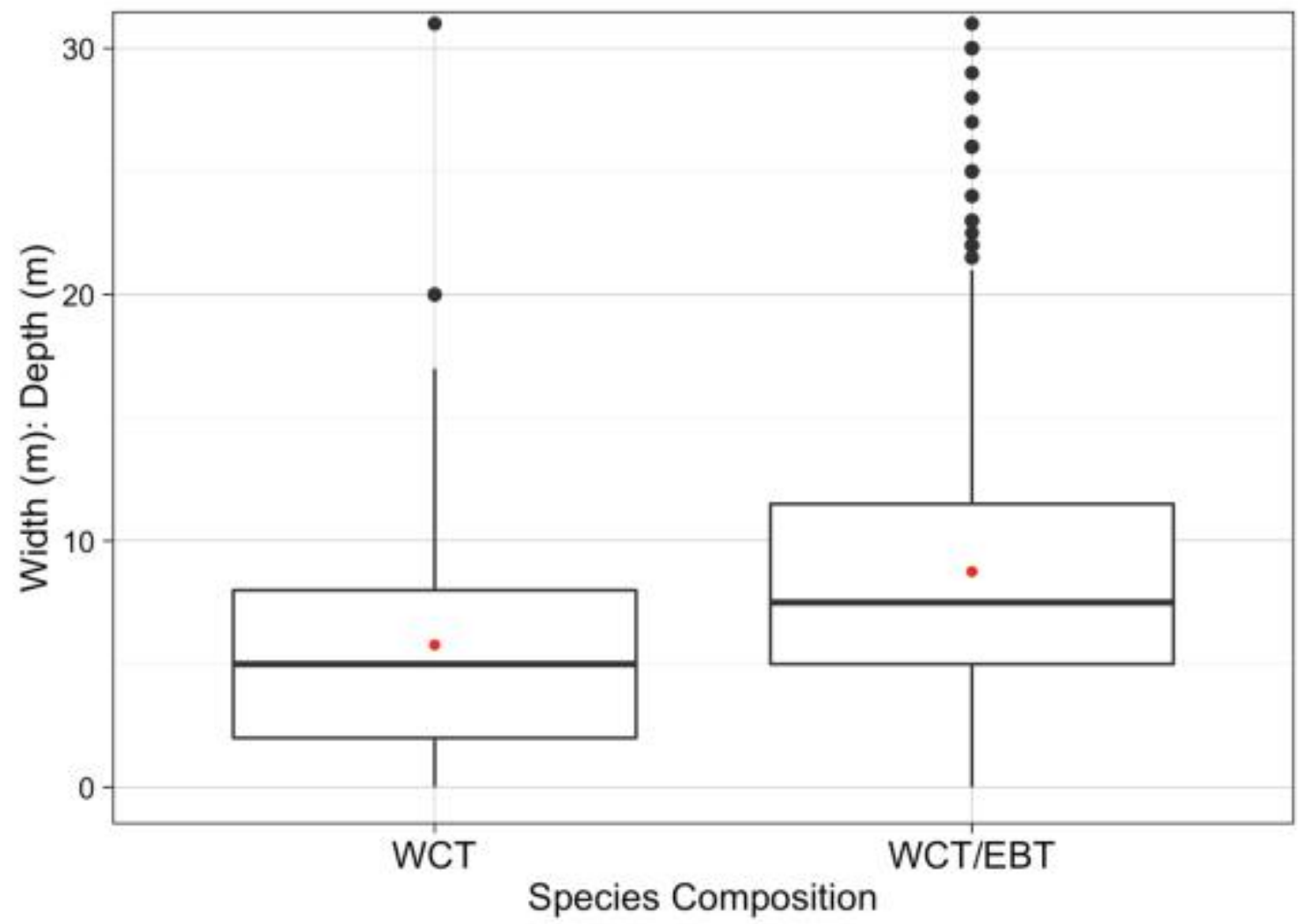

Figure 2-11. Comparison of channel unit width to depth ratios sediments based on occurrence of IWCT populations in the MSFMC project area (IWCT= populations of allopatric WCT existing above 4 blocking culverts, WCT/EBT=sympatric populations of WCT and EBT.). See Figure 2-6 for a detailed explanation of boxplot components. 


\section{Discussion}

In general, the study area provided ample habitat for two species of fish, WCT and EBT based on the high percentage of fish bearing designations applied to surveyed streams (73\%). Across both watersheds (Middle Fork and South Fork; MSFMC project area) EBT were more widely distributed and existed solely in sympatry with WCT. The only locations where WCT existed without the influence of EBT was above four blocking culverts in highly fragmented disconnected headwater stream habitat. In general, stream habitat in the Middle and South Forks of Mill Creek had limited large substrate, fine sediment was much more prevalent than gravel substrate in some areas, and exhibited pool-riffle channel morphology, which is common in the CNF (Archer et al. 2012) and across the western US. This research presented an opportunity to examine important thermal refuge habitat under severe environmental conditions (i.e. drought) and begins to document potential distribution trends with further changes in the warming climate. Hybridization of WCT and invasive trout (Rainbow trout Oncorhynchus mykiss, EBT, etc.), as well as competitive superiority of invasive non-natives, are both hypothesized to be more likely in warmer, low-elevation streams (Muhlfeld et al. 2009). If this hypothesis is valid, WCT would be expected to be more common in headwater reaches, which are generally associated with colder water, less disturbance, and are typically farther from hybridized populations.

Expectedly, IWCT pool habitat was significantly smaller, in terms of volume and surface area, than WCT/EBT pool habitat largely due to the headwater nature of IWCT presence. Additionally, due to the extreme drought conditions during 2015, stream flow 
was substantially diminished in the study area. This condition caused headwater reaches to be highly fragmented and largely disconnected from the rest of the stream channel. These conditions would also be expected to have provided warmer water conditions in areas unaffected by hyporheic discharge. However, despite this high degree of fragmentation, pool composition was around 50\% for both IWCT and WCT/EBT, which, is generally considered suitable fish habitat (Sullivan et al. 1987).

Fine sediments were generally higher in headwater reaches supporting IWCT, significantly in pools and riffles. This was unexpected, mainly because they exist above sediment delivery points in the longitudinal extent of the system. However, it is possible that these structures were acting as sediment traps by creating hydraulic pinch points, impounding water upstream and thus causing fine sediments to accumulate behind improperly sized road crossing structures. The degree to which sediment might be trapped depends on the stream gradient directly upstream of the structure, and the flow field conditions created upstream from barriers. Sediment transport relies on the amount of flow present in the system, greater flow allows for the transport of larger substrates such as cobble and boulders, while fine sediment tends to be transported by a wider range of flows (Sullivan et al. 1987). However, Sullivan et al. (1987) noted that sand particles (fine sediment) introduced into some salmonid spawning streams were only transported during high flows and were otherwise stored on the streambed between high flow events. Fine sediment can present numerous problems for spawning and incubating eggs, particularly when more than $20 \%$ of the stream channel contains fine sediments (Bjornn et al. 1977). It is directly related to incubation and hatching success of salmonid eggs and 
emergence of post-hatch alevins, and the provision of seasonal high flows that often carry suitable sediments downstream away from spawning areas (Lisle and Lewis 1992). The composition of streambed substrate determines the types and amounts of bed particles available for downstream transport, streambed roughness, hyporheic permeability, and habitat suitability for aquatic biota (Allan and Castillo 2007). Westslope Cutthroat Trout are thought to spawn in small tributaries, as resident fish typically in $1^{\text {st }}-3^{\text {rd }}$ order streams (see Young et al. 1995). However, high sediment burdens could be due to the presence of improperly sized culverts downstream of IWCT. As described in Chapter 1, improperly placed or sized culverts can jeopardize both the longitudinal temporal migration of native WCT and the overall morphological characteristics upstream of the structure (see pg. 7). Overall, channel units directly upstream $(<100 \mathrm{~m})$ of road crossings had a median fine sediment composition of $25( \pm 30.86)$.

Overall, I concluded that differences in physical habitat conditions above and below blocking culverts were not driving WCT distributions in the study area during 2015. However, this study was limited due to the lack of collection of biological and ecological data, spatial variability and temporal variability, and most importantly small IWCT sample size (21\%). Had IWCT been observed and examined in streams across numerous watersheds, a stronger correlation between physical habitat characteristics may have been present. Due to this critical source of limitation it can only be inferred that the habitat observed occupied by IWCT represents neither the best nor the worst in terms of suitability for IWCT. It may merely be representative of future distributional patterns in a species of fish that will be continually tested by a variable suit of abiotic and biotic 
stressors. Another confounding factor could be that WCT/EBT was too broadly defined. Further spatial categorization of population abundances, distributions, and densities would likely illicit more pronounced differences in physical stream habitat. Most conspicuously absent, were water temperature data, which could mask effects of physical habitat suitability. In other words, suitable physical habitat conditions could exist in areas that are and are not thermally suitable. Without knowing the temperature conditions, it is difficult to accurately assess effects of physical habitat on presence and absence of WCT. Ideally a stratified design including different physical habitat conditions within areas that are all thermally suitable would be required to separate the confounded effects of temperature and physical habitat suitability on occupancy.

While this study did not find consistent statistically significant differences in physical stream habitat characteristics supporting IWCT and WCT/EBT populations, it did exemplify and identify important refuge habitat in areas currently stressed by climate change effects. Additionally, the observed distribution of WCT in the study area may represent the minimum viable periphery habitat required for WCT under constant increased environmental stressors. Numerous studies have discussed using artificial barriers to reduce range expansion of invasive species into important refuge habitat for native salmonids (Novinger and Rahel 2003, Peterson et al. 2008, Fausch et al. 2009, Muhlfeld et al. 2012). Specific focus should be given to the finding that over two-thirds of the channel units containing IWCT during fish distribution mapping in our study did not contain water during stream habitat assessments, which is likely the most important limiting factor present in the study area. The limited amount of water present during 
habitat surveys exemplifies the need for focused monitoring aimed at understanding seasonal variability of water availability in these important refuge areas. This could indicate that during peak summer months, important refuge from interspecific species competition is being squeezed by limitations of water availability. Because the limited water availability in this study was tied directly to extreme drought conditions during the summer of 2015 , long term research is needed to understand how refuge habitats will change with increased frequency and intensity of drought in the Pacific Northwest, and how these changes may affect persistence of IWCT.

\section{Minimum Viable Periphery Habitat}

The idea of minimum viable population size has been studied extensively ( $s e e$ Caughley 1994) and is a critical concept in preserving and studying fragmented and peripheral populations (i.e., populations existing in the distributional margins of a species range). Populations found at the margins of the species range (i.e. geographically isolated from central populations) can strongly affect the genetic variability across a geographic range within the species as a whole (Taylor et al. 2003). In general, large patches of habitat contain greater species diversity than smaller patches of habitat (Angermeier and Schlosser 1989). However, it is unclear how much habitat is needed to support peripheral populations, (Taylor et al. 2003, Haak et al. 2010, Isaak et al. 2012a, Roberts et al. 2013) or edge populations (Aikens and Roach 2014). Peripheral populations are often genetically distinct and divergent from central populations, and often contain much of the species genetic and ecological diversity (Taylor et al. 2003, Williams et al. 2009). This 
highlights the need for these isolated populations to be prioritized in conservation and restoration efforts.

Inland cutthroat trout present an ideal opportunity to better understand and evaluate the distribution of peripheral and central populations because of the wide range of habitat they occupy (Haak et al. 2010). Our study provides an example of inland cutthroat existing at the margins of their geographic and habitat suitability during a year of extreme environmental conditions characterized by low water volumes (stream discharges) and high temperatures. As aquatic species continue to be affected by diminishing patches of thermally suitable habitat, understanding the minimum amount of habitat required to support peripheral populations at sustainable levels becomes increasingly important. This is especially relevant in areas likely to be most strongly affected by climate change across the western United States (Williams et al. 2009). Often times invasive trout species, such as EBT or rainbow trout, benefit from increasingly variable climate patterns (Rieman et al. 2006). Additional studies across thermally sensitive salmonids (e.g. inland cutthroat trout and bull trout; Salvelinus confluentus) have shown that increasing temperatures limit native species to isolated headwater reaches (e.g. Dunham et al. 2002, Novinger and Rahel 2003, Shepard 2004, Rieman et al. 2006), which are generally impacted most significantly by shifts in climate patterns (Isaak et al. 2012b). It is likely that increases in temperature and biotic interactions with invasive trout species will further contribute to the decline of WCT (Wenger et al. 2011b). Thus, quantifying and identifying the minimum viable periphery 
habitat type and conditions will only become more pertinent as these trends continue and advance in severity. 
Chapter 3 - Use of a Logistic Regression Model and Physical Habitat Data to Predict Isolated Westslope Cutthroat Trout (Oncorhynchus clarki lewisi) Presence Above Four Migration Barriers in Headwater Streams in Northeastern Washington During Severe Drought Conditions

\section{Introduction}

Trout and salmon are iconic to the western United States, and both have declined in abundance since the early 1900s in part due to climatic and human driven forces (Quinn 2011). Westslope Cutthroat Trout (Oncorhynchus clarki lewisi; WCT) historically occupied headwater streams, large rivers, and mountain lakes with drainages throughout the inland west (Bear et al. 2007), and were once the most widely distributed subspecies of cutthroat trout throughout the western United States (Shepard et al. 2005). However, WCT have been referred to as the "canary in the mine", meaning they are "usually the first species to go in a disturbed environment" (Behnke 2007). Abundance and distribution of many WCT populations are declining for a multitude of reasons, including non-native species invasion, habitat loss and degradation, and overexploitation (Shepard et al. 2005).

Habitat loss and degradation are reducing WCT population abundance since these fish rely on coldwater pools for thermal refuge during warm summer periods. Coldwater pools are formed and impacted by stream morphological characteristics as well as watershed and regional land uses and climate change admits effects on hydrology (Frissell et al. 1986, Montgomery and Buffington 1997) (see Figure 2-1). At the geomorphic unit scale, pool habitat may be disproportionately affected due to the loss of 
riparian vegetation, warming stream temperatures, reduced precipitation, loss of spawning gravel, catchment development and fire regimes (Harig and Fausch 2002, Isaak et al. 2015). At the stream scale, persistent adult WCT populations require adequate amounts of suitable habitat that provide refuge from high flow events, clean gravels (embedded with little to no silt substrate), and thermal refuge from high summer temperatures (Harig and Fausch 2002). Many of these high quality habitat features are optimized or in some cases enabled solely by intact fluvial processes (e.g., ecological flows, flood dynamics, floodplain connectivity, and robust riparian and upland communities including beaver).

Invasive species such as Eastern Brook Trout (Salvelinus fontinalis, EBT) play a dynamic role in the persistence of WCT by competing for limited resources, limiting their range, and contributing to introgression or introgressive hybridization (Dunham et al. 2002). Eastern Brook Trout invasions have been shown to cause cutthroat trout to disperse to headwater areas and persist in isolated, often fragmented stream habitat (Harig and Fausch 2002). Eastern Brook Trout displace native WCT by outcompeting them for resources including habitat and food (Dunham et al. 2002). Westslope Cutthroat Trout and EBT have slightly different habitat requirements in terms of stream gradients, temperature, channel slope, habitat structure, disturbance, and human influences (barriers, fish stocking, angling, etc.) (Dunham et al. 2002). Often times, EBT will inhabit higher order stream reaches while WCT will occupy lower order headwater streams. Migration barriers such as waterfalls or dysfunctional road culverts can limit or prevent upstream migration of the populations of fish existing downstream. Moreover, allopatric 
populations of native trout often exist upstream from migration barriers (natural and anthropogenic) (Harig and Fausch 2002, Guy et al. 2008, Muhlfed et al. 2012) indicating the need for focused conservation efforts. While passage barriers can protect upstream WCT populations from further invasion and hybridization by non-native salmonids from downstream areas, they can also restrict these WCT populations to small and fragmented areas of habitat (Harig and Fausch 2002).

Westslope Cutthroat Trout are thermally sensitive organisms that require cold stream temperatures for persistence (Roberts et al. 2013), with preferred temperature ranges between 9.5 and $18.0^{\circ} \mathrm{C}$ (Bear et al. 2007). Westslope Cutthroat Trout historically occupied headwater streams, large rivers, and mountain lakes in drainages throughout the inland American West (Bear et al. 2007) and exhibit fluvial, adfluvial, and resident life histories (Young et al. 1995). However, the physical conditions associated with upstream boundaries of trout distributions are not clearly understood (Latterell et al. 2003). This is particularly true for future climate scenarios, which are predicted to be warmer and dryer that current scenarios, and within WCT known ranges (Isaak et al. 2012b, 2014, 2015).

Thus, identifying key habitat metrics across watersheds that can identify and quantify the ecological refuges required by WCT will help resource managers and conservation biologists to better protect and restore vital habitats. This is especially important given current and predicted future warming and drying trends, and additive effects of catchment development pressures (see Figure 2-1).

Metrics that are likely to be important predictors of WCT presence are those specific to refuge and cover, such as the number of pools, percent composition of 
substrate, the presence of large woody debris, as well as the overall productivity of the system. Furthermore, these physical habitat characteristics are influenced by catchment and regional-scale processes, and thus should reflect management and conservation strategies and considerations at multiple spatial scales (Frissell et al. 1986).

This study aims to determine the most informative stream morphological characteristics for predicting allopatric WCT presence above migration barriers. Data for this study were collected during the extreme drought conditions of 2015, so data may represent minimum habitat suitability requirements for WCT during maximum temperature and minimum stream flow conditions. I hypothesized that physical stream characteristics that form coldwater pool habitat will be stronger predictors of WCT presence than those associated with poor WCT habitat conditions, such as limited large wood, low canopy coverage, abundance of fine substrates, and narrow and shallow stream channel units. Results of this analysis will help resource managers identify and preserve suitable habitat for native WCT populations in headwater stream reaches existing above migration barriers.

Several studies have used physical stream attributes to predict the presence and carrying capacity of salmonids across the western United States (Latterell et al. 2003, Cramer and Ackerman 2009). These and other studies (Bozek and Hubert 1992, Clarkson and Wilson 1995, Montgomery et al. 1999, Harig and Fausch 2002) provide a sound basis for this study. These studies were able to consistently use stream habitat metrics, similar to those used in this study, to estimate juvenile salmonid rearing capacity or the occurrence of trout in disturbed and undisturbed systems. These studies demonstrate the 
direct relationships between stream channel characteristics and the success of salmon and trout species in those streams. The current study investigates the relationship between WCT and physical stream characteristic during extreme drought conditions, at WCT distribution margins upstream from migration barriers. Studies such as Cramer and Ackerman (2009) focused primarily on larger streams and did not specifically address habitat located at species distribution margins. Therefore, this study aims to test the transferability of these general relationships between physical stream attributes and isolated WCT presence above migration barriers by identifying stream characteristics associated with population presence or absence (Figure 2-2) in eastern Washington streams, one of the areas where important coldwater refuge for this subspecies remains in the interior west (Isaak et al. 2015). 
Methods

\section{$\underline{\text { Study Area }}$}

This analysis used the same dataset described in the preceding chapter, collected in the Mill Creek drainage northeast of Colville, WA in the Colville National Forest. A detailed description of the study area can be found in the Study Area section of Chapter 2 (see Figure 2-2). Isolated populations of WCT (IWCT) were observed upstream from four migration barriers in both the Middle and South Fork Mill Creek watersheds as a result of the following fish and habitat surveys: 1) extent of fish, 2) stream habitat assessment and quantification, and 3) road crossing assessment. Detailed descriptions of each survey type can be found in the Methods section of the previous chapter.

\section{Analytical Approach}

All data analyses were performed using $\mathrm{R}$ statistical software ( $\mathrm{R}$ version 3.2.2, CRAN Team) and included both data exploration and analysis methods (Figure 3-1). Data from fourteen potential predictor variables and the binary response (IWCT presence/absence) were first summarized, including range, mean, standard deviation, and variance. Next, graphic displays were created for visual inspection, and statistical tests were performed to determine whether the data were normally distributed and exhibited equal variance, although neither are required for logistic regression. Predictor variables were grouped into the three categories to better identify potential issues of multicollinearity: 1) channel unit morphology, 2) substrate coverage, and 3) wood/shelter 
variables. Because some variables fell into each category, increasing the likelihood of multi-collinearity, correlation matrices were used to determine the level of collinearity among variables each category. Additionally, a classification tree was used on the original data to test for significant interactions among predictor variables, and to assess the explanatory importance of these predictors in explaining IWCT presence and absence. Interaction terms were added if results from the classification tree analysis indicated that greater than 1 branch minimized the associated prediction error below 1 minus the standard error associated with each split in the tree. No data transformations were performed for the classification tree analysis since normal distribution and equal variance are not inherent assumptions.

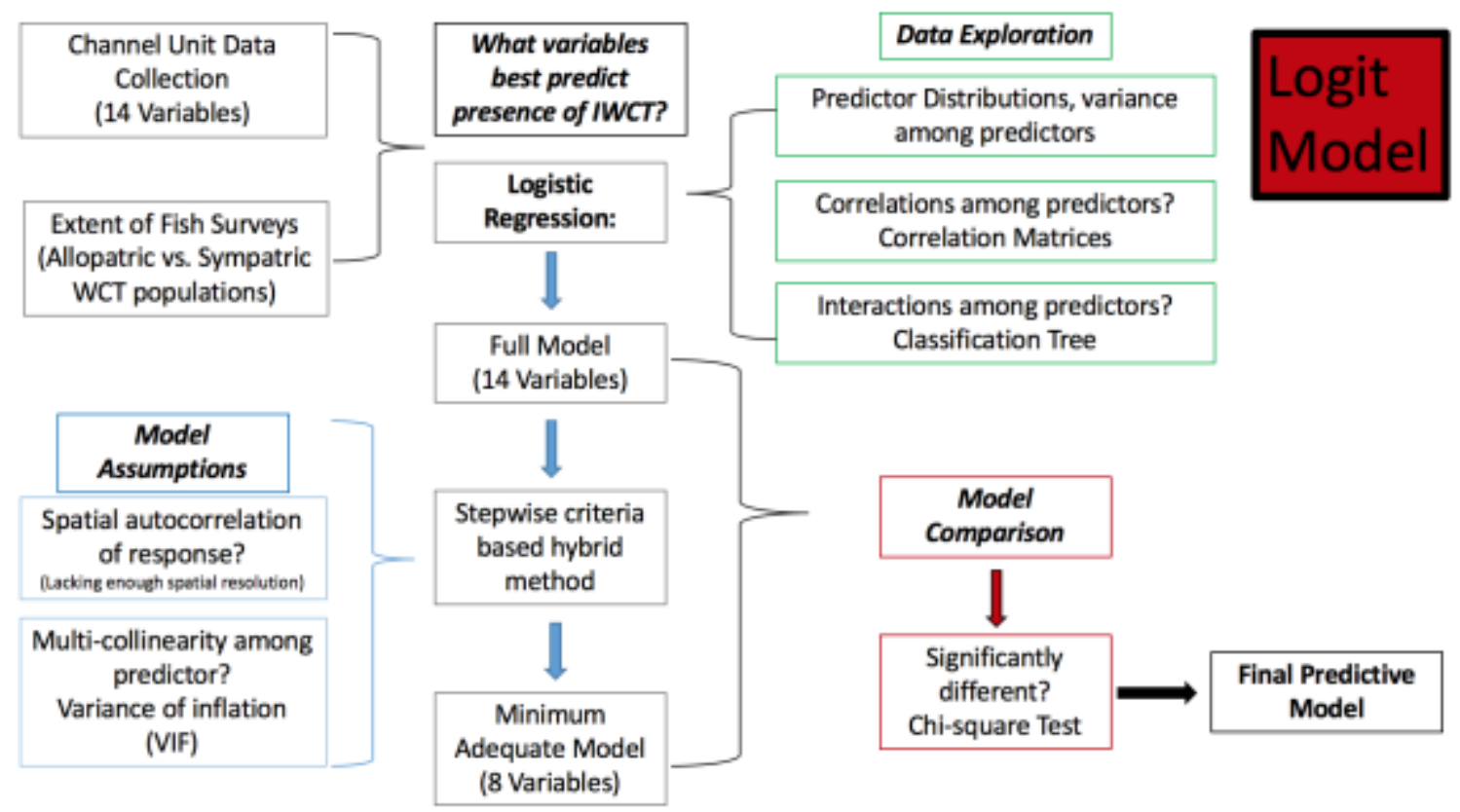

Figure 3-1. Methodology followed for data exploration, analysis methods, and model selection. 
Following data exploration, a model including all habitat predictors was analyzed using logistic regression for binary data to quantify the relationships between species composition occurrence (IWCT and WCT/EBT) and measured habitat variables. Logistic regression is a special type of regression modeling that analyzes the strength of continuously measured factors using a dichotomous response variable instead of a continuous random variable (Gotelli and Ellison 2013). The relationship between the species composition occurrence (IWCT and WCT/EBT) and habitat variables is therefore not linear but rather a sigmoidal, or logistic curve that originates with a minimum habitat value and ends at a maximum habitat asymptote. The occurrence of species composition, discrete variable, is then transformed using the logit transformation to convert the sigmoidal logistic probability curve function into a straight line. Even though the logistic transformation of the WCT presence leads to a linear relationship between the response variable and habitat predictor variables, it is not possible to use least-squares analysis for the error terms because the residuals follow a binomial distribution. Therefore, a maximum likelihood approach is used for hypothesis testing that includes an estimate of the regression coefficients and error variance. The final logistic regression model then maximizes the likelihood of WCT presence with the best available habitat predictor parameters.

To avoid over parameterization and pitfalls associated with overfitting models to data, model selection criteria often focus on optimizing the fit (and thus predictive capacity) of a minimum to the data, while minimizing the number of factors included (Gotelli and Ellison 2013). Thus, to determine the minimally adequate model, a stepwise 
criteria-based hybrid method was utilized. This method began with the full model and removed individual predictor variables until the model Akaike Information Criterion (AIC) value stopped decreasing. Following the selection of a minimum adequate model, the full model was compared to the minimum adequate model using an Analysis of Variance (ANOVA) with a Chi-square test. The Chi-square test was performed to determine if the minimum adequate model was significantly different from the full model. If the two models were not significantly different statistically, then the minimum adequate model was selected to increase the degrees of freedom associated with a lower number of predictor variables and easier model interpretation.

Logistic regression analysis does not require normally distributed or equal variance for residuals, but does require that observations are independent and that predictor variables are not correlated. The final model was examined using a confusion table which attempts to calculate the overall misclassification rate of the model as well as its ability to correctly classify species composition occurrence. This is one way to assess model fit. Basically, a 20\% subsample of the original is used to determine the misclassification rate of a model developed from the remaining $80 \%$ of the data. This is done randomly, and thus each time the table is developed the results will be slightly different. I use this here as one way of assessing model fit. An accompanying test statistic that aids in the interpretation of the confusion table is the Kappa statistic. The Kappa statistic essentially determines if the model is able to predict species composition occurrence better than what would be expected from chance alone. The Kappa statistic is calculated by subtracting the expected accuracy from the observed accuracy and then 
dividing the result by 1 - expected accuracy. The higher the Kappa statistic the greater the difference between the model accuracy and what would be expected simply from chance alone.

In addition to the confusion table I also use a receiver operating characteristic curve (ROC) which is determined as the rate of a true positive classification vs the rate of false positive classification (See DeLong et al. 1988). Measuring the area under the curve (AUC) is a way to validate the model, an AUC value closer to 1 indicates strong model predictive power. I generate ROC curves for both the full and reduced models in order to compare predictive capabilities of each model iteration. Should the full model have a substantially different AUC value than the reduced model then the full model likely has a greater predictive capacity compared to the reduced model. AUC values between 0.9 and 1 are considered excellent model fit, 0.8-0.9 are considered a good fit and anything $<0.8$ is considered a poor model fit (Manel et al. 2001).

Autocorrelation is common in large datasets, particularly in time series or spatial datasets. It is important to note that stream surveys will likely generate spatially auto correlated data because of the continuous longitudinal gradient measured. Spatial autocorrelation of predictive variables is likely in both the full and reduced models due to the longitudinal connectivity (spatial proximity) of the stream channel. However, I was unable to test for this due to the lack of collection of precise location data (latitude and longitude) during field surveys. To identify any multi-collinearity among the predictors, a Variance of Inflation Factor (VIF) analysis was performed on the full model and on the 
final model. Multi-collinearity is likely to exist when variables have VIF scores of four or greater.

Results

\section{Spatial Variation of Stream Habitat Conditions}

The 26 streams in the study were relatively small given their longitudinal position in the study area watersheds and were characterized by high gradient topology and confined channels (Figure 2-2). Sampled streams ranged from $0.4 \mathrm{~km}$ to $7.2 \mathrm{~km}$ (Table 2-5) in length and were generally dominated by pools and riffles both in reaches supporting IWCT and WCT/EBT (Table 3-1and Figure 2-4).

A total of 2,112 channel units were sampled in the project area, of which 369 $(17.5 \%)$ were dry and were removed from analysis due to the difference in timing of the extent of fish surveys and stream habitat assessments which occurred about a month and a half apart. Of the 1,743 channel units containing water, 367 (21\%) supported populations of IWCT located upstream from migration barriers. Interestingly, of the total channel units containing IWCT $(n=563) 35 \%$ were absent of water $(n=196)$ when completing stream habitat assessments and were not included in this analysis. 
Table 3-1. Number of channel unit types grouped by species occurrence (IWCT and WCT/EBT).

Channel Unit Type

WCT/EBT

14

136

709

27

490
IWCT

9

36

180

Rapid

Riffle

Of the five channel morphology variables observed (Table 3-2), habitat unit length had the largest variance while wetted depth and thalweg depth (see Table 2-1) was the least variable. In addition, all of the stream channel substrate observations had high variances (Table 3-2). Of the 2,679 total pieces of wood observed, $82 \%$ were small.

Table 3-2. Summary statistics for channel morphology, percent habitat unit substrate, active channel wood observations, and percent canopy cover $(n=1,743)$. See Table $2-1$ for a detailed description of each variable. 


\begin{tabular}{|c|c|c|c|c|c|}
\hline Variable & Median & Mean & $S D$ & $S E$ & Variance \\
\hline Length (m) & 3.60 & 5.19 & 5.32 & 0.14 & 28.28 \\
\hline Width (m) & 1.40 & 1.59 & 1.01 & 0.03 & 1.02 \\
\hline Depth (m) & 0.20 & 0.20 & 0.16 & 0.00 & 0.02 \\
\hline $\begin{array}{c}\text { Active } \\
\text { Channel } \\
\text { Width (m) }\end{array}$ & 2.20 & 2.46 & 1.22 & 0.03 & 1.48 \\
\hline $\begin{array}{l}\text { Thalweg } \\
\text { Depth (m) }\end{array}$ & 0.40 & 0.38 & 0.14 & 0.00 & 0.02 \\
\hline $\begin{array}{c}\% \text { Fine } \\
\text { Substrate }\end{array}$ & 30.00 & 38.23 & 30.57 & 0.80 & 934.66 \\
\hline $\begin{array}{l}\% \text { Gravel } \\
\text { Substrate }\end{array}$ & 50.00 & 50.25 & 28.27 & 0.74 & 799.31 \\
\hline $\begin{array}{l}\% \text { Cobble } \\
\text { Substrate }\end{array}$ & 0.00 & 6.69 & 11.11 & 0.29 & 123.37 \\
\hline $\begin{array}{l}\text { \%Boulder } \\
\text { Substrate }\end{array}$ & 0.00 & 3.89 & 8.93 & 0.23 & 79.80 \\
\hline $\begin{array}{l}\% \text { Bedrock } \\
\text { Substrate }\end{array}$ & 0.00 & 0.72 & 7.15 & 0.19 & 51.18 \\
\hline $\begin{array}{l}\text { Wood } \\
\text { Complexity } \\
\text { Rating }\end{array}$ & 2.00 & 2.10 & 1.07 & 0.03 & 1.15 \\
\hline $\begin{array}{c}\text { Large Woody } \\
\text { Debris } \\
\text { (small) }\end{array}$ & 1.00 & 1.49 & 1.82 & 0.05 & 3.32 \\
\hline $\begin{array}{l}\text { Large Woody } \\
\text { Debris (large) }\end{array}$ & 0.00 & 0.33 & 0.86 & 0.02 & 0.74 \\
\hline $\begin{array}{l}\text { Canopy } \\
\text { Cover Rating }\end{array}$ & 14.00 & 12.98 & 3.05 & 0.08 & 9.28 \\
\hline
\end{tabular}


Three pairs of variables in the channel unit morphology group showed positive, moderate correlation coefficients between 0.03 and 0.58 (Figure 3-2). Three pairs of variables in the substrate coverage group showed moderate collinearity with correlation coefficients ranging from -0.81 to 0.36 (Figure 3-3). Variables in the wood/shelter group had correlation coefficients ranging from 0.00 to 0.44 (Figure 3-4). None of the variables appeared to conform to a normal distribution, nor did they pass a Shapiro-Wilk test of normality $(\mathrm{p}<0.001)$. Therefore, only statistical tests that were not subject to assumptions of normality for either the predictor or response variables were used in this analysis. 


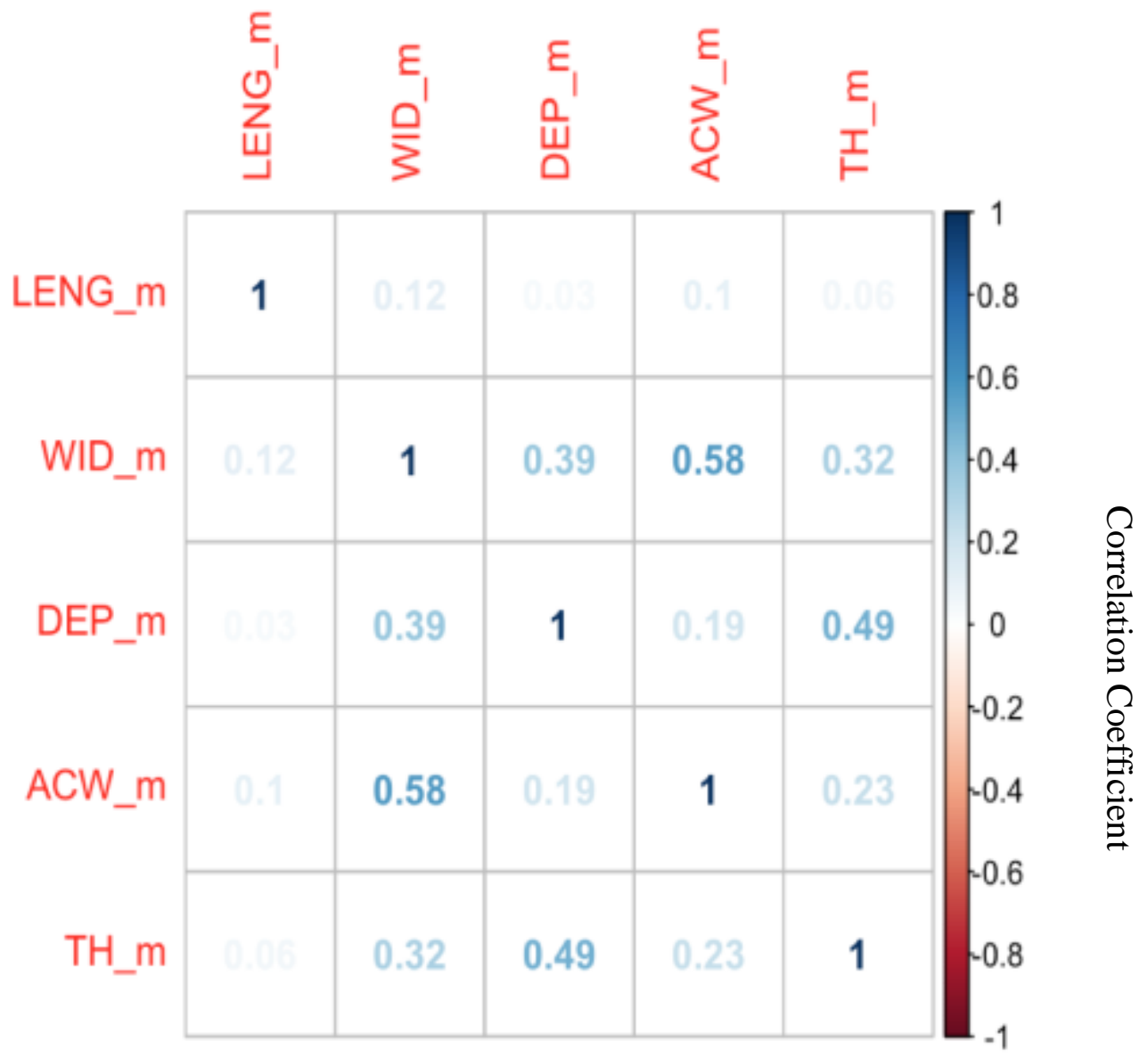

Figure 3-2. Correlation matrix for channel unit morphology predictor variables (see Table 2-1 for predictor abbreviations). 


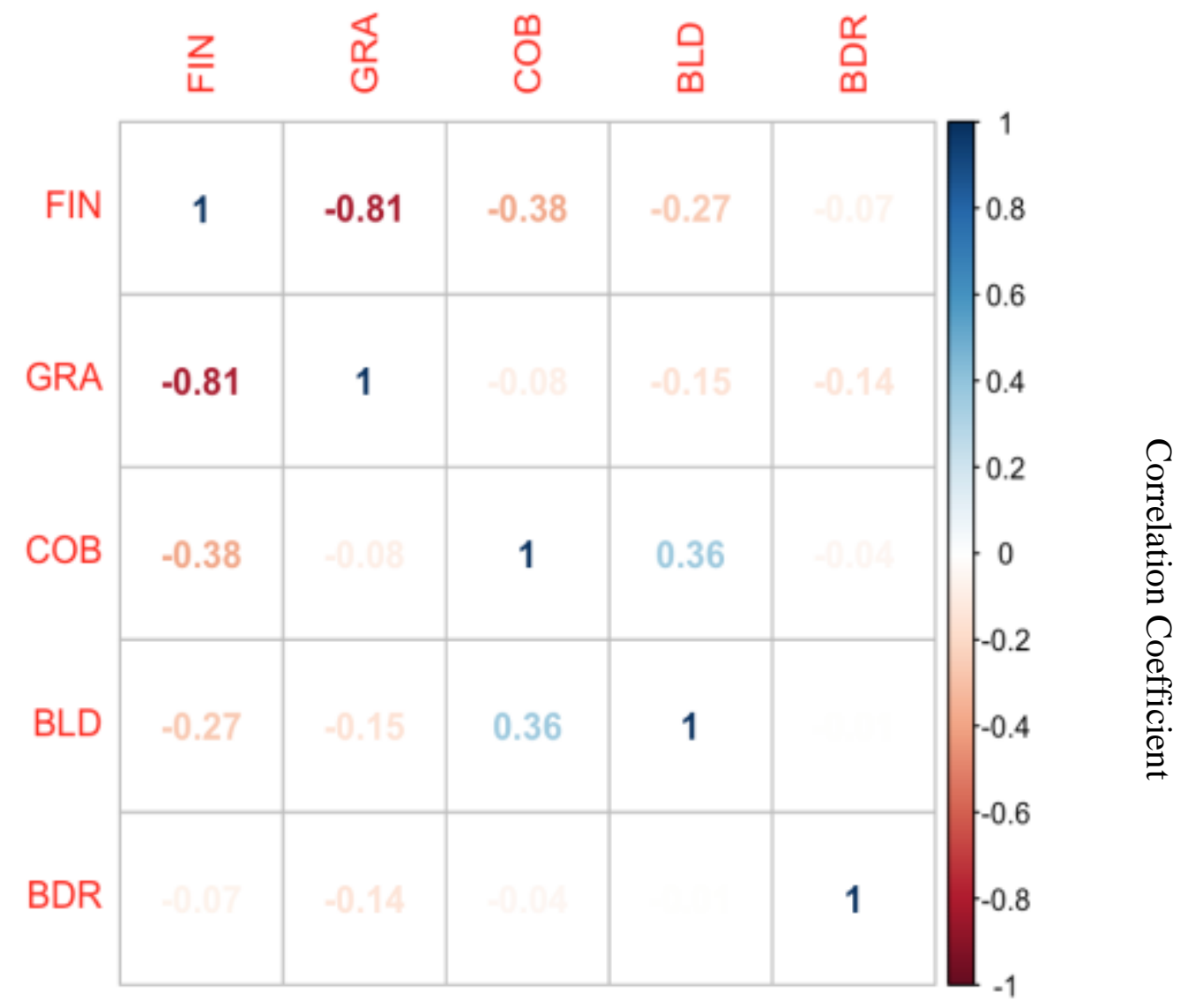

Figure 3-3. Correlation matrix for substrate predictor variables (see Table 2-1 for predictor abbreviations). 


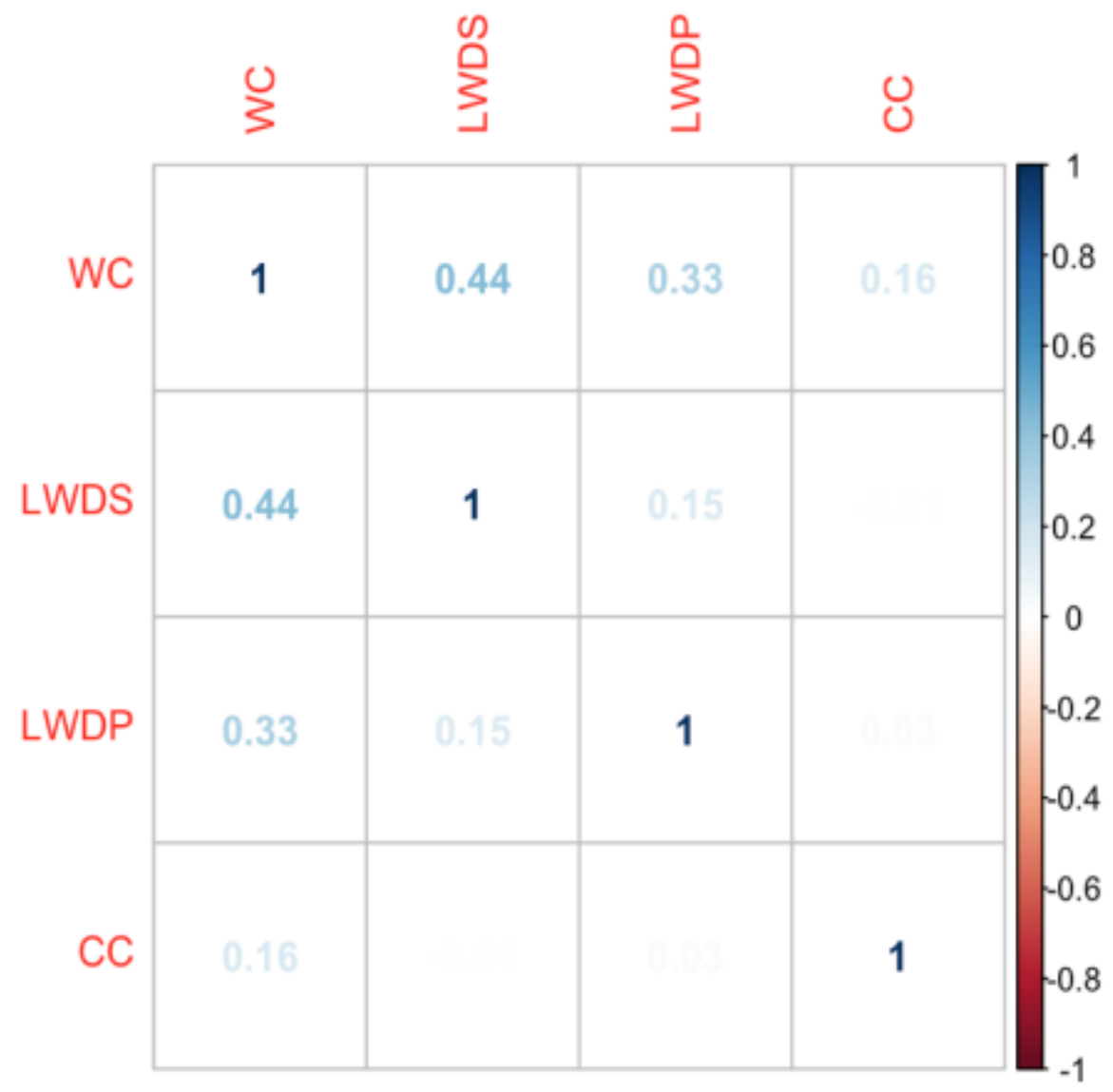

Figure 3-4. Correlation matrix for wood/shelter predictor variables (see Table 2-1 for predictor abbreviations).

\section{Effects of Stream Habitat on Isolated WCT Presence}

The classification tree indicated that significant interactions did not exist among the predictor variables since additional predictors and tree branches did not increase the explanatory power of IWCT presence. Model predictive error was minimized at the first split and remained below 1-standard error with the addition of more branches. Therefore, no interaction terms were added to the full or reduced models. 
Channel units supporting IWCT populations were associated with stream habitat conditions present during surveys. The full model included all fourteen predictor variables and the binary response variable of WCT presence for a sample size of 1,743 channel units surveyed for WCT as well as physical habitat data (adjusted $\mathrm{R}^{2}=0.178$ ). The resulting model equation had significant z-scores for the variables Channel Unit Length, Channel Unit Width, Channel Unit Depth, Active Channel Width, and Large Wood Debris, and an AIC score of 1,192. However, this model included the two variables, Fines and Gravel, with a variance of inflation factor over 40 indicating the full model most likely did not meet the assumption of no multi-collinearity.

The minimum model resulted in eight predictor variables and an AIC score of 1,185. Of the predictor variables selected, Channel Unit Width, Unit Depth, Active Channel Width, Gravel, Boulder and Bedrock Substrate, and Large Wood Debris were all significant while Channel Unit Length was not. However, removing Channel Unit Length increased the AIC value, so this variable was left in the minimum model. All eight of the variables in the minimum model had VIF scores lower than two. Therefore, the final minimum model was as follows:

(IWCT - probability $)=$ 1.92 - 0.044(Channel Unit Length)- 0.346(Channel Unit Width) 4.89(Channel Unit Depth)- 0.511(Active Channel Unit Width)- 0.0210(Gravel) + 0.0230(Boulder)- 0.216(Bedrock) + 0.529(LWDP) 
The adjusted $\mathrm{R}^{2}$ of the minimum model was 0.174 , only $0.3 \%$ less than the full model, indicating that the minimum model fits as well as the full model. Moreover, the null hypothesis that there is not a significant difference between the reduced and full model was not rejected, indicating that the minimum adequate model, as a whole, fits the data as well as the full model $\left(\chi^{2}=246 ; d f=5 ; p\right.$-value $\left.=0.7892 ; \alpha=0.05\right)$. Since the Chi-square tests found no significant difference between the full and minimum adequate model, the minimum model was selected to explain WCT presence.

\section{Fish presence explained}

A $20 \%$ subsample $(n=297)$ of the original observations was used to check the model misclassification rate. Table 3-3 shows a confusion table for the final minimum model which indicated that the minimum model correctly predicted $37.5 \%$ of the fish presence observations and $96.5 \%$ of the fish absence observations. The final model was also better in terms of classifying species composition occurrence than what would be expected by chance alone $(\kappa=0.814)$. The table indicated that the model did not have great accuracy for predicting WCT presence and should be interpreted with caution given the imbalance of species composition occurrence observations in the dataset. This model may, in fact, be useful in identifying limited habitat due to the fragmented nature of reaches supporting IWCT.

When ROC curves are compared, similar AUC values are determine for the full and reduced models, 0.82 and 0.81 respectively (Figure 3-5). These values indicate that 
model fit is "good" and consistent across the full and reduced model further validating the reduced model as the final model.

Table 3-3. Confusion table, correct classification rate of IWCT presence $=36.5 \%$ based on a random subsample of $80 \%$ of the full data set $(n=1422)$, with $20 \%$ of the original data used for prediction validation. Misclassification rate of $17.5 \%$.

\section{Observed}

\begin{tabular}{|lcc|}
\hline & WCT/EBT & IWCT \\
Predicted & 914 & 135 \\
WCT/EBT & 33 & 81 \\
\hline IWCT & 33 \\
\hline
\end{tabular}

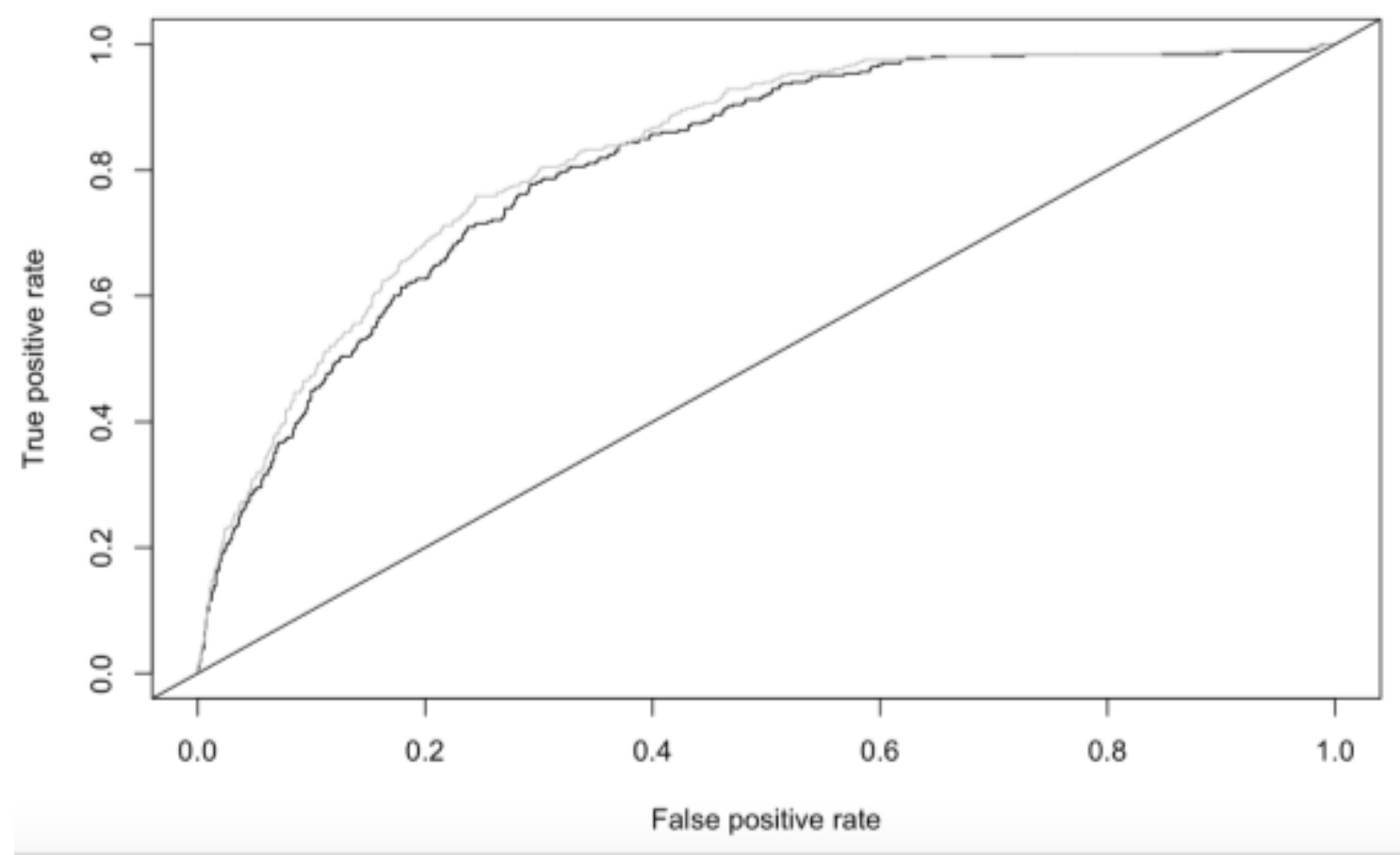

Figure 3-5. A plot of receiver operating characteristic curves (ROC) for the full (grey line) and reduced (black curved line) models. The straight black line represents the performance of a uniform random variable, the further away the ROC curve is from the uniform random variable. The area under the curve is used to assess the model predictive capacity. A value of 1 is considered perfect model fit. The full model had an associated AUC value of 0.82 and the reduced was very similar, 0.81 indicating that both models fit the data relatively well and do not have significantly different predictive capabilities. 


\section{Discussion}

The final model included eight of the original fourteen habitat variables, and was able to predict IWCT presence correctly $37.5 \%$ of the time, and was not significantly different from the full model which included all original fourteen habitat variables. If a reduced model is significantly different from the full model, then information risks being lost by removing potentially predictive factors of the model. The model variables selected in the reduced model also suggested the importance of complex cascade habitat for WCT presence during drought-limited summer conditions. The reduced probability of WCT presence and the relatively low assignment of presence collectively explained by the physical habitat variables used in analysis could be due to the constraints applied by interactions with EBT, migration barriers, or unusual climate conditions during the study year (2015). Inclusion of water temperature data may have increased the predictive power of this model due to the strong relationship between water temperature and WCT habitat suitability.

Channel unit length, width, depth, active channel width (see page 28 and Table 2-1 for a description of channel unit dimension metrics) as well as gravel and bedrock substrates, were all negatively associated with WCT presence. However, boulder substrate and large wood were positively associated with WCT presence. These relationships suggest that WCT are more likely to occur in small, shallow cascade units with high shelter complexity, due the positive association with boulders and woody debris. Cascade units often provide pool-like conditions due to the step nature of their formation (Montgomery et al. 1999), which may be why cascade units were positively 
associated with WCT presence in this study. Our results were consistent with previous work, which reported positive associations of WCT with complex pool habitat (Griffith 1970, Pratt 1984, Lider 1985, Montgomery et al. 1999, Milner et al. 2000, Cramer and Ackerman 2009). In addition, the formation of suitable pools during low summer flows in higher gradient rapid and cascade units likely occurred, and when flow increases, these pocket pools become highly turbulent and are no longer habitable for WCT (Montgomery and Buffington 1997, Montgomery et al. 1999). This also suggests that during the summer months when flow reaches critical low levels, woody debris and large substrate can be important in maintaining habitable depths for fish by slowing and deepening flow (see Lisle 1986 in (Sullivan et al. 1987)

Large woody debris and boulders were positively correlated to WCT presence, likely because both are important in the formation of pools and cascades (Montgomery et al. 1999, Jackson and Sturm 2002). High densities and abundance of WCT have also been observed to be associated with pool-dominated streams, suggesting the importance of pool formation features on WCT presence (Young et al. 1995). Others have shown that streams with a high frequency of large woody debris exhibit shorter spacing between individual pools (Montgomery and Buffington 1997) suggesting that fish may not have to migrate as far when attempting to reach a different habitat for varying biological requirements. Thermally impaired stream reaches can often create migration issues for fish, particularly if coldwater is only available in some pool habitats. Increased hyporheic exchange can improve thermal heterogeneity in a fluvial system (Caldwell et al. In review). Hyporheic exchange becomes most effective at regulating temperature in 
systems with high substrate depth or large substrate which allows for greater hyporheic exchange (Caldwell et al. In review). Therefore cascade step-pool habitat may be more important than pool-riffle habitat in this study because cascades step-pools potentially offer more shelter, oxygenated conditions, and spawning gravel, due to the higher stream velocity, coarse-substrate, large wood material and increased hyporheic exchange (Montgomery et al. 1999). It will be important to include water temperature and water availability data in future efforts.

Metrics associated with large and deep habitat areas (e.g. Channel width, channel depth, and active channel width) were negatively associated with WCT presence, which may have been due to WCT occurring more frequently in small, cascade step pool units than in larger and deeper glides and pools existing in higher order stream sections. Large habitats may have been disproportionately impacted by drought conditions, with more species moving to these remaining, large habitats when other shallower habitats dry up during summer low flows. Such movements may increase the density of fish in pools and glides, and thus increase competition for valuable oxygen, food, and shelter resources. Predator avoidance may also be more difficult, due to the lack of substrate and vegetative shelter in more open pool habitat than in smaller cascades units. Cascades therefore may offer less dense and thus less competitive conditions for WCT in headwater streams during drought years.

Substrate size is an important habitat metric due to its importance to both adult spawning success and the survival of early life stages of salmonids. Fine substrates are associated with poor emergence conditions for WCT fry, since eggs are less likely to 
receive well oxygenated water during incubation (Young et al. 1995). Adult WCT rely on gravel substrates in fast-flowing riffle habitat units for spawning success, yet gravel was negatively associated with the presence of WCT (Young et al. 1995). This may have been due to the data set including the presence of all WCT life stages, which may have confounded the importance of substrate classifications smaller than boulders. Boulders provide shelter from high stream flow conditions through eddy formation and predator refuge due to undercut formation, which can benefit both juvenile and adult WCT fish. Cobble substrate is likely too large for resident WCT to utilize for spawning and may not be large enough to provide cover opportunities, hence the negative relationship with WCT presence.

Channel unit length is a good predictor of WCT occurrence and abundance (Harig and Fausch 2002, Roberts et al. 2013, Isaak et al. 2015). However, channel unit length was not found to be a statistically significant predictor of IWCT in our study. Nonetheless, channel length was included in the final model selection, primarily because removing it as a predictor increased the overall AIC score. This predictor was also included because of the important biological concerns and known relationship between stream length and WCT presence and increased abundance. This also could be attributed to the lack of channel connectivity because of the severe drought conditions and lack of water in the entirety of the channel. A full sampling effort may reveal a stronger relationship between WCT presence and channel length, as patch size has been shown to be an important factor in other research) (Angermeier and Schlosser 1989, Harig and Fausch 2002, Franken and Hik 2004). A similar effort at a larger spatial scale attempted 
to develop a model for predicting species occurrence using three habitat features; elevation, gradient, and wetted width (Bozek and Hubert 1992). They were able to consistently, similar to the model developed in this paper, predict the absence of species rather than the presence and identify wetted stream width and stream size differences as driving the occurrence of species in the longitudinal extent of the stream (Bozek and Hubert 1992). Similar to the results of this study, Bozek and Hubert (1992) attribute other factors as influencing the distribution of trout rather simply the three variables they utilized. They suggest that future work should take advantage of variables that incorporate the multiple dimensions of stream habitat as well as the natural variability present in each dimension (Bozek and Hubert 1992).

\section{Climate Implications}

The study area was surveyed during a thermally stressful year for WCT when substantial sections of channel were observed to be absent of water. This study begins to identify relationships between stream channel attributes, WCT, and changing patterns of flow and precipitation. As flow decreases, stream temperatures typically rise, which further degrades and fragments stream habitat (Wenger et al. 2011b), this in turn shrinks suitable habitat and reduces population size and connectivity (Rieman et al. 2007). The spatial trend observed in the MSFMC study area allowed for channel characteristics to be identified that are important not only for the presence of WCT, but likely for the presence of WCT during especially stressful environmental conditions when pushed to the edge of their spatial extents. Thus, climate extremes may disproportionally affect peripheral 
populations, which are thought to be some of the most important populations for speciation and harboring of unique and valuable genetic variation (Taylor et al. 2003). A continuation of this study, including watershed scale attributes and data from historical climate data or data from climate prediction models could provide important insights into the relationship of climate processes and physical stream attributes in regards to the presence of WCT. As habitat becomes increasingly fragmented from anthropogenic encroachment, changes in precipitation patterns, and water temperatures as a result of climate change, headwater systems will become increasingly important to the persistence of coldwater species like WCT (Isaak et al. 2012a, 2014, 2015) particularly when peripheral populations are exposed to multiple stressors.

\section{$\underline{\text { Study Limitations and Suggestions for Further Research }}$}

This study focused on physical characteristics of habitats, but there are other variables that likely influence the presence of WCT. For instance, catchment development, stream gradient, invasive species, and water temperature can all influence habitat availability and quality for WCT. Since WCT thrive in stream gradients between six and fourteen percent (Young et al. 1995), adding stream gradient as a predictor of WCT presence may improve model performance. Additionally, catchment development in the form of roads and dams can create habitat barriers. These can prevent WCT passage to high quality habitat, which could confound a model aiming to predict the importance of habitat characteristics on WCT presence. WCT are also known to prefer colder temperatures, so they are more likely to be found in locations with cooler waters 
(Shepard et al. 2005, Williams et al. 2009, Roberts et al. 2013, Isaak et al. 2015). A measure of canopy cover was included in this study and canopy cover is inversely related to stream temperature (Tait et al. 1994). Because temperature data were not available to determine the degree of multi-collinearity between these two variables, canopy cover could not be used as a surrogate for temperature. Finally, invasive EBT may also influence the presence of WCT since these fish were often found downstream of WCT in this study. Interspecific competition between EBT and WCT has been identified as one of the main mechanisms of WCT displacement in the western United States (Dunham et al. 2002). Eastern brook trout began invading WCT habitat in the early 1800's and are a driving factor in their population decline (Dunham et al. 2002). Eastern brook trout are not as well adapted to particularly coldwater and may not be able to survive or compete with WCT, making headwater habitat particularly important when EBT exist downstream. This model could easily be enhanced by including species abundance estimates throughout the watershed to gain an understanding of the effect of the EBT invasion on native populations of WCT.

Spatial auto correlation was likely present in the final reduced model due to the longitudinal connectivity of channel units within the stream network, often referred to as the river continuum concept (Vannote et al. 1980). The river continuum concept refers to the gradient of physical habitat variables and associated biological community composition and ecological functions present from headwaters to mouth and can provide a possible explanation of the likely spatial autocorrelation present in this study. Future 
work should make an effort to thoroughly document the spatial relationships between channel units supporting IWCT and WCT/EBT. 
Chapter 4 - Conclusions

As anthropological and climate change influences continue to affect and change native species historical distributions and ranges it will become increasingly important to develop and implement strategies to predict and monitor changes to the habitats supporting native species. In the western United States particular focus has already been given to culturally and economically important native species such as salmon and trout, and a plethora of literature exists documenting historical species distributions and habitat requirements. However, as the additive effects of habitat degradation, climate change, and non-native introductions intensify, understanding the ecological conditions and minimum amounts of suitable habitat required to support peripheral populations will be crucial for conserving and managing WCT populations. Studies have identified habitat features both at the macro- and micro-scale that are imperative to the persistence of native aquatic species (i.e., Harig and Fausch 2002, Haak et al. 2010), but few have attempted to develop a framework for calculating and identifying the minimum viable periphery habitat required for marginal native populations, specifically under climate change predictions.

The two analyses described in this thesis attempt to understand the relationship between a coldwater specific species and fragmented headwater stream habitat located above artificial migration barriers. I took advantage of an observational dataset and tested for correlations between physical habitat measures of the stream environment and the spatial distribution of native and non-native fish species. Key limitations existed in this study that should be acknowledged when drawing conclusions from the results of these 
two analyses. The major source of limitation was the unequal sample size between IWCT (allopatric WCT existing above barriers) and WCT/EBT (sympatric populations of WCT and EBT). Results may have been confounded by multiple factors, in addition to unequal sample size, including barrier effect, biological factors such as temperature, and abiotic factors including water availability. However, despite these key limitation a few important points can be taken away from this exercise. They are as follows: WCT are likely experiencing shrinking coldwater habitat throughout their current range, the observed fragmented habitat may represent the minimum viable periphery habitat for valuable broodstock populations, and areas of streams containing steep cascade like channel units may present an opportunity to conserve and support populations located at distributional margins.

\section{$\underline{\text { Restoration Implications }}$}

As a result of the Mill Creek A-to-Z projects, four road crossings were identified as precluding the upstream movement of EBT and supporting IWCT populations above. Careful consideration must be taken when replacing or improving passage through improper culverts especially if removal or improvement would facilitate additional nonnative species invasion (i.e. EBT) into previously blocked areas, negatively impacting native trout populations located upstream from current barriers (Fausch et al. 2006, Peterson et al. 2008, Muhlfeld et al. 2012). Prior to removal or replacement of these four blocking culverts with IWCT existing above, managers need to better understand if the upstream habitat will support IWCT throughout the year, particularly during extreme 
environment events such as droughts (i.e. summer 2015). Retention of migration barriers in aquatic environments has been shown to provide refuge habitat for native species by precluding the upstream invasion of non-natives (Dunham et al. 2002, Fausch et al. 2006, Muhlfeld et al. 2012) and should be taken into consideration when proposing road crossing replacement or improvement (Muhlfeld et al. 2012) that would allow for further colonization by non-natives further compromising the habitat and genetic integrity of populations located upstream. Due to the limited availability of water observed in these reaches it may be more beneficial to the populations of IWCT to reconnect to the rest of the stream network as isolated populations are especially vulnerable to large-scale landscape disturbances (Guy et al. 2008). However, in other cases it may be more beneficial to retain blocking fish migration barriers to impede upstream invasion of nonnative trout species (EBT) as long as enough suitable habitat exists upstream to sustain the persistence of IWCT.

Williams et al. (2015) identified three primary strategies for conserving and protecting important trout habitat: 1) protecting headwater sources of coldwater, 2) reconnecting the fragmented stream network, and 3) restoring mainstem reaches such as valley bottoms. In that regard, conservation and management efforts aimed at protecting headwater sources may benefit from identifying headwater areas dominated by cascade and step-pool channel morphology based on initial findings from Chapters 2 and 3. 


\section{Future Directions}

This study documented an important spatial relationship between two trout species in the Pacific Northwest: WCT and EBT. However, this analysis was limited in the types of data collected, and therefore warrants further research into this documented distribution trend. Future research would benefit from focusing on the interactions between WCT and EBT within the study area. One way to examine the degree of interspecific interaction among WCT and EBT would be an in-depth genetic analysis aimed at quantifying the degree of introgression or hybridization. Genetic techniques using environmental DNA have been used to effectively map species distributions as well as estimate the overall biomass of particular species in aquatic systems (see following section). In addition, long-term monitoring of abiotic habitat conditions (i.e., temperature, solar radiation, precipitation, discharge, etc.) would allow researchers and managers to better understand how fragmented habitat and its suitability for native and non-native species is changing in response to observed and predicted climatic variability. Long-term monitoring would also allow researchers to narrow in on the idea of the minimum viable periphery habitat required to support isolated headwater populations. Finally, actively managing and improving habitat quality and quantity to increase the frequency of cold deep water pools could greatly benefit native WCT. 


\section{Genetic Investigation}

It is well documented and understood that WCT and EBT often occupy much of the same aquatic stream habitat (see Bozek and Hubert 1992, Dunham et al. 2002, Taylor et al. 2003b, Rieman et al. 2006, Wenger et al. 2011a, Walker et al. 2015, King et al. 2016) and that WCT are typically displaced by EBT to headwater stream reaches (Shepard 2004, Bear et al. 2007, Peterson et al. 2008, Isaak et al. 2014). When WCT and EBT occur in the same habitat it is also well understood that they can hybridize or introgress (Dunham et al. 2002, Novinger and Rahel 2003, Muhlfeld et al. 2009). Understanding the degree of WCT and EBT hybridization occurring in this study area would further inform management decisions to remove, retain, or replace artificial migration barriers. Investigating the genetic structure of these populations would determine whether the populations of IWCT are genetically distinct from sympatric WCT/EBT populations existing downstream of these migration barriers. An increasingly popular and affordable method for understanding and mapping the extent of bioinvasions is that of environmental DNA (eDNA) (Blankenship et al. 2011, Dejean et al. 2011, Thomsen et al. 2012, Yoccoz 2012, Takahara et al. 2013). Environmental DNA identifies species-specific DNA present in the aquatic medium and therefore does not require directly sampling target organisms, which significantly lowers the impact of sampling on the ecosystem and target populations (Takahara et al. 2013). Current fish distribution, abundance, and habitat models could be supplemented with eDNA data to develop comprehensive population models that could be affordably updated (Isaak et al. 2015). Annual replication of this study with increased spatial referencing, additional 
species abundance, genetic, and water temperature data would greatly enhance the understanding of the complex aquatic environment and allow for more explicit differences to be identified between the two groups of fish populations present in the study area.

\section{Quantifying Minimum Viable Periphery Habitat}

Future research could also further our understanding of the minimum viable periphery habitat required for isolated populations of trout to persist in the face of increasing abiotic and biotic stressors. A similar approach could be taken as described in Harig and Fausch (2002), but modeled across various climate scenarios. In order to begin to grasp what minimum amount of habitat is required to support isolated fragmented populations it will be important to understand the minimum viable population size for a study area such as the MSFMC by examining and estimating population abundance and densities. Once that is determined, managers could begin to quantify the minimum amount of habitat required to support the minimum viable population. This approach would allow conservation and restoration efforts to identify important refuge areas and develop strategies to increase or improve those areas as needed to protect and conserve important peripheral populations.

In closing, as predicted climate scenarios evolve and slowly alter the lotic ecosystems in the Pacific Northwest, stream habitat that provides adequate refuge from thermal, invasive species, and flow stressors will become increasingly important to 
sustaining important peripheral populations of WCT. It is likely, based on the results presented in this study, that WCT distributions throughout the western United States are not determined by physical stream characteristics but more by seasonal water availability and competition with non-native trout species, such as EBT. 


\section{Literature cited}

Aikens, M.L., and Roach, D.A. 2014. Population dynamics in central and edge populations of a narrowly endemic plant. Ecology 95(7): 1850-1860.

Allan, J.D., and Castillo, M.M. 2007. Stream Ecology. In Second Edi. Springer.

Angermeier, P.L., and Schlosser, I.J. 1989. Species-Area Relationship for Stream Fishes. Ecology 70(5): 1450-1462. Ecological Society of America. doi:10.2307/1938204.

Archer, E.K., Scully, R.A., Henderson, R., Roper, B.B., and Heitke, J.D. 2012.

Effectiveness monitoring for streams and riparian areas: Sampling protocol for stream channel attributes. Unpubl. Pap. file a t http//www. fs. fed. us/biology/fishecology/emp.

Bear, E.A., McMahon, T.E., and Zale, A. V. 2007. Comparative thermal requirements of westslope cutthroat trout and rainbow trout: implications for species interactions and development of thermal protection standards. Trans. Am. Fish. Soc. 136(4): 11131121. doi:10.1577/T06-072.1.

Beechie, T.J., and Sibley, T.H. 1997. Relationships between channel characteristics, woody debris, and fish habitat in northwestern Washington streams. Trans. Am. Fish. Soc. 126(2): 217-229. Taylor \& Francis.

Behnke, R.J. 2007. About Trout. The Lyons Press.

Bisson, P.A., Montgomery, D.R., and Buffington, J.M. 2006. Valley segenments, stream reaches, and channel units. In Methods in Stream Ecology, 2nd edition. Edited by F.R. Hauer and G.A. Lamberti. Academic Press (Elsevier) Publishers. pp. 23-50.

Bjornn, T.C., Brusven, M.A., Molnau, M.P., Milligan, J.H., and Klamt, R.A. 1977. Transport of granitic sediment in streams and its effects on insects and fish.

Blankenship, S.B., Teply, M., Dominguez, L., and Schumer, G. 2011. Sampling and analysis to assess brook trout (Salvelinus frontalis) population trends in High Lake (Oregon) using environmental DNA monitoring. Cramer Fish Sci. Genidaqs Rep.

Bozek, M.A., and Hubert, W.A. 1992. Segregation of resident trout in streams as predicted by three habitat dimensions. Can. J. Zool. 70(5): 886-890. NRC Research Press. doi:10.1139/z92-126.

Caldwell, L., Timm, R., Anders, P., and Roni, P. (n.d.). Thermal benefits: an overlooked component of in-stream habitat restoration. Fisheries.

Caughley, G. 1994. Directions in Conservation Biology. J. Anim. Ecol. 63(2): 215-244. [Wiley, British Ecological Society]. doi:10.2307/5542.

Clarke, A., MacNally, R., Bond, N., and Lake, P.S. 2008. Macroinvertebrate diversity in headwater streams: a review. Freshw. Biol. 53(9): 1707-1721. doi:10.1111/j.13652427.2008.02041.x.

Clarkson, R.W., and Wilson, J.R. 1995. Trout biomass and stream habitat relationships in 
the White Mountains area, east-central Arizona. Trans. Am. Fish. Soc. 124(4): 599612. Taylor \& Francis.

Cole, M.B., and Lemke, J.L. 2003. Eastern Washington Last Fish Variability Characterization Resurvey. ABR Rep.

Cramer, S.P., and Ackerman, N.K. 2009. Prediction of stream carrying capacity for steelhead: the Unit Characteristic Method. Am. Fish. Soc. Symp. 71: 255-288.

Dejean, T., Valentini, A., Duparc, A., Pellier-Cuit, S., Pompanon, F., Taberlet, P., and Miaud, C. 2011. Persistence of environmental DNA in freshwater ecosystems. PLoS One 6(8): e23398. doi:10.1371/journal.pone.0023398.

DeLong, E.R., DeLong, D.M., and Clarke-Pearson, D.L. 1988. Comparing the areas under two or more correlated receiver operating characteristic curves: a nonparametric approach. Biometrics: 837-845. JSTOR.

Dunham, J.B., Adams, S.B., Schroeter, R.B., and Novinger, D. 2002. Alien invasions in aquatic ecosystems: Toward an understanding of brook trout invasions and potential impacts on inland cutthroat trout in western North America. Rev. Fish Biol. 12: 373-391.

Fausch, K.D., Rieman, B.E., Dunham, J.B., Young, M.K., and Peterson, D.P. 2009. Invasion versus Isolation: trade-offs in managing native salmonids with barriers to upstream movement. Conserv. Biol. 23(4): 859-870. Wiley Online Library.

Fausch, K.D., Rieman, B.E., Young, M.K., and Dunham, J.B. 2006. Strategies for conserving native salmonid populations at risk from nonnative fish invasions: tradeoffs in using barriers to upstream movement.

Franken, R.J., and Hik, D.S. 2004. Influence of habitat quality, patch size and connectivity on colonization and extinction dynamics of collared pikas Ochotona collaris. J. Anim. Ecol. 73: 889-896.

Frissell, C.A., Liss, W.J., Warren, C.E., and Hurley, M.D. 1986. A hierarchical framework for stream habitat classification: viewing streams in a watershed context. Environ. Manage. 10(2): 199-214. Springer.

Gotelli, N.J., and Ellison, A.M. 2013. A primer of ecological statistics. In Second Edi. Sinauer Associates, Inc. .

Griffith, J.S. 1970. Interaction of brook trout and cutthroat trout in small streams. Moscow, ID: University of Idaho. Ph. D. dissertation.

Guy, T.J., Gresswell, R.E., and Banks, M.A. 2008. Landscape-scale evaluation of genetic structure among barrier-isolated populations of coastal cutthroat trout, Oncorhynchus clarkii clarkii. Can. J. Fish. Aquat. Sci. 65(8): 1749-1762. NRC Research Press.

Haak, A.L., Williams, J.E., Neville, H.M., Dauwalter, D.C., and Colyer, W.T. 2010. Conserving Peripheral Trout Populations: The Values and Risks of Life on the Edge. 
Fisheries 35(11): 530-549. Taylor \& Francis Group. doi:10.1577/1548-844635.11.530.

Hankin, D.G., and Reeves, G.H. 1988. Estimating total fish abundance and total habitat area in small streams based on visual estimation methods. Can. J. Fish. Aquat. Sci. 45(5): 834-844. NRC Research Press.

Harig, A.L., and Fausch, K.D. 2002. Minimum habitat requirements for establishing translocated cutthroat trout populations. Available from http://www.fs.fed.us/rm/boise/publications/BTWorkshop/Harig and Fausch 2002 Ecol Appl.pdf [accessed 20 November 2015].

Hodder, K.H., and Bullock, J.M. 1997. Translocations of native species in the UK: implications for biodiversity. J. Appl. Ecol.: 547-565. JSTOR.

Isaak, D.J., Muhlfeld, C.C., Todd, A.S., Al-chokhachy, R., Roberts, J., and Fausch, K.D. 2012a. The Past as Prelude to the Future for Understanding 21st-Century Climate Effects on Rocky Mountain Trout. Fisheries 37(12): 542-556. doi:10.1080/03632415.2012.742808.

Isaak, D.J., Wollrab, S., Horan, D., and Chandler, G. 2012b. Climate change effects on stream and river temperatures across the northwest U.S. from 1980-2009 and implications for salmonid fishes. Clim. Change 113(2): 499-524. doi:10.1007/s10584-011-0326-z.

Isaak, D.J., Young, M.K., Nagel, D., and Horan, D. 2014. Coldwater as a climate shield to preserve native trout through the 21st century. Wild Trout Symp. XI - Look. Back Mov. Forw. (October 2015): 110-116.

Isaak, D.J., Young, M.K., Nagel, D.E., Horan, D.L., and Groce, M.C. 2015. The coldwater climate shield: delineating refugia for preserving salmonid fishes through the 21st century. Glob Chang Biol. doi:10.1111/gcb.12879.

ISAB. 2007. Climate change impacts on Columbia River basin fish and wildlife.

Jackson, C.R., and Sturm, C.A. 2002. Woody debris and channel morphology in firstand second-order forested channels in Washington's coast ranges. Water Resour. Res. 38(9): 16-1-16-14. doi:10.1029/2001WR001138.

Kasprak, A., Hough-Snee, N., Beechie, T., Bouwes, N., Brierley, G., Camp, R., Fryirs, K., Imaki, H., Jensen, M., and O'Brien, G. 2016. The blurred line between form and process: a comparison of stream channel classification framew orks. PLoS One 11(3): e0150293. Public Library of Science.

King, S., O’Hanley, J.R., Newbold, L.R., Kemp, P.S., and Diebeld, M.W. 2016. A Toolkit for Optimizing Fish Passage Barrier Mitigation Actions. J. Appl. Ecol. Wiley Online Library.

Kruse, C.G., Hubert, W.A., and Rahel, F.J. 1997. Geomorphic influences on the distribution of Yellowstone cutthroat trout in the Absaroka Mountains, Wyoming. Trans. Am. Fish. Soc. 126(3): 418-427. Taylor \& Francis. 
de la Hoz Franco, E.A., and Budy, P. 2005. Effects of biotic and abiotic factors on the distribution of trout and salmon along a longitudinal stream gradient. Environ. Biol. Fishes 72(4): 379-391. Springer.

Latterell, J.J., Naiman, R.J., Fransen, B.R., and Bisson, P.A. 2003. Physical constraints on trout (Oncorhynchusspp.) distribution in the Cascade Mountains: a comparison of logged and unlogged streams. Can. J. Fish. Aquat. Sci. 60(8): 1007-1017. doi:10.1139/f03-088.

Lewis, S.L. 1969. Physical factors influencing fish populations in pools of a trout stream. Trans. Am. Fish. Soc. 98(1): 14-19. Taylor \& Francis.

Lider, E. 1985. Fisheries habitat and fish abundance in the North Fork of the Coeur d'Alene River. USDA For. Serv. Coeur d'Alene Natl. For. Fernan Dist. Coeur d'Alene, Idaho.

Lisle, T.E., and Lewis, J. 1992. Effects of sediment transport on survival of salmonid embryos in a natural stream: a simulation approach. Can. J. Fish. Aquat. Sci. 49(11): 2337-2344. NRC Research Press.

Manel, S., Williams, H.C., and Ormerod, S.J. 2001. Evaluating presence-absence models in ecology: the need to account for prevalence. J. Appl. Ecol. 38(5): 921-931. Wiley Online Library.

Milner, A.M., Knudsen, E.E., Soiseth, C., Robertson, A.L., Schell, D., Phillips, I.T., and Magnusson, K. 2000. Colonization and development of stream communities across a 200-year gradient in Glacier Bay National Park, Alaska, USA. Can. J. Fish. Aquat. Sci. 57(11): 2319-2335. NRC Research Press.

Milner, N.J., Elliott, J.M., Armstrong, J.D., Gardiner, R., Welton, J.S., and Ladle, M. 2003. The natural control of salmon and trout populations in streams. Fish. Res. 62(2): 111-125. doi:http://dx.doi.org/10.1016/S0165-7836(02)00157-1.

Montgomery, D.R., Beamer, E.M., Pess, G.R., and Quinn, T.P. 1999. Channel type and salmonid spawning distribution and abundance. Can. J. Fish. Aquat. Sci. 56(3): 377387. doi:10.1139/cjfas-56-3-377.

Montgomery, D.R., and Buffington, J.M. 1997. Channel-reach morphology in mountain drainage basins. Geol. Soc. Am. Bull. 109(5): 596-611. Geological Society of America.

Muhlfeld, C.C., D’Angelo, V., Kalinowski, S.T., Landguth, E.L., Downs, C.C., Tohtz, J., and Kershner, J.L. 2012. A Fine-scale assessment of using barriers to conserve native stream salmonids: a case study in akokala creek, glacier national park, USA. Open Fish Sci Journ 5: 9-20. Citeseer.

Muhlfeld, C.C., McMahon, T.E., Boyer, M.C., and Gresswell, R.E. 2009. Local Habitat, Watershed, and Biotic Factors Influencing the Spread of Hybridization between Native Westslope Cutthroat Trout and Introduced Rainbow Trout. Trans. Am. Fish. Soc. 138(5): 1036-1051. doi:10.1577/T08-235.1. 
Novinger, D.C., and Rahel, F.J. 2003. Isolation Management with Artificial Barriers as a Conservation Strategy for Cutthroat Trout in Headwater Streams. Conserv. Biol. 17(3): 772-781. [Wiley, Society for Conservation Biology]. Available from http://www.jstor.org.proxy.lib.pdx.edu/stable/3095235.

Paul, A.J., and Post, J.R. 2001. Spatial Distribution of Native and Nonnative Salmonids in Streams of the Eastern Slopes of the Canadian Rocky Mountains. Trans. Am. Fish. Soc. 130(3): 417-430. doi:10.1577/15488659(2001)130<0417:SDONAN>2.0.CO;2.

Penaluna, B.E., Dunham, J.B., Railsback, S.F., Arismendi, I., Johnson, S.L., Bilby, R.E., Safeeq, M., and Skaugset, A.E. 2015. Local variability mediates vulnerability of trout populations to land use and climate change. PLoS One 10(8): e0135334. Public Library of Science.

Peterson, D.P., Fausch, K.D., and White, G.C. 2004. Population Ecology of an Invasion: Effects of Brook Trout on Native Cutthroat Trout. Ecol. Appl. 14(3): 754-772. Ecological Society of America. Available from http://www.jstor.org.proxy.lib.pdx.edu/stable/4493578.

Peterson, D.P., Rieman, B.E., Dunham, J.B., Fausch, K.D., and Young, M.K. 2008. Analysis of trade-offs between threats of invasion by nonnative brook trout (Salvelinus fontinalis) and intentional isolation for native westslope cutthroat trout (Oncorhynchus clarkii lewisi). Can. J. Fish. Aquat. Sci. 65(4): 557-573. NRC Research Press.

Pratt, K.P. 1984. Habitat use and species interactions of juvenile cutthroat and bull trout in the Upper Flathead River Basin. Master's thesis. Univ. Idaho, Moscow.

Quinn, T.P. 2011. The behavior and ecology of Pacific salmon and trout. UBC Press.

Richmond, G., Fryxell, R., Neff, G., and Weis, P. 1965. The Cordilleran ice sheet of the northern Rocky Mountains and related Quaternary history of the Columbia Plateau. Edited byH.J. Wright and D. Frey. Princeton University Press.

Rieman, B.E., Isaak, D., Adams, S., Horan, D., Nagel, D., Luce, C., and Myers, D. 2007. Anticipated climate warming effects on bull trout habitats and populations across the interior Columbia River basin. Trans. Am. Fish. Soc. 136(6): 1552-1565. Taylor \& Francis.

Rieman, B.E., Peterson, J.T., and Myers, D.L. 2006. Have brook trout displaced bull trout along longitudinal gradients in central Idaho streams. Can. J. Fish. Aquat. Sci. 63: 63-78.

Roberts, J.J., Fausch, K.D., Peterson, D.P., and Hooten, M.B. 2013. Fragmentation and thermal risks from climate change interact to affect persistence of native trout in the Colorado River basin. Glob. Chang. Biol. 19(5): 1383-1398. doi:10.1111/gcb.12136.

Shepard, B.B. 2004. Factors That May Be Influencing Nonnative Brook Trout Invasion 
and Their Displacement of Native Westslope Cutthroat Trout in Three Adjacent Southwestern Montana Streams. North Am. J. Fish. Manag. 24(3): 1088-1100. doi:10.1577/M03-105.1.

Shepard, B.B., May, B.E., and Urie, W. 2005. Status and Conservation of Westslope Cutthroat Trout within the Western United States. North Am. J. Fish. Manag. 25(March 2015): 1426-1440. doi:10.1577/M05-004.1.

Sloat, M.R., White, R.G., and Shepard, B.B. 2001. Status of westslope cutthroat trout in the Madison River basin: the influence of dispersal barriers and stream temperature. Montana State University, Bozeman.

Sullivan, K., Lisle, T.E., Dolloff, C.A., Grant, G.E., and Reid, L.M. 1987. Stream channels: the link between forests and fishes.

Tait, C.K., Li, J.L., Lamberti, G.A., Pearsons, T.N., and Li, H.W. 1994. Relationships between Riparian Cover and the Community Structure of High Desert Streams. J. North Am. Benthol. Soc. 13(1): 45-56. [University of Chicago Press, Society for Freshwater Science]. doi:10.2307/1467264.

Takahara, T., Minamoto, T., and Doi, H. 2013. Using environmental DNA to estimate the distribution of an invasive fish species in ponds. PLoS One 8(2): e56584. doi:10.1371/journal.pone.0056584.

Taylor, E.B., Stamford, M.D., and Baxter, J.S. 2003. Population subdivision in westslope cutthroat trout (Oncorhynchus clarki lewisi) at the northern periphery of its range: evolutionary inferences and conservation implications. Mol. Ecol. 12(10): 26092622. doi:10.1046/j.1365-294X.2003.01937.x.

Thomsen, P.F., Kielgast, J., Iversen, L.L., Wiuf, C., Rasmussen, M., Gilbert, M.T., Orlando, L., and Willerslev, E. 2012. Monitoring endangered freshwater biodiversity using environmental DNA. Mol Ecol 21(11): 2565-2573. doi:10.1111/j.1365-294X.2011.05418.x.

Tohver, I., Hamlet, A.F., and Lee, S.-Y. 2014. Impacts of 21st century climate change on hydrologic extremes in the Pacific Northwest region of North America. J. Am. Water Work. Assoc.: 1-16. doi:10.1111/jawr.12199.

USFS. 2015. History and Culture Colville National Forest. Available from http://www.fs.usda.gov/main/colville/learning/history-culture [accessed 10 May 2015].

Vannote, R.L., Minshall, W.G., Cummins, K.W., Sedell, J.R., and Cushing, C.E. 1980. The river continuum concept. Can. J. Fish. Aquat. Sci. 37: 130-137.

Walker, B.M., Bean, N.J., Baker, W.P., and Olson, J.A. 2015. Westslope cutthroat trout salvage and reintroduction framework for Pend Oreille River Tributaries, Washington. Washington Department of Fish and WildlifeKalispel Tribe of Indians.

Washington Department of Fish and Wildlife. 2009. Fish passage and surface water diversion screening assessment and prioritization manual. Olympia, Washington. 
WDNR. 2002. Forest Practices Board Manual.

Wenger, S.J., Isaak, D.J., Dunham, J.B., Fausch, K.D., Luce, C.H., Neville, H.M., Rieman, B.E., Young, M.K., Nagel, D.E., Horan, D.L., and Chandler, G.L. 2011 a. Corrigendum: Role of climate and invasive species in structuring trout distributions in the interior Columbia River Basin, USA. Can. J. Fish. Aquat. Sci. 68(8): 15101510. doi:10.1139/f2011-102.

Wenger, S.J., Isaak, D.J., Luce, C.H., Neville, H.M., Fausch, K.D., Dunham, J.B., Dauwalter, D.C., Young, M.K., Elsner, M.M., Rieman, B.E., Hamlet, A.F., and Williams, J.E. 2011b. Flow regime, temperature, and biotic interactions drive differential declines of trout species under climate change. Proc. Natl. Acad. Sci. 108(34): 14175-14180. doi:10.1073/pnas.1103097108.

Wentworth, C.K. 1922. A scale of grade and class terms for clastic sediments. J. Geol. 30(5): 377-392. JSTOR.

Williams, C.K., Kelley, B.F., and Smith, B.G. 1995. Forest plants associations of the Colville Nation Forest. Pacific Northwest Research Station.

Williams, J.E., Haak, A.L., Neville, H.M., and Colyer, W.T. 2009. Potential Consequences of Climate Change to Persistence of Cutthroat Trout Populations. North Am. J. Fish. Manag. 29(3): 533-548. doi:10.1577/M08-072.1.

Williams, J.E., Neville, H.M., Haak, A.L., Colyer, W.T., Wenger, S.J., and Bradshaw, S. 2015. Climate Change Adaptation and Restoration of Western Trout Streams: Opportunities and Strategies. Fisheries 40(7): 304-317. doi:10.1080/03632415.2015.1049692.

Yoccoz, N.G. 2012. News and views: The future of environmental DNA in ecology. Mol. Ecol. 21: 2031-2038.

Young, M.K., McIntyre, J., and Rieman, B. 1995. Conservation assessment for inland cutthroat trout. Gen. Tech. Rep. RM-GTR-256. (February): 1-16. 